\title{
FILE-TO-FACTORY Transferring Design Intent to Manufacture
}

Maya Robinson 
This content is unavailable.

Kaiser, Larsson, \& Girhammar 2019 


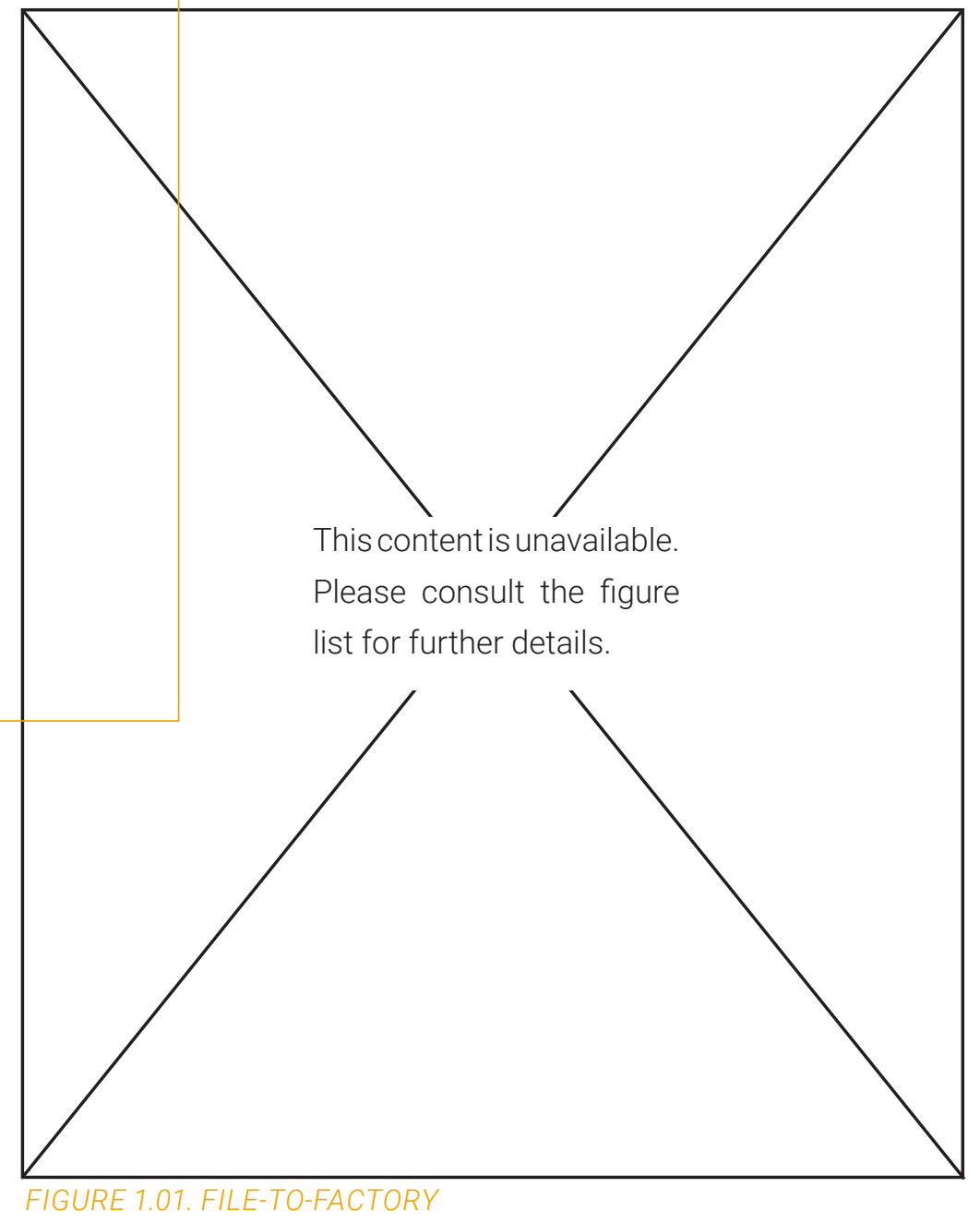

\section{FILE-TO-FACTORY}

Transferring Design Intent to Manufacture 


$$
\text { | }
$$




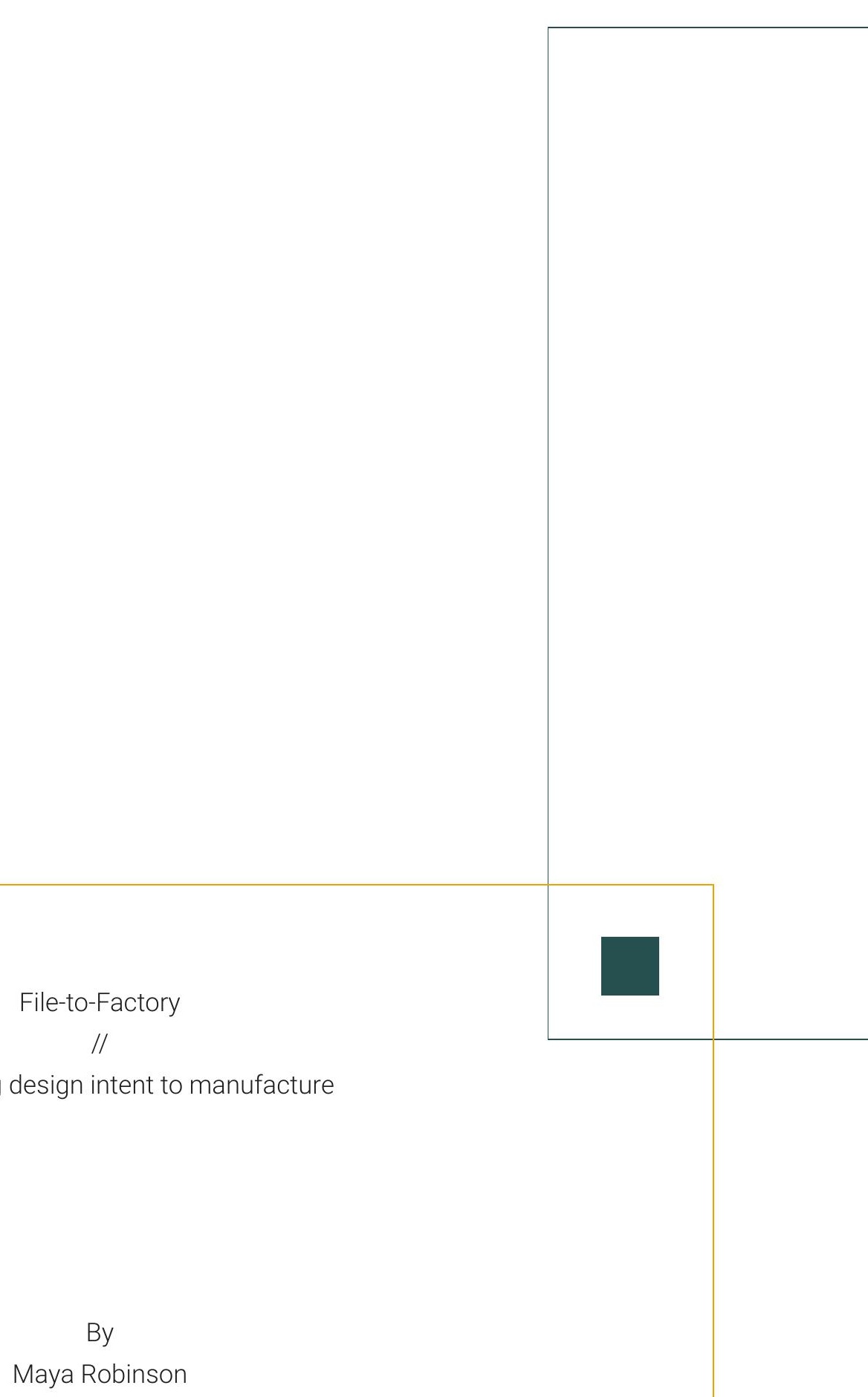

Maya Robinson

A 120-point thesis submitted to the Victoria University of Wellington in partial fulfilment of the requirements for the degree of Master of Architecture (Professional)

Victoria University of Wellington

School of Architecture 


$$
\text { | }
$$


To my family. 


$$
\text { | }
$$


Firstly, a thank you to my supervisor, Dr Antony Pelosi. Thank you for always being there to listen, for your encouragement, and guidance.

Thank you to all the industry professionals that have helped this research come together.

Many thanks to my family for their relentless support and my friends who have kept me sane.

Thank you again to all above, I could not have done it without you. 


$$
\text { | }
$$


Research ethics approval was obtained from Victoria University Human Resource Committee in order to conduct this thesis.

Approval number 0000027413

The participant information sheet and consent form are included as Appendices A and B. 


$$
\text { | }
$$


Digital fabrication has become a common way of producing and constructing designs more efficiently, challenging the traditional methods of construction, and the way we design. Despite the new technologies used to enhance the design process, there is still a disconnect between design and construction. Building Information Modelling (BIM) has been a step towards creating a more fluid workflow. However, it is not currently being fully utilised within New Zealand. Along with a lack of interoperability, this has contributed to the limited productivity of the construction industry. The ability to take a BIM model direct to manufacture is critical to leverage the information of the model and reduce expensive remodelling. The use of BIM tools not only aims to maximise efficiency when delivering a project but also provides a new way of working and a solution to improve file-to-factory production.

Design for Manufacture and Assembly (DfMA), although relatively new to the architecture and building industry, could have substantial benefits for the way architecture projects are designed and constructed. This process consists of a set of guidelines that take into consideration the manufacturability and assembly of the design from the very beginning. Qualitative and experimental methods have been used for initial and developed testing drawn from case studies, a review of the literature, and data from interviews with industry professionals. Five interviews were conducted with industry professionals across the design to manufacturing spectrum. The interviews identified current issues within the architecture and building industry directly related to file-to-factory.

A new file-to-factory workflow has been developed utilising BIM tools and DfMA principles to explore the impact this process could have on the buildings we design and construct in New Zealand. The workflow does not consist of new processes or tools, but instead couples the two together. By utilising the existing BIM technology and implementing DfMA, this means the designer can consider both the requirements of the design and how the design will be manufactured and assembled. The collaborative workflow can eliminate the need for remodelling, and reduce errors, cost, and time. This is significant to the industry because it begins to streamline the design-to-construction process and allow for the industry to grow, advance, and increase productivity. 


$$
\text { | }
$$


$\boldsymbol{A E C}$ - Architecture, Engineering and Construction

BCA - Building Consent Authorities

BIM - Building Information Modelling

CAD - Computer Aided Design

CAM - Computer Aided Manufacturing

CNC - Computer Numerically Controlled

DfMA - Design for Manufacture and Assembly

IPD - Integrated Project Delivery

RFP - Request for proposal

RFT - Request for Tender

n.d. - No Date 
Dedications

Acknowledgements.

.$v \mathrm{i}$

Ethics..

Abstract.

viii

. $\mathrm{x}$

Abbreviations

I NTRODUCTION

1.1 Problem Statement

1.2 Objectives.

1.3 Research question

1.4 Research scope

1.5 Research methods

1.6 Methodology.

LITERATURE REVIEW • • • • • • • • • • • . 12

Overview . . . . . . . . . . . . . . . . . . . . . . . . . . . . . 14

2.1 File-to-Factory. . . . . . . . . . . . . . . . . . . . . . . . . . . . 15

2.2 Project Delivery Processes . . . . . . . . . . . . . . . . 19

2.3 Building Information Modelling . . . . . . . . . . . . . . . 25

2.4 CAM . . . . . . . . . . . . . . . . . . . . . . . . 28

2.5 CNC Technology . . . . . . . . . . . . . . . . . . . . . 29

2.6 Construction Productivity In New Zealand . . . . . . . . . 30

2.7 Case Studies and Precedents . . . . . . . . . . . . . . . 31

Overview . . . . . . . . . . . . . . . . . . . . . . . . . 31

2.7.1 File-to-Factory Case Studies . . . . . . . . . . . . . . 32

2.7.2 DfMA Case Study. . . . . . . . . . . . . . . . . . . . . 36

2.7.3 IPD Precedents. . . . . . . . . . . . . . . . . . . . . . . . . 37

Findings from Case Studies and Precedents . . . . . . . . . . . 41

Summary . . . . . . . . . . . . . . . . . . . . . . . . . . 43

D ATA COLLECTION. • • • • • • • • • • . . . 46

Overview . . . . . . . . . . . . . . . . . . . . . . . . 47

3.1 Main Findings . . . . . . . . . . . . . . . . . . . . . . . . 48

Summary . . . . . . . . . . . . . . . . . . . . . . . . . . 49

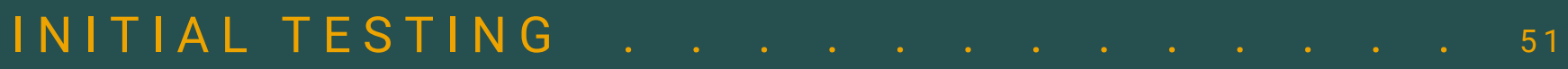

Overview . . . . . . . . . . . . . . . . . . . . . . . . . . . 54

4.1 Software Plugins for Revit . . . . . . . . . . . . . . . . . 55

4.2 MWF Pro Wood. . . . . . . . . . . . . . . . . . . 56

4.3 Hut Series. . . . . . . . . . . . . . . . . . . . . . . 57 
4.4 Early Testing. . . . . . . . . . . . . . . 59

Summary . . . . . . . . . . . . . . . . . . 64

DEVELOPED TESTING . . . . . . . . . . . . 66

Overview . . . . . . . . . . . . . . . . . 68

5.1 Developed Testing . . . . . . . . . . . . . . . 69

5.2 Templates. . . . . . . . . . . . . . . . . . 70

5.3 MWF Pro Wood Potential . . . . . . . . . . . . 74

5.4 Observations and Issues . . . . . . . . . . . . . 75

5.5 CNC Output . . . . . . . . . . . . . . . . 76

Summary . . . . . . . . . . . . . . . . . . . . . 77

DISCUSSION AND OUTCOMES... . . . . . 79

Proposed Workflow. . . . . . . . . . . . . . . 81

6.1 What was learnt?. . . . . . . . . . . . . . . . 84

6.2 Limitations . . . . . . . . . . . . . . . . 85

6.3 What Does It Mean For the Industry. . . . . . . . 86

Future Work . . . . . . . . . . . . . . . . 87

CONCLUSION . . . . . . . . . . . . . . 90

Conclusion . . . . . . . . . . . . . . . . . 91

B I B L IOGRAPHY . . . . . . . . . . . . . . . 93

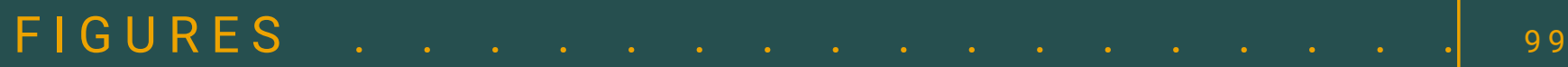

CHAPTER FIGURES . . . . . . . . . . . . 102

APPENDICES . . . . . . . . . . . . . . 104

Appendix A - Ethics Participant Info Sheet. . . . . . . 105

Appendix B - Ethics Consent Form. . . . . . . 106

Appendix C - Creating A template. . . . . . . . . . 107

Appendix D - Creating An AutoJoin Rule Set....... . . 108 

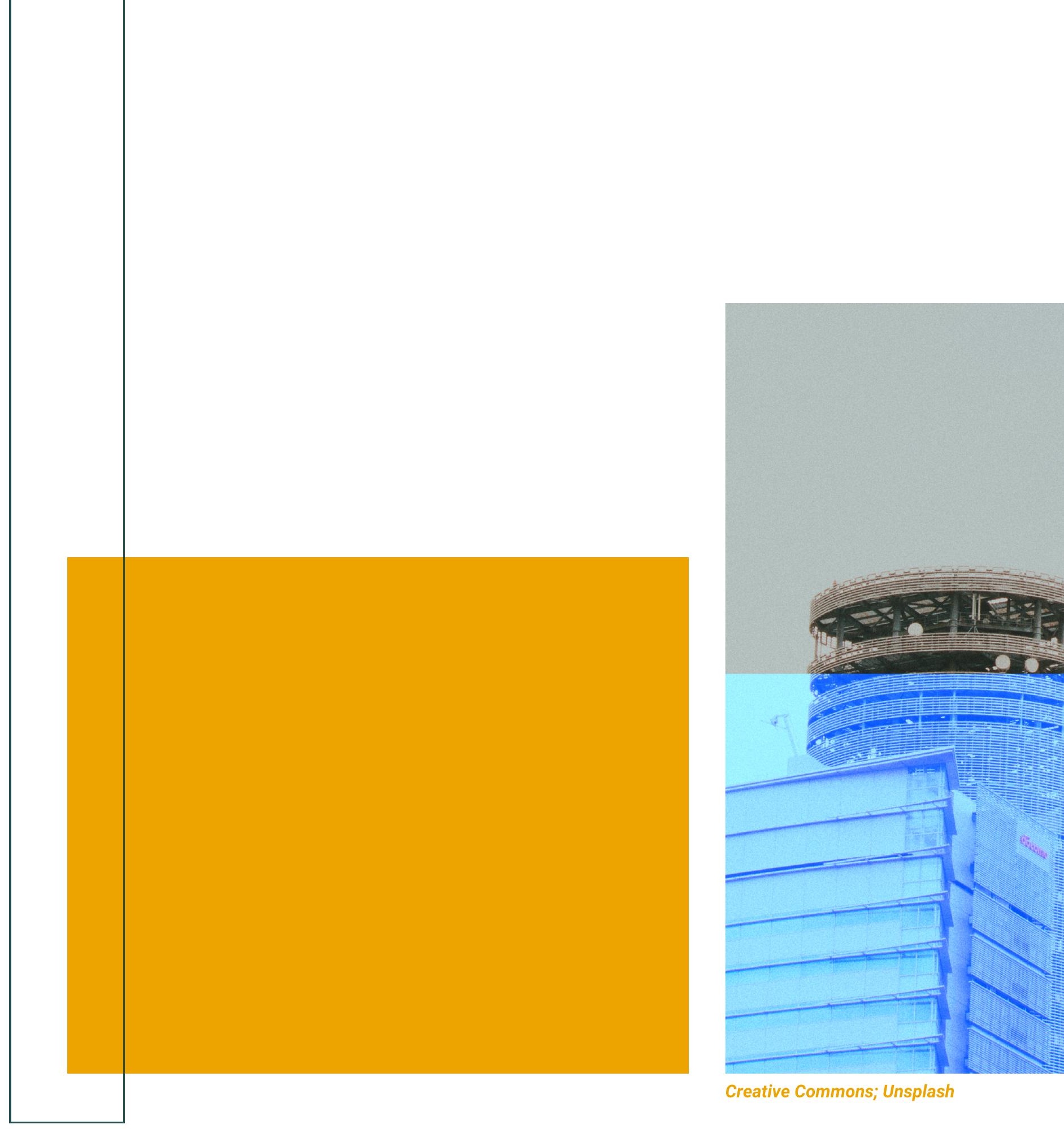

Creative Commons; Unsplash

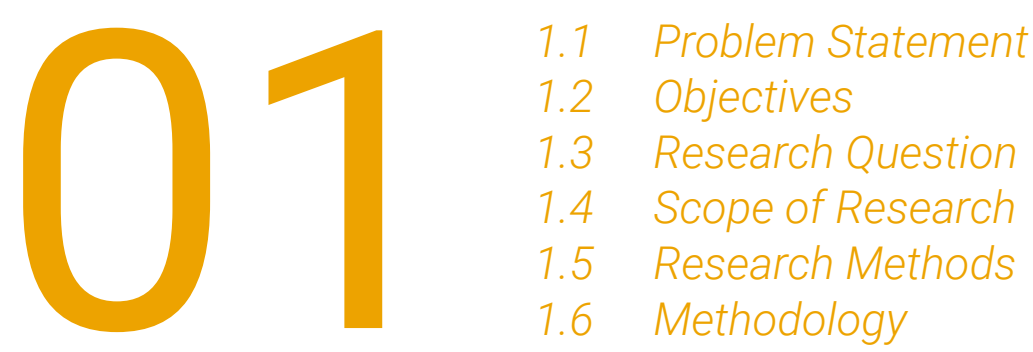

INTRODUCTION 


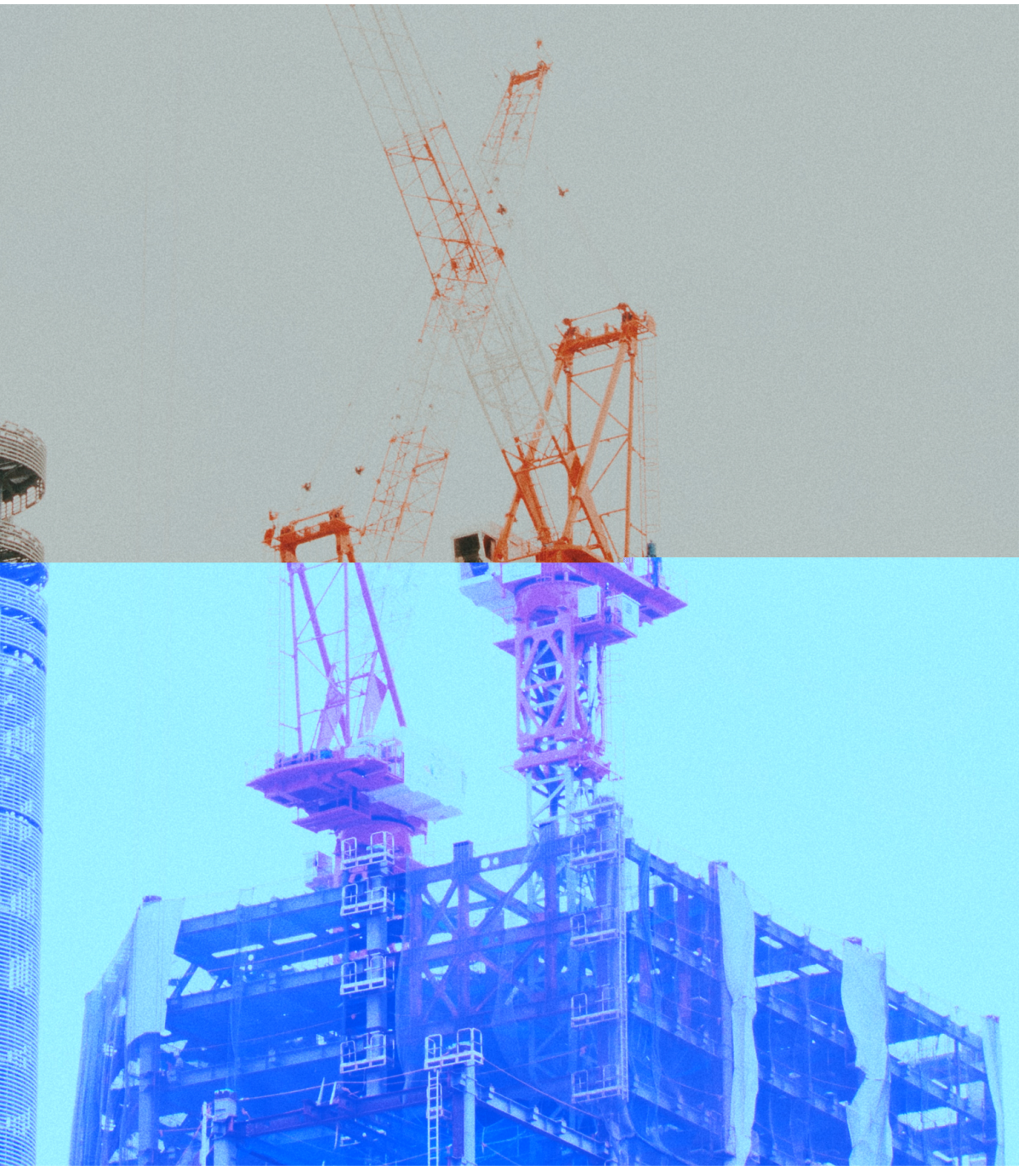




\subsection{PROBLEM STATEMENT}

While the digital age has allowed for new technologies and a new way of building to bring design and construction together, there is still a disconnect between the two. Building Information Modelling (BIM) has provided the opportunity for algorithmic form generation and computer simulation. However, as the complexities of tectonic and formal constraints of design increase, it is essential for architects to understand the means of production (Pigram \& McGee, 2011). New Zealand has consistently delivered projects using the traditional design-bid-build construction procurement process. This process, while widely understood, can be lengthy and contractually separates design from construction. Compared to other delivery processes, this process can be inefficient especially when it comes to file-to-factory.

Even with this shift towards digital, part- or entire shop drawings are still predominately translated through dedicated machine programming software packages by specialists (Pigram \& McGee, 2011). The current system or workflow when transferring design intent to manufacture is fragmented, stifling the flow of information. This translation stage is subject to delay, human error, and inaccuracies. Design for Manufacture and Assembly (DfMA) is another delivery process which could begin to solve some of the issues with the file-to-factory process. This DfMA process provides a set of guidelines aimed to effectively manufacture and assemble with high speed at low cost (Bogue, 2012; Xie, 2003). The utilisation of BIM and DfMA to bring design and construction may impact the way architecture projects are designed and constructed. 


\subsection{OB JECTIVES}

1. Conduct interviews with manufacturers and designers

2. Create a series of test models to explore the limitations and opportunities through the use of digital tools

3. Examine the potential of MWFPro Wood and its adaptability for inputting and programming it to work with New Zealand timber sizes and building code

4. Initial design of a system to improve the design of a building

5. Development of parameters to define what would be required for a better way of working

6. Achieve different levels of scale and detail from joinery to the framing of a building 

What impact could a file-to-factory workflow have on the way architectural projects are designed and constructed in New Zealand? 


\subsection{RESEARCH SCOPE}

This research aimed to address the impact a file-to-factory workflow could have on the way we design and construct architectural projects in New Zealand. The intent of this investigation was to address and identify the implications of automating the file-to-factory process. This thesis does not include the design of a building, but rather the design of a workflow for timber framed walls and joinery adhering to NZS3604. By explicitly exploring the capabilities of being able to program and control an automated generating system this will demonstrate the potential for using this technology in the industry for other elements than timber framing.

The initial testing explored a series of small huts to test the potential of the plugin for BIM software (Revit) and identify the key limitations and opportunities. The architectural modelling program Revit was chosen for this investigation because it is commonly used in the architecture industry and provides not only design modelling but also services and engineering. The developed testing explored the ability to program the software to meet New Zealand building standards and evaluate the potential of taking a design in BIM directly to manufacture. This led to the design and development of a workflow process for architects to improve the design of a building. The outcome of the research provides a workflow or new way of working that can act as a framework for architects and designers to include manufacturing and assembly data into their drawings and improve the fileto-factory process through the use of digital tools. 


\subsection{RESEARCH METHODS}

For the purpose of this thesis, I have structured the research into two types of testing, the "initial testing" and "developed testing". The initial testing consisted of a series of small huts generated through qualitative and experimental methods drawn from literature review, case studies, and data from interviews with industry professionals about any current issues. BIM tools and alternative delivery principles were identified. The developed testing investigated the ability to program the plugin to New Zealand Building Code NZS 3604. This led to a practical investigation of currently available tools to create a new file-to-factory workflow. The workflow has been investigated to test the impact it could have on the way architectural projects are designed and constructed. A methodology diagram has been included (see Figure 1.02).

\section{The thesis structure documents the seven different phases of the research as follows:}

1. Introductory research, explored what has already been done previously through literature reviews, case studies and documentation of the current file-to-factory process. This is described in Chapter 2.

2. Interviews were undertaken to understand the developments and pin point direct issues manufacturers and designers currently have regarding the file-to-factory process. Chapter 3 discusses the findings from phase 2.

3. Numerous potential plugin options were identified and the initial testing began.

4. The initial testing phase focused on a series of test models, influenced by the literature review and case studies, to identify the limitations and opportunities of the plugin software MWF Pro Wood. Both phases 3 and 4 are discussed in Chapter 4.

5. Chapter 5 covers phase 5 , the developed testing phase. This phase focused on testing the ability to apply New Zealand building standards to the plugin. This led to a development of the parameters which consisted of trouble shooting, testing and problem solving. The results were refined and iterated until the desired outputs were achieved.

6. From the findings of phase 5 , the design of a new 'workflow' was created.

7. Final development, adjustments and evaluation. Chapters 6 and 7 describe and discuss the new workflow and provide conclusions to the research. 
Phase 1

Introductory Research

\begin{tabular}{ll}
\hline Theory & Building processes \\
- literature review & - understanding the \\
& different types of delivery
\end{tabular}

Case studies

- improvements made towards file-to-factory

- project implementing DfMA

- projects that used integrated project delivery

Phase 2

Interviews

Industry professionals

- interviews undertaken to understand the

developments and pin point current issues with

file-to-factory

Document

and reflect

Phase 3

Plugin Options

Identify

- numerous potential plugin options were

identified and initial testing began

Phase 4

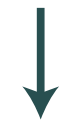

Initial Testing

Phase 5

Test models were created

based on case studies and literature review

- to identify the limitations and opportunities of the plugin software MWF Pro Wood

Refine, Reflect and Repeat until aimed

results are achieved

Phase 6

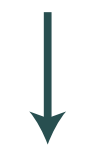

\section{New Workflow}

From the findings in phase 5 , the design of a new 'workflow' was created

Phase 7

Testing the ability to apply New Zealand building standards (NZS 3604) to the plugin

- digital development

- testing/solving of digital problems

\section{Final Outcome}
Final development, adjustments and evaluation assess significance of findings




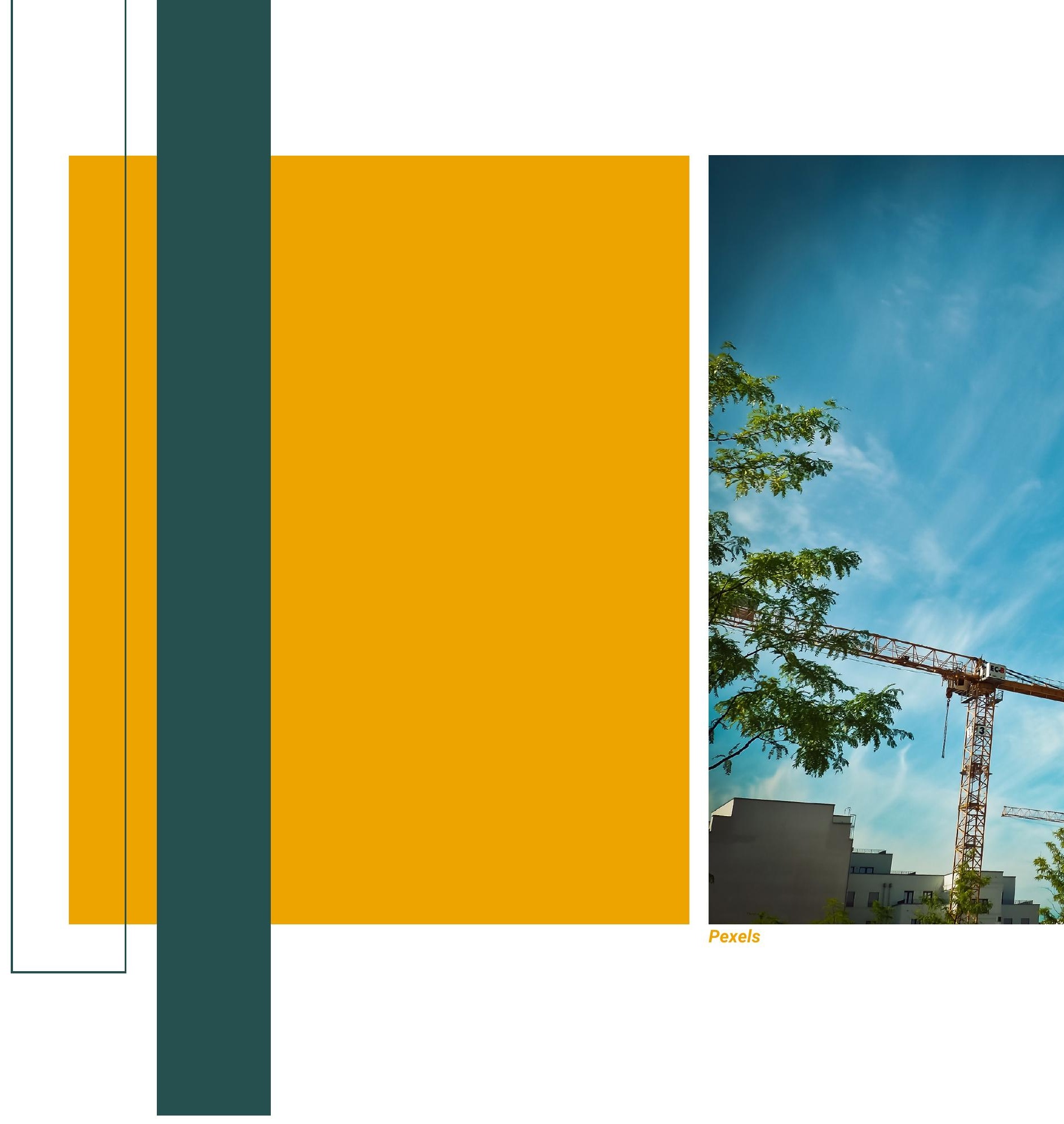



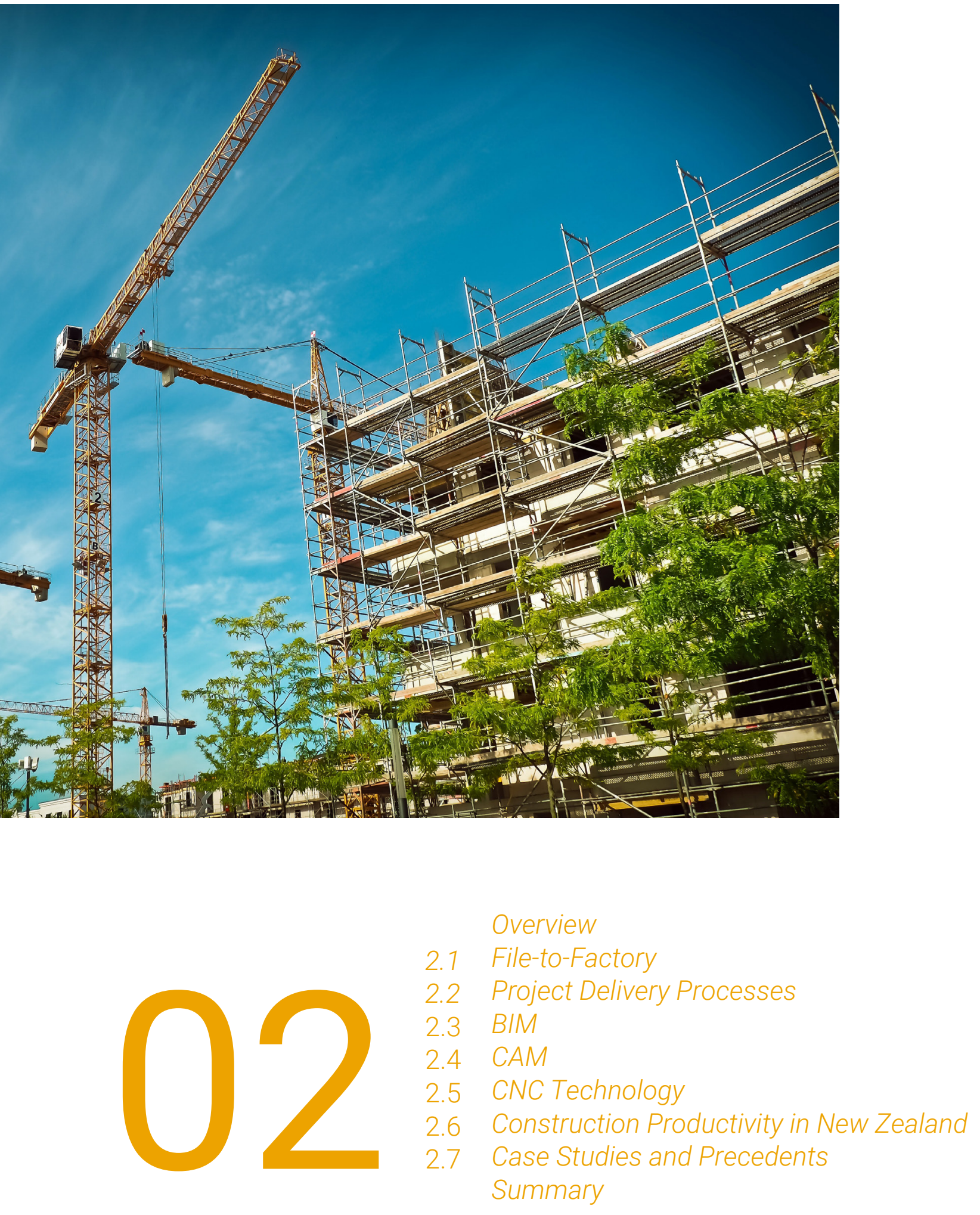

LITERATURE REVIEW 


\section{O VER VIEW}

This chapter describes the current literature review work that has been completed relating to the file-to-factory process. The chapter breaks down into sections firstly addressing the file-to-factory work that has been previously investigated. There are many different approaches addressing the design to production process. This part of the literature looks at the utilisation of digital tools to establish a continuous digital workflow and demonstrates the design potential through the understanding of building processes, methods, and tools.

The different types of project delivery processes are also discussed. The current, most common, delivery process is the traditional design-bid-build although because this process separates design from construction alternative delivery methods have also been examined. These alternative processes are researched to see if in combination with digital tools a new file-to-factory workflow can be created to address the construction productivity and improve the transfer of information flows.

The literaturealso discusses BIM as another key process and tool along with the benefits/challenges, interoperability, legal issues, and the current use of BIM in New Zealand. A section on Computer Aided Manufacturing (CAM), Computer Numerically Controlled (CNC) technology, and the Construction Productivity in New Zealand has also been discussed.

Case studies have been researched for the design-to-construction process and those that used Integrated Project Delivery (IPD). These have been explored and discussed to identify the current processes and digital tools that are being utilised in architecture projects. 


\subsection{FILE-TO-FACTORY}

File-to-Factory is the digital transition of information from the design process into fabrication. This refers to a process that involves the "direct transfer of data from a 3D modelling software to a CNC (Computer Numerically Controlled) machine"(Oosterhuis, Bier, Aalbers, \& Boer, 2014, p. 294). The idea of this process is to fully utilize the digital tools at hand in particular referring to BIM that can provide a smooth transition going from design to manufacture. This not only creates a new workflow that can affect the way we design buildings but also aims to maximise the efficiency when delivering a project.

\subsubsection{File-to-Factory in Architecture}

File-to-Factory is a process that aims to avoid having a fragmented transition between the design phase and the construction of the design. The use of digital tools and technologies has allowed for a more direct transfer of data (Oosterhuis et al., 2014).

This thesis proposes to utilise existing BIM tools to their full potential in combination with DfMA processes to address the gap between design and production. This workflow will explore the impact this file-to-factory workflow could have on the way architecture projects are designed and constructed and begin to streamline the design to production process. The literature has emphasised the importance of having a seamless digital workflow when moving from design to production and highlights the value of having a collaborative work environment. There are multiple approaches towards file-to-factory, currently providing no standard or streamlined process to address the issues when going from design to production. Many of these researchers have utilised digital tools or created their own in efforts to establish a continuous digital workflow. Some researchers have also investigated how this was able to give rise to new innovative solutions pushing the design potential throughout the design to production process.

\subsubsection{Utilisation of Digital tools to establish a continuous workflow}

Most researchers investigating the file-to-factory process have utilised digital tools in efforts to establish a continuous digital process or workflow (Kaiser, Larsson, \& Girhammar, 2019; Larsson, Kaiser, \& Girhammar, 2012; Oosterhuis et al., 2014; Pigram \& McGee, 2011). Oosterhuis et al. (2014) utilised and created their own digital tools to explore complex geometric shapes and making use of NURBS geometry, parametric design, scripting, and programming. Their platform is accessible by participants from a common database on the internet and allows for a collaborative environment. The design data are then converted into instructions for CNC (Computer numerically controlled) machinery production. Similarly, Larsson et al. (2012) have developed their own grid algorithm that programs and parametrically defines the housing blocks. Their algorithm also defines the supporting structure. This huge multi-storey timber lattice housing structure has been parametrically designed, to "take data from the system and collates it into instructions for the factory, which in turn manufactures the parts in accordance with 
a predefined time schedule" (Larsson et al., 2012, p. 452). Pigram and McGee (2011), like Oosterhuis et al. (2014), explored developing a software platform that allowed for a seamless transition between design and fabrication minimising the one-way translation thresholds. The research proposed to eliminate the "fissure between the processes that bring forth a design and the operations that will lead to its eventual fabrication" (Pigram \& McGee, 2011, p. 123). This provided feedback loops into bi-directional workflow. Unlike Oosterhuis et al. (2014), Pigram \& McGee (2011) investigated this type of workflow for robotic fabrication. Pigram and McGee note with the increase of complexity in formal and tectonic constraints there is a need for architects to fully understand the production process.

While all look into utilising digital tools and creating their own through parametric design they each investigated at different scales. Oosterhuis et al. (2014) examined the use of an online interactive interface that focused on the design for housing based on the concept of mass-customisation. Oosterhuis et al. (2014) note that their platform "allows not only for automated 3D modelling of building components according to the script, but also allows for automated generation of quantitative and qualitative data to control the CNC fabrication of the components" (p. 297). Collaborative design and construction has also been proven to be effective because of the direct communication and link between the main stakeholders involved in the project; client, architect, and manufacturer. However, Larsson et al. (2012) explored multi-timber buildings using Swedish timber structural systems and incorporates the file-to-factory process into this large scale design.

Although their system doesn't "define a single parametrically controlled detail", data was taken from the system and turned into instructions for factory and the manufacturing begins based on the predefined time schedule (Larsson et al., 2012, p. 452). This can create an agile building process eliminating the need for 2D shop drawings. The process takes the 3D centralised model converting into instructions for the machine and then getting manufactured. If an annotation system has been correctly set up this generates an easy assembly process lining up one marked up panel to the next (Larsson et al., 2012). Comparatively, Pigram and McGee (2011) explored at a smaller scale, testing the real limitations of their new software platform. By using the 3D modelling environment Rhinoceros 3D with its embedded scripting program they created "an open-ended set of process-specific variables and calculations" (Pigram \& McGee, 2011, pp. 123-124). This set of instructions has allowed for capabilities typically included in CAM software packages to be utilised in a parametric modelling environment.

Both Oosterhuis et al. (2014) and Larsen et al. (2012) identified the opportunities these approaches would have if real-time data were added and the letting the shape and content manipulate itself based on the data input. One of Oosterhuis et al. (2014)'s architectural designs Trans-ports changes shape and content in real-time according to the input data. However, Kaiser et al. (2019) aimed to utilise compound algorithms to create a process where the grid of the structure can be manipulated and "generate the construction drawing for the smallest scale details" $(p$. 4). This algorithm would respond to inputs based on the environment and contextual data creating feedback loops. The use of a data-to-site feedback loop would "not only maximise efficiency throughout the building process, but also increase the building's performance" (Kaiser et al., 2019, p. 4). 


\subsubsection{Design potential through the understanding of building processes, methods, and tools}

Others (see Duro-Royo \& Oxman, 2015; Larsen \& Schindler, 2008) took a different approach and investigated the design potential /non-standard architecture by acquiring insights into the fabricator's software, digital production machinery, fabrication constraints, and material properties. Although they looked into understanding the full building process and how this could affect the design this in itself has explored ways of creating a better workflow through this new knowledge. Duro-Royo and Oxman (2015) examined the limitations associated with computational tools and demonstrate systems looking to "bridge the gap between virtual geometric-based design platforms and physical material-based fabrication tools" ( $p$. 1). There is a lack of information on material properties and fabrication constraints in the design workflow. This research explored the potential of understanding these qualities. Likewise, Larsen and Schindler (2008) believe the way to demonstrate the design potential is to acquire and understand the fabrication process, software, limitations, and machinery. By acquiring this knowledge about the real building process, methods, and tools this will begin to bridge the gap between design and fabrication.

Duro-Royo and Oxman (2015) aimed to push designs by "devising virtual tools that operate with non-geometric design parameters" (p. 2). The term "Fabrication Information Modelling" was coined to present a new methodology that explored design processes and blur the lines between design phases to create feedback loops between the sequential phases. Duro-Royo and Oxman's (2015) new methodology "attempts to expand the design process so that parameters given by each phase are integrated in a multi-level and multi-disciplinary computational design methodology" (p. 2). Duro-Royo and Oxman (2015) have pushed the design potential using a decentralised construction system they have encoded with fabrication constraints. By creating rule sets to set certain conditions and automate certain actions this allows for a more fluid workflow and transition between design and fabrication especially since the fabrication constraints are already encoded into the system.

Whilst Larsen and Schindler (2008) also investigated the understanding of the building process, their approach was very different to Duro-Royo and Oxman. Their research focused around the case studies their students had carried out through the university involving unique timber structures. Two methods were used, one they defined as "sophistication of the detail" and the other "variation of the element" (Larsen \& Schindler, 2008, p. 398). Larsen and Schindler's (2008) comprehensive exploration into understanding the fabrication methods, tools, and techniques differed from the other research approaches. Instead of exploring and creating their own digital tools they used the CAM software, Cadwork, for creating the fabrication model leading to the CNC output of their timber design. A crucial observation Larsen and Schindler (2008) make in regards to the digital production chain "is the interface between CAD and CAM which up to now still requires a lot of manual interaction" (p. 405).

One of their projects, the Camera Obscura, "focused on the characteristics of the automated joinery machine's CNC tools" (Larsen \& Schindler, 2008, p. 407). The structure consisted of 16 wall planks that each consisted of different geometry. Four glulam sill and top beams were used to accommodate the wall planks through rather complex cuts (Larsen \& Schindler, 2008). However, a main challenge of the production involved the complex cuts of the sill 
and top beams with the Hundegger Speedcut machine operating in four axes and a five axis machine would be required. Another challenge involved the length of the glulam beams since the joinery machine's constraints were underestimated due to not utilising the CAM software Cadwork early on in the design. Had this been used earlier, potential problems and technical feasibility would have been identified and able to be solved earlier because of the detail and precision the model provided.

Larsen and Schindler (2008) prove that understanding the building process, methods, and tools will affect the design potential and can begin to establish a continuous digital process between design and fabrication. Despite this, there is still a separation between design and fabrication because of the manual input that is still required in the digital chain when transferring the design intent to manufacture. Similar to Duro-Royo and Oxman (2015), this thesis makes use of rule sets and conditions that allow for the automatic generation of timber framing through the utilisation of BIM tools that take into consideration the manufacture and assembly of the design.

Overall these studies clearly indicate the importance of working collaboratively and emphasise the impact a seamless information file-to-factory workflow could have on the design to production process. It is implied there is a disconnection between design software such as CAD and BIM with manufacturing software CAM. Although this thesis will not demonstrate the potential of design, some authors (Duro-Royo and Oxman, 2015; Larsen and Schindler, 2008) approach through understanding real building processes, methods, and tools is important to note. This thesis looks to take the understanding of manufacturing and assembly methods in combination with BIM tools to create a new file-to-factory workflow. This workflow will be explored to see how this could impact the way architecture projects are designed and constructed. 


\subsection{PROJECT DELIVERY PROCESSES}

\subsubsection{Traditional Design-Bid-Build}

The traditional design-bid-build process is the most commonly used project delivery method in New Zealand (Fuemana, Puolitaival, \& Davies, 2013) (see Figure 2.01). This process contractually separates design from construction, typically consisting of the owner separately contracting with a designer/ architect and contractor (Spellerberg, 2019). Once the design documents have been completed, the owner looks to receive bids from contractors to perform the work (Eastman, Teicholz, Sacks, \& Liston, 2011). This method is less collaborative with others especially with the designer and contractor working separately. The owner is the one bearing all the risk when it comes to providing completed design documents to the contractors and from there the contractor becomes liable for the work (Spellerberg, 2019).

The primary benefit of delivering projects in a traditional manner is the competitive bidding that occurs to achieve the lowest possible price for an owner. However, this delivery process presents many disadvantages and is problematic when it comes to the file-to-factory process (Fuemana et al., 2013). Due to the separation between design and construction, when the design gets handed off to the contractor to begin the manufacturing and construction process a translation stage is required (see Figure 2.02). Often, before any work can begin, contractors, sub-contractors, and fabricators have to redraw and "produce their own shop drawings to reflect accurate details of certain items" (Eastman et al., 2011, p. 5). If there is any uncertainty or inconsistencies in the design this can set the whole project back making it difficult to fabricate these materials off-site. This causes the majority of fabrication and construction to take place onsite only after exact conditions have been
FIGURE 2.01.TRADITIONAL PROJECT DELIVERY

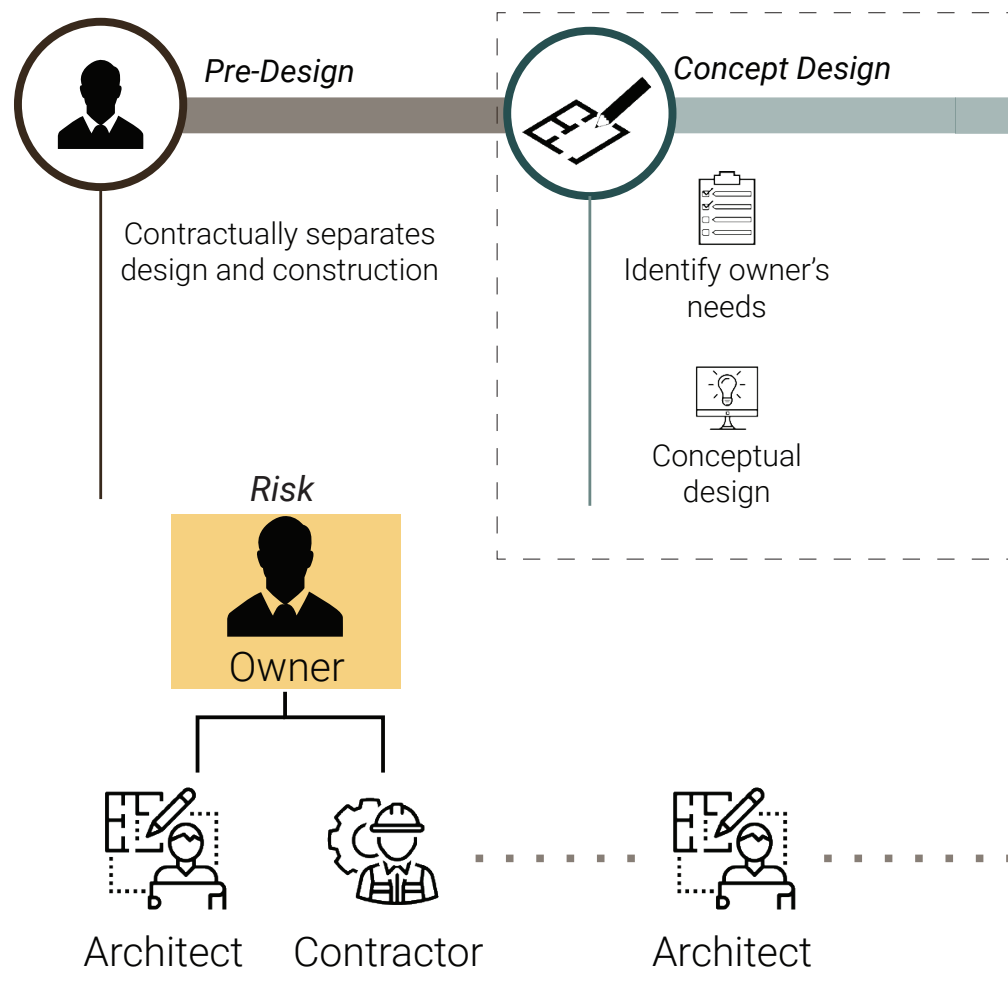

established which can be costly, time-consuming and produce errors (Eastman et al., 2011).

The traditional process "does not allow early collaboration in projects or encourage collaboration during the construction stage" which can affect the entire project (Fuemana et al., 2013, p. 3). This is because during the construction stage there are often numerous changes that are made to the design. This is a result of "previously unknown errors and omissions, unanticipated site conditions, changes in material availabilities, questions about the design, new client requirements, and new technologies" (Eastman et al., 2011, p. 6). Consequently these changes impact the entire process, requiring there to be responsibility assignments, evaluation of time and cost implications and how the issue will be addressed (Eastman et al., 2011). 


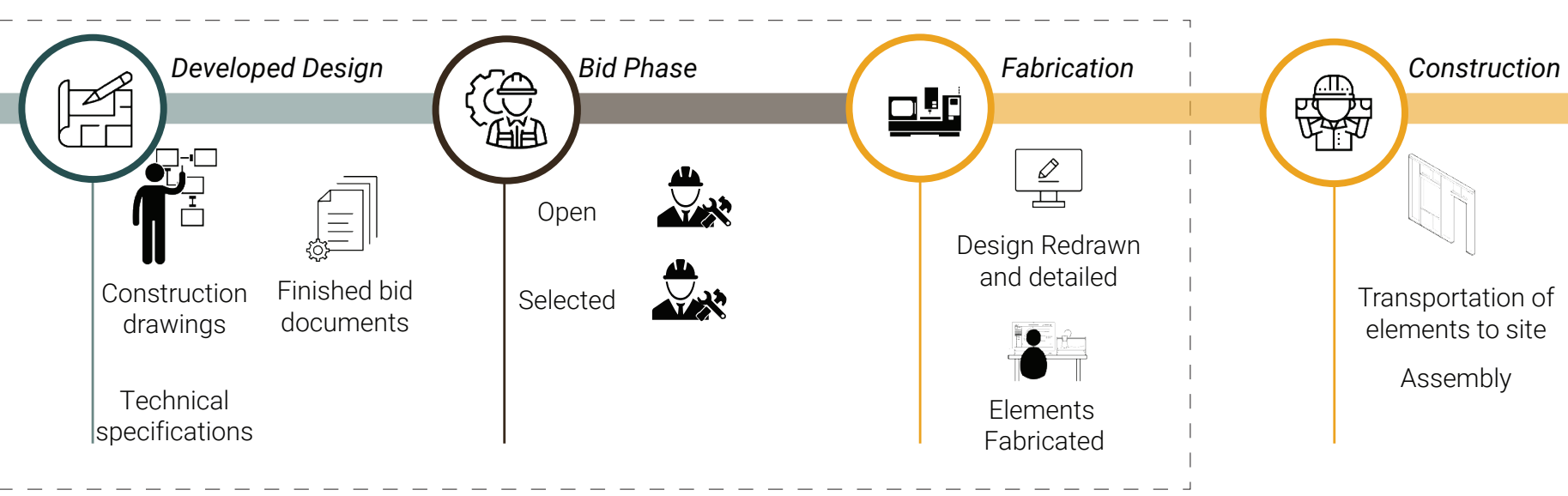

People involved
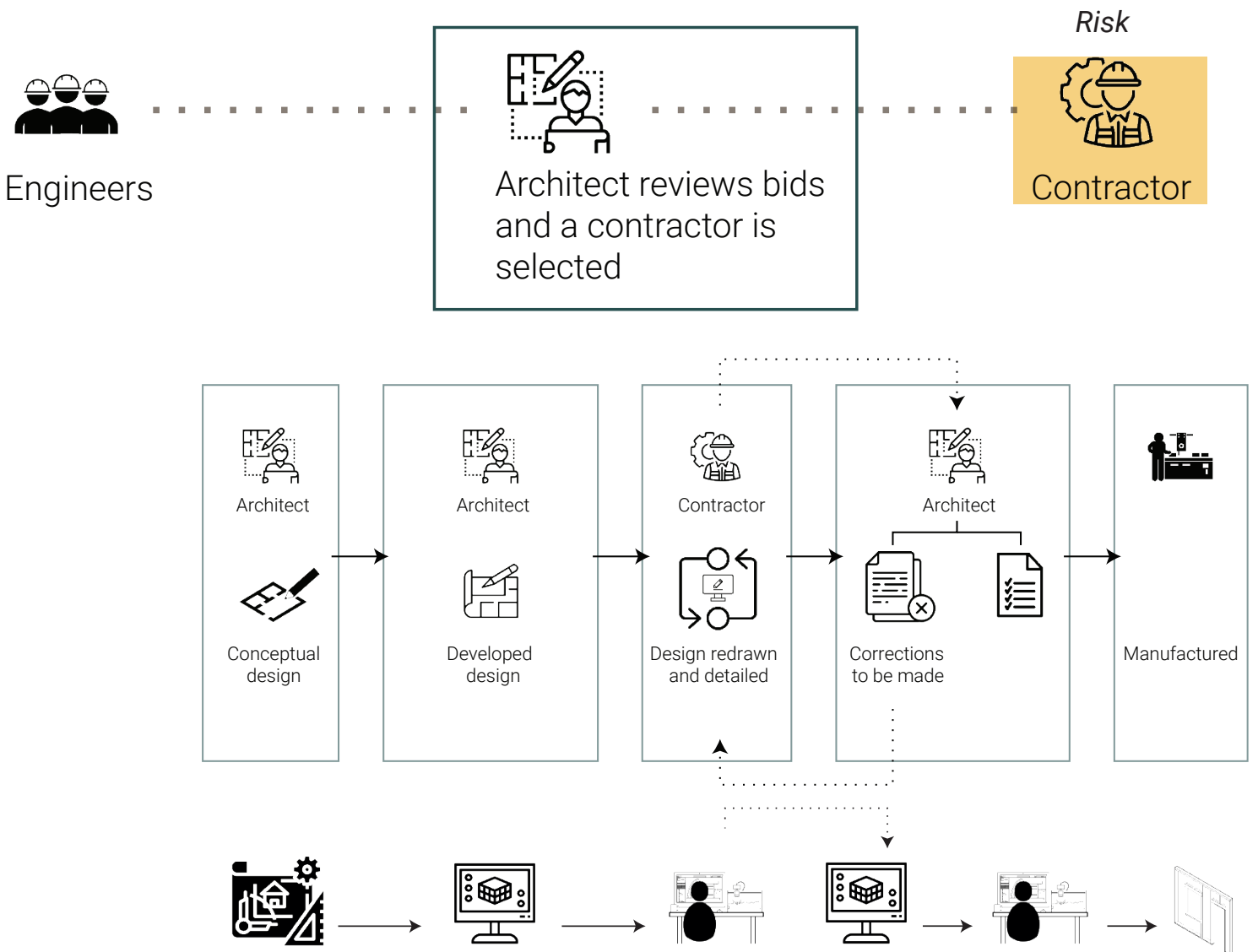

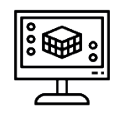

Revit

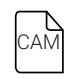

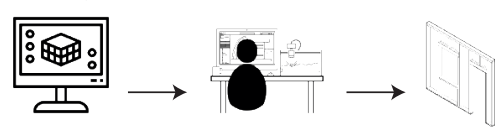

Revit

MiTek or Pryda

BIM

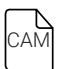




\subsubsection{Integrated Project Delivery}

Integrated Project Delivery (IPD) is a collaborative project delivery approach typically consisting of a multi-contract between the main stakeholders, owner, primary designer, and primary builder (Lean IPD, 2019) (see Figure 2.03). This approach is typically used for larger scaled projects. In comparison to the traditional design-bid-build, profit is at risk. Depending on how well the project goals are met will determine the profit at the end (Lean IPD, 2019). It attempts to bring design and construction together and have early contractor involvement from the very beginning of the project. There are several different types of contracts. Each type is built to benefit the members of the team and prevent them from sliding off track (Stencil \& Powell, 2018). Typically, IPD aims to optimise the whole project rather than parts, improve the working relationships between disciplines by really collaborating, couple learning with action, manage projects as a network of commitment, and increase relatedness to all parties (Pease, 2019). The approach can be enhanced by incorporating lean concepts to integrates, people, design and construction and works to reduce errors, waste, and improve the efficiency of delivering a project from start to finish (Lean IPD, 2019).

Figure 2.04 demonstrates the comparison between an integrated and traditional delivery process. In the integrated delivery process the main stakeholders are all involved from the start. The conceptualisation phase in the integrated delivery is longer, however, allows time for manufacturing and assembly processes to be considered for the design early in the design phases.
FIGURE 2.03.INTEGRATED PROJECT DELIVERY
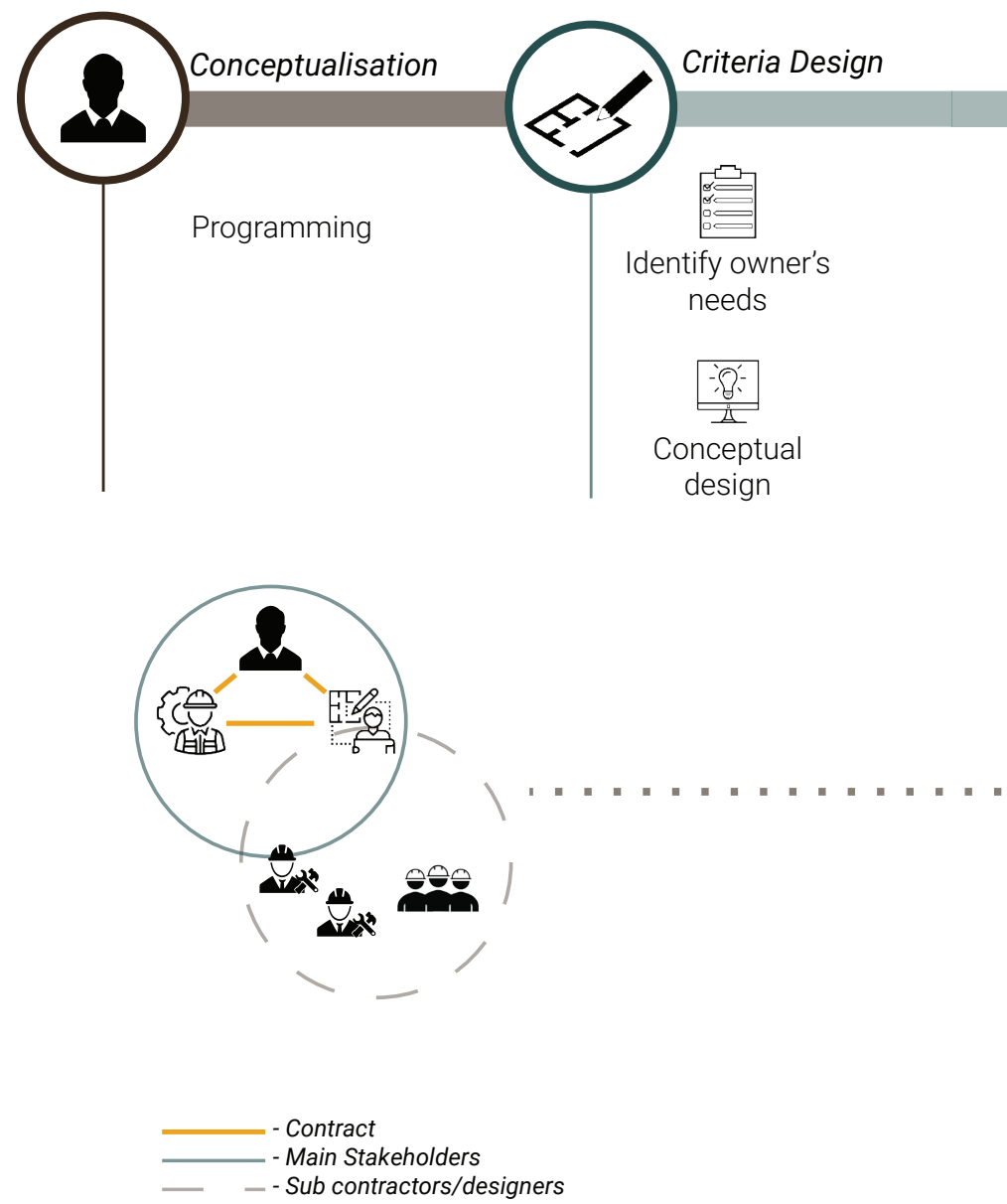

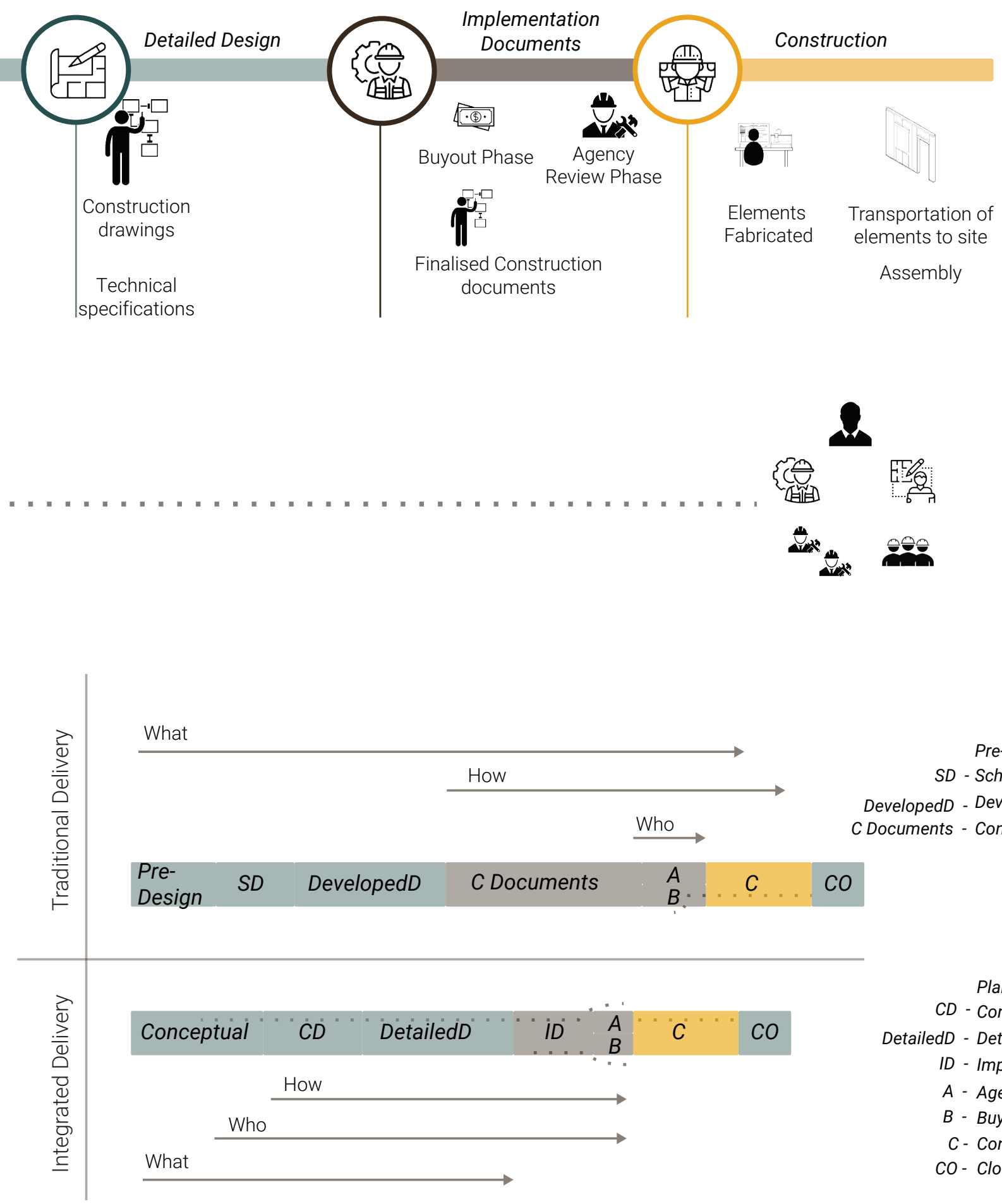


\subsubsection{Design for manufacture and assembly}

Design for Manufacture and Assembly (DfMA) is a set of principles and guidelines that emerged in the late 1960s to early 1970s, aimed to create a way of working that could effectively manufacture, increase the quality, decrease the cycle time, and be assembled with high speed, and at a low cost (Bogue, 2012, Xie, 2003). DfMA combines two methods Design for Manufacture (DfM) and design for assembly (DfA) (see Figure 2.05). DfM focuses on the building components being designed easily and cost-effectively while DfA focuses on the assembly of these individual components (Bogue, 2012, Xie, 2003). DfMA has been used consistently in the engineering and product design industries, however is still relatively new to the architecture industry.

The implementation of DfMA brings a range of different benefits to the architecture and building industry. The main benefits come from a set of rules or guidelines that have been put into place at the beginning of the project (Bogue, 2012). Many of the overall benefits include improved efficiency, reduced costs, simplified assembly, improved reliability, fewer manufacturing processes, and reduces the need to rework incorrectly assembled parts (Bogue, 2012, Xie, 2003).

DfMA can also be introduced and utilised in the construction industry "to improve the current design system (or process) of prefabricated buildings" (Yuan, Sun, \& Wang, 2018). While BIM has made huge advancements in the architecture and construction industry, the existing BIM tools have not been fully utilised when it comes to prefabricated components and buildings (Yuan et al., 2018). Yuan et al. (2018) mention that many of the existing BIM tools do not consider the "new process that building components are produced in factory and moved to construction site for assembly" (p. 14). Designers and architects often do not understand how their designs will be manufactured and then later assembled on site. By utilising the existing BIM technology and implementing DfMA this can impact the way we produce projects within New Zealand and improve the efficiency, and reduce errors, and cost. 


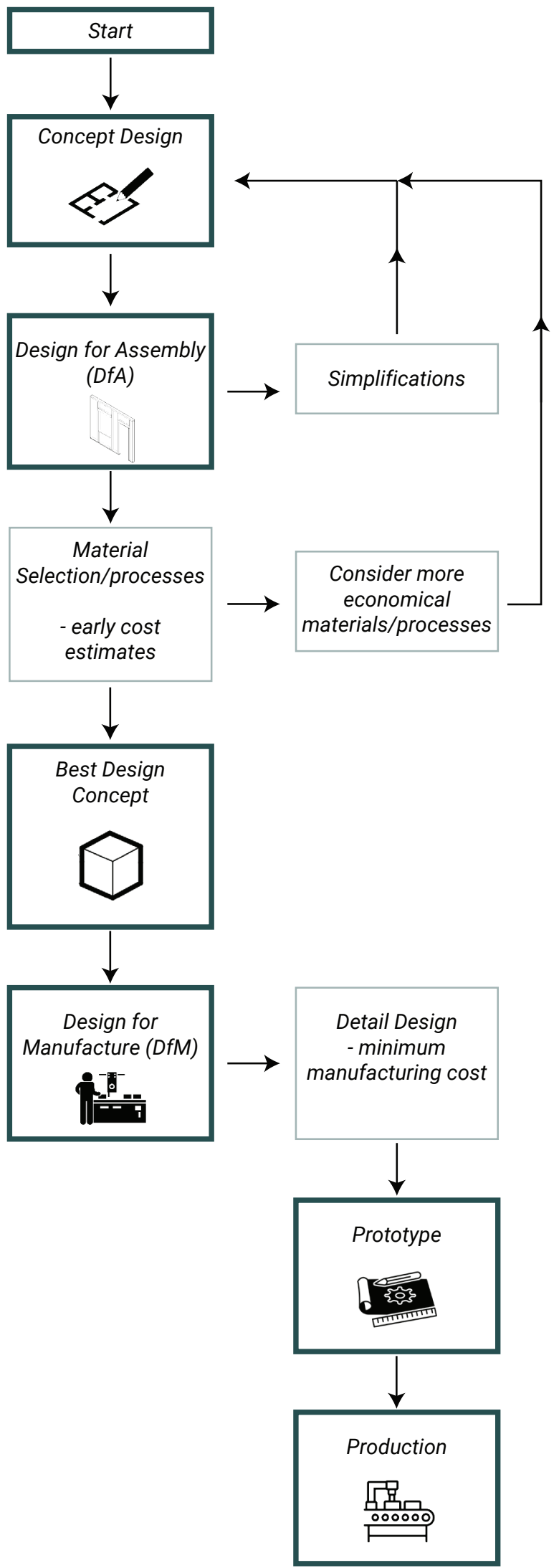




\subsection{BUILDING INFORMATION MODELLING}

\subsubsection{BIM}

Building Information Modelling (BIM) has increasingly become a regularly used digital process and tool within the architecture and building industry. It is "one of the most promising developments in the architecture, engineering, and construction (AEC) industries" (Eastman et al., 2011, p. 1). BIM as defined by the BIM Acceleration Committee (BAC) (2019), "is a coordinated set of processes, supported by technology, that add value through the sharing of structured information for buildings and infrastructure assets" (p. 4). When successfully implemented, BIM facilitates a more integrated process of design and construction resulting in improved quality of buildings at lower cost and greater efficiency (Eastman et al., 2011).

\subsubsection{Benefits}

There are many benefits to using and implementing BIM into the project delivery workflow for owners, architects/ engineers, and contractors. Benefits to the owners of using BIM include the concept, feasibility, and design benefits, increased building performance and quality, and the improved collaboration using IPD (Eastman et al., 2011). Many of the design benefits arise from the collaboration it allows between the different disciplines which, in turn, allows for earlier consultation and verification of consistency to the design intent, clash detection, and generation of accurate 2D drawings and 3D views (Eastman et al., 2011).

BIM is a way to bring design and construction together, creating a fluid workflow. Garber (2014) states "Through cohesive integration, BIM has the ability to resolve traditionally oppositional aspects of architecture such as theory/practice, academy/profession and design/construction" (p. 19). BIM also has the ability to improve the communication and relationships between stakeholders of a project such as the architect, contractor, and client and allows for much earlier engagement in the design process when their inputs are of greatest value (BAC, 2019). "The duality inherent in BIM brings construction and design together under the rubric of a shared information model, while still promoting the architect as a creative director of sorts - who authors design intent, or a project's general features, and then supervises a collaborative team of experts who each input data, or variable aspects, into the model" (Garber, 2014, p. 17).

BIM also benefits construction, fabrication, and post construction. The construction and fabrication benefits include using the design model as a basis for fabricated components, quick reaction to design changes, early error and clash detection before construction, and better implementation of lean techniques. Lean construction has been explained further in the following paragraph to expand on these lean techniques. 
Lean construction is a "method of production aimed at reducing costs, materials, time and effort" (Mackie, 2019). It has a focus on productivity and how it can be maximised by managing flows and maximising value. This methodology and way of working is similar to those for the architecture and manufacturing industry equivalent. The main differences between lean construction and other construction methods is the management and the way it is set out. Everyone has a clear set of goals, benchmarks and objectives. This not only improves productivity within the construction sector but also provides a better synchronization of procurement with design and construction (Eastman et al., 2011; Garber, 2014). As for the post construction benefits, these are the integration of facility operation and improved commissioning and handover of this information as well as better management and operation of facilities (Eastman et al., 2011).

\subsubsection{Revit}

Revit Architecture is a well-known BIM platform and considered a "BIM market leader" (Eastman et al., 2011, p. 77). It is the most common BIM software used in the architecture and building industry worldwide. Revit consists of several integrated products Revit Architecture, Revit Structure, and Revit MEP and is compatible with Microsoft Windows (Eastman et al., 2011). By creating an integrated 3D model of the different disciplines Revit allows for the design to be visualized as a whole before the end of construction.

\subsubsection{Interoperability}

There is currently a lack of interoperability opportunities with BIM, particularly with Revit. The file exchange formats that have been traditionally relied on are DXF (Drawing eXchange Format) and IGES (Initial Graphic Exchange specification) (Eastman et al., 2011). While these file formats can be useful for importing geometries however, once imported, customizing the design becomes very limited because the files cannot be readily edited.

The Industry Foundation Class (IFC) is a building product data model for the design and full lifecycle of buildings (Eastman et al., 2011). While this schema is more promising for interoperability it is still limited. Eastman et al. (2011) mention "interoperability, at the minimum, eliminates the need to manually copy data already generated in another application" (p. 100). However, even with interoperability there can still be errors and inconsistency.

The main challenge of interoperability is from platform to platform usually from design software to manufacturing software since there is limited interoperability, for example Revit to MiTek (design software to engineering software) (Eastman et al., 2011). The programs necessary for detailing the design in the shop drawing phase before manufacture consist of different computer aided manufacturing (CAM) software with no interoperability with BIM. Utilising BIM to its full potential would eliminate the need for interoperability by providing a direct transfer of information from the BIM model to manufacture. Even in the early stages of the design, BIM would allow the manufacturer to access the 3D model in a collaborative digital workflow. 


\subsubsection{Legal Issues}

Although BIM provides a more collaborative approach between stakeholders and those involved there are some legal concerns that present challenges. The legal implications of BIM are pertinent to drawing up the contract between the main parties, specifically when there is either consultant or contractor involvement (BAC, 2019). A request for proposal (RFP) should be drawn up by the client discussing the project BIM brief, any relevant expectations of the consultant, and the goals. The scope and responsibilities of the project should also be included for timeliness, completeness, and quality of deliverables. The project BIM brief, client's goals and benefits, and design models are required when submitting a Request for Tender (RFT) for contractor engagement. Intellectual property and model disclaimers are also important to address (BAC, 2019). In particular these apply to ownership rights and responsibility for parts of the model (Eastman et al., 2011). It is also important for users to understand the extent they can rely on the models, fabrication, or analysis of these and who pays for them (BAC, 2019; Eastman et al., 2011).

\subsubsection{BIM in New Zealand}

While BIM has been implemented into the way New Zealand delivers projects, it is still not being used to its full potential due to limited support from contractors and their suppliers (BAC, 2019). BRANZ an independent research organisation, has recently indicated in their Industry Transformation agenda priorities for improving the industry. One of their priorities is to improve information flows and data so that the information can be used proactively "to speed up projects without compromising quality" and "improve the capture and flow of information data across the value chain" ("Transformation is Happening," n.d.). Their main goals are to provide the industry to have access to the best practice information when and where they need it, manage large volumes of data in real time, and reduce miscommunications ("Transformation is Happening," n.d.).

Due to the inefficiencies that can occur during the shop drawing file-to-factory process with the traditional design-bid-build procurement process, alternative delivery processes have been investigated to facilitate a better workflow. IPD is a more collaborative delivery process that, when used properly with BIM, can deliver projects more effectively and create a smooth transition/workflow from design-to-construction (Eastman et al., 2011; Garber, 2014). However, the IPD delivery method is typically used for larger scaled projects. It is not generally used within New Zealand which could be a result of New Zealand's market primarily consisting of small to medium enterprises (Patel, 2017). Other reasons, such as too many legal barriers, high learning curve and training costs, or workers being ambivalent about change, could also be contributing factors. 
DfMA provides another solution, better suited to New Zealand's market. It is a collaborative way of working while focusing on being able to identify and analyse the manufacturing and assembly problems at the early stages of design (Xie, 2003). The potentials and opportunities of BIM technology makes it capable of supporting DFMA and "DFMA makes BIM more suitable for prefabricated buildings" (Yuan et al, 2018, p. 16). The combination of BIM and DFMA makes for a promising and efficient way of delivering projects. By coupling these processes together, the designer not only considers the requirements of the design but also the requirements of the manufacture and assembly stage while using BIM technology to produce a 3D model (Yuan et al, 2018).

\subsection{A M}

The advances in Computer-aided design (CAD) and Computer-aided manufacturing (CAM) technologies have impacted the way buildings are designed and construction practices in the industry (Kolarevic, 2001). Digital fabrication has emerged from the use of CAD/CAM since it utilizes "computer-controlled machines as tools with which to cut or make parts" (Dunn, 2012, p. 20). Although CAD/CAM is still a relatively new process in the architecture industry, these processes have been around for more than 50 years integrated into automotive, aerospace and shipbuilding industries (Leach, 2002; Dunn, 2012). With this new way of working, all data are compiled into a computer model facilitating a greater fluidity between the different stages of design and fabrication (Dunn, 2012).

CAD/CAM introduced new opportunities "allowing production and construction of very complex forms that were until recently very difficult and expensive to design, produce, and assemble using traditional construction techniques" (Kolarevic, 2001, p. 269). It wasn't until computer modelling and digital fabrication emerged that design thinking was energised and the boundaries of architectural form and construction were expanded (Iwamoto, 2009). This was achieved through software such as BIM and CAD/CAM. Although, BIM is technically a CAD program, the term 'CAD' typically refers to drafting (CADlearning, 2016). Unlike 'CAD', BIM is an integrated workflow and modelling tool that provides $3 \mathrm{D}$ and $2 \mathrm{D}$ information about a project from design through to construction (CADlearning, 2016). From 3D models, CAM provides the ability to take it directly to manufacture being able to produce full-scale building components (Kolarevic, 2001). 


\subsection{CNC TECHNOLOGY}

Computer Numerically Controlled (CNC) machines are the underlying digital making technologies for digital fabrication. CNC essentially "uses a computer system to generate coded instructions that in turn control the movements of a machine tool" (Dunn, 2012, p. 96). Through short computer scripts, CNC machines can coordinate multiple different tasks at any given time. These actions can consist of motion control, tool changes, and spindle operations. CAD/CAM technicians refer to the instructions or "preparatory codes" as G-code as a result of the majority of the functions being designated with the letter "G" (Dunn, 2012, p. 96). These instructions are often sorted into the following primary commands; rapid move, a controlled move in a straight line or arc, and series of controlled moves, or to set tool information (Dunn, 2012, p. 96).

CNC was intentionally designed to match the specifications and requirements of the building industry aimed towards timber construction. Larsen and Schindler (2008) note "CNC machines for timber construction were specifically developed for their trade" (p. 400). This enabled them to meet the requirements of the industry, such as the specific tolerances, low budgets and a high processing speed (Larsen \& Schindler, 2008). In the building industry, the most widely known CNC machinery is used for preparing components such as beams, frames and trusses. These are then assembled into larger elements or panels (Larsen \& Schindler, 2008). The arrangement and number of different components that are produced can be maximised through G-code, often reducing the amount of waste material. This process can "facilitate effective and relatively economical making of nonstandard components" (Dunn, 2012, p. 96). 


\subsection{CONSTRUCTION PRODUCTIVITY}

\section{IN NEW ZEALAND}

Construction productivity in New Zealand is both lacking international standards and appears to be declining (Fuemana et al., 2013). The decline in productivity within New Zealand between 2006 and 2009 has been mainly attributable to the manufacturing and construction sectors (Bascand, 2011). BRANZ states the "productivity for construction in New Zealand is about 50\% worse than in the UK" (2010, p. 7). The reasons why New Zealand's construction sector has poor productivity is unclear, but the New Zealand Building and Construction Sector Productivity Taskforce (as cited in Fuemana et al., 2013, p. 680) mentions key factors are "innovation, regulation, procurement practice, management capability, skills, and job churn".

One of the main drivers of New Zealand's low productivity is the wide spread usage of traditional procurement methods. The use of traditional methods leaves little room for innovation or the use of new methods (Fuemana et al., 2013). There are many disadvantages to using the traditional procurement method within New Zealand due to the lengthy time and cost, client changes, and contractor quality. The lack of innovation is heavily coupled with the procurement practice in New Zealand limiting the design potential and innovation opportunities. The improvements and innovation that has been made in the construction sector has primarily focused on improving quality rather than enhancing efficiency (Fuemana et al., 2013). 


\subsection{CASE STUDIES AND PRECEDENTS}

\section{O VER VIEW}

These file-to-factory case studies were chosen to explore and assess what improvements have been made towards the design-to-construction process. It discusses the ability to create a streamlined construction process. These case studies have been explored and discussed to identify the current processes and digital tools that are being utilised in architectural projects. A case study from Europe demonstrated the potential of implementing DfMA principles into their workflow. The impact from the integration of DfMA and BIM tools on their delivery process has been discussed.

The IPD precedents were chosen to explore and assess what was found to be successful and challenging with each individual one. This was mainly to analyse how well BIM had been utilised and implemented into the projects. These precedents are a reflection on how effective and efficient the IPD process was. This method of delivery is the most widely used within the United States. The key factors contributing to a project's success were based on the lean and IPD principles. These 6 principles involved; 1. Team Implementation, 2. Team Formation, 3. Goals, 4. Cost and Decision, 5. Project Management, and 6. The utilisation of BIM.

This content is
unavailable.
Please consult the
figure list for further
details.
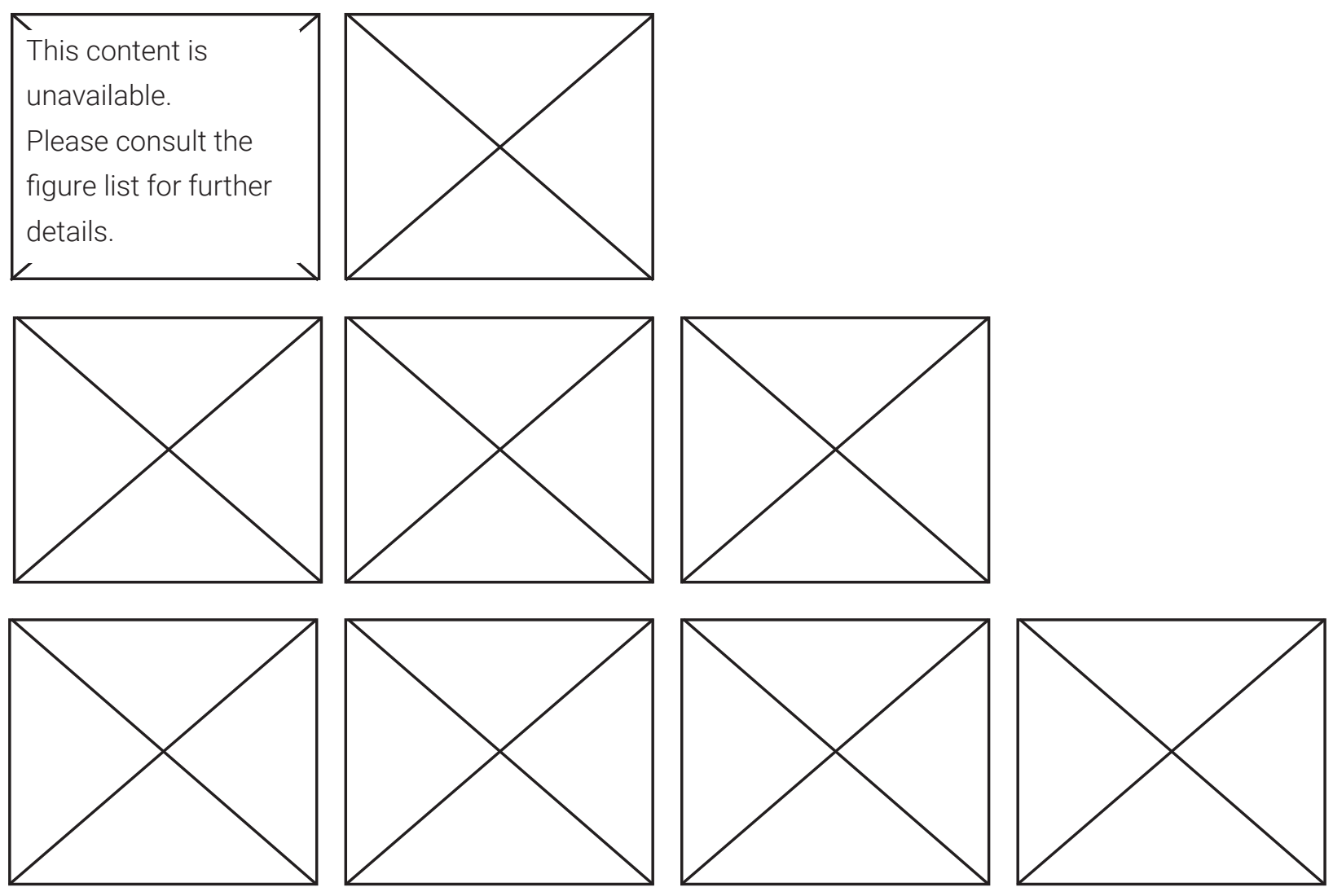

Case Studies and Precedents 


\subsubsection{FILE-TO-FACTORY CASE STUDIES}

\section{K90}

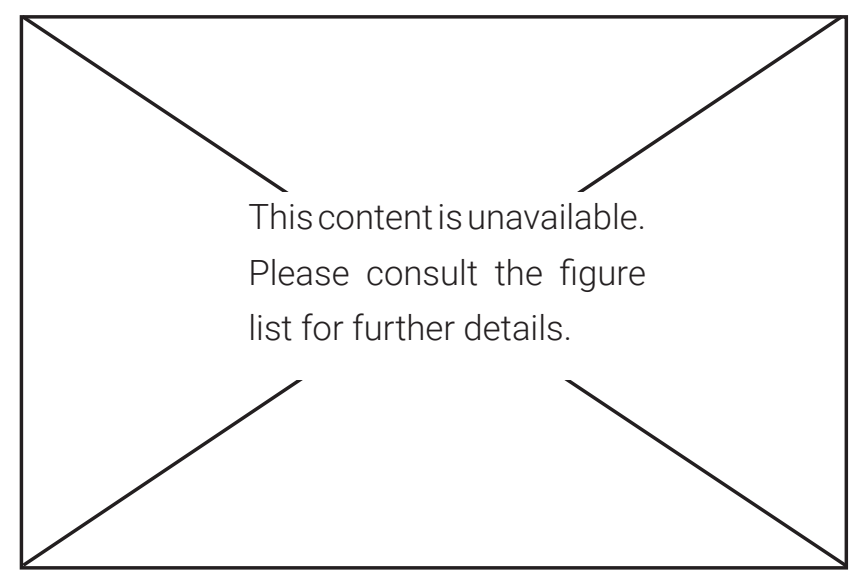

FIGURE 2.06. K90 BUILDING SITE

Project: $\mathrm{K} 90$

Location: Las Vegas, Nevada

Design and Construction Company: Katerra

K90 represents a successful approach to the file-to-factory process and fabrication techniques. This 24-Unit garden-style multi-family building was built in 86 days with a deadline of 90 days (Katerra, 2019 b). A manufacturing mindset was implemented to find ways of optimising the design and building process (Katerra, 2019 a). Katerra the company that designed and built the project utilises technology to address some of the building industry's challenges. From the very start this was a fully integrated team project with everyone working collectively towards the overall project timeline goal (Katerra, 2019 a). The project consisted of repeatable and predictable manufacturing which benefited the construction as the assembly was streamlined. While working from a standard kit of parts such as floor systems, and exterior and interior wall panels, mass customisation allowed for a large number of design opportunities (Katerra, 2019 a). The utilisation of BIM allowed for a fully integrated model and early identification of potential issues (Katerra, 2019 a). The key achievement made on K90 was the speed at which the building was framed. Due to their panelised structural system of pre-wired panels with an increased level of completion offsite this allowed for there to be a streamlined onsite assembly process. 


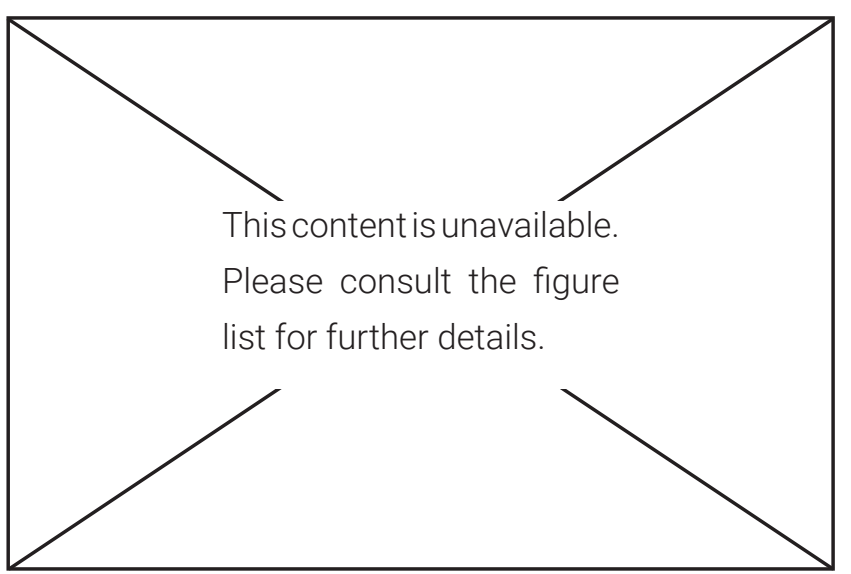

FIGURE 2.07. DFAB HOUSE

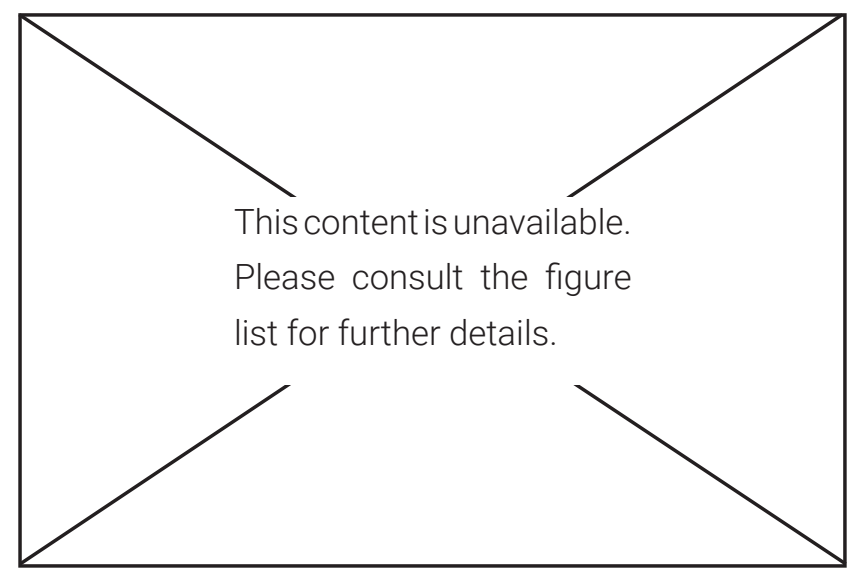

FIGURE 2.08. SPATIAL TIMBER ASSEMBLIES

Project: DFAB house

Location: Switzerland

Researcher: ETH Zurich

DFAB house was designed by several different ETH Zurich researchers to explore and test the implications of digital fabrication on the way we design and build (see Figure 2.07). The house was digitally designed and uses a variety of digital processes such as spatial timber assemblies (DFAB House, n.d). The spatial timber assemblies utilise technology by robotically fabricating the frames (see Figure 2.08). This robotic joining technique provides precision, one robot taking the timber beam and guiding it to be sawed to the correct size while the other drills the required holes (ETH Zürich, 2018). CAM software was used to program the robot to cut and arrange the timber beams. If there are any changes, the computer model could be adjusted continually to meet the new requirements (ETH Zürich, 2018). ETH Zurich (2018) created its own algorithm for the robots so that the path of motion was constantly recalculating based on the stage of construction. This new innovative timber construction method differed from the traditional frame construction by eliminating the need for reinforcement plates due to the rigidity and load-bearing result of the geometric structure (ETH Zürich, 2018). The integrated digital architecture process closed the gap between design, planning, and execution. The process is not only efficient for construction and assembly, it also opened up a range of possibilities for timber frame construction in regards to creativity while saving on material. 


\section{KB Home ProjeKt}

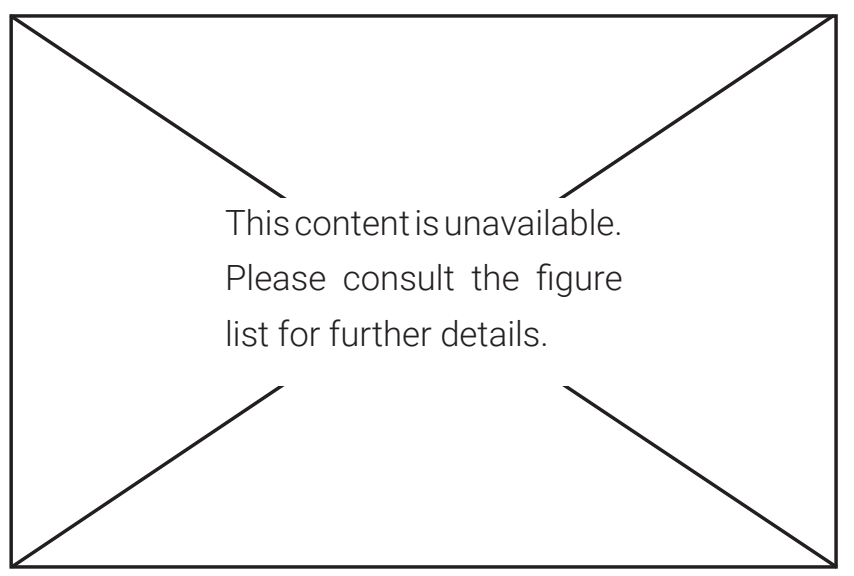

FIGURE 2.09. KB HOME PROJECKT

Project: KB Home ProjeKt

Location: Henderson, Nevada

Construction Company: Entekra

The KB Home ProjeKt offered an immersive experience utilising wellness technology and flexible space in a home. The project focused on utilising technology and innovative design while making it as sustainable and innovative as possible (Kingspan Group, n.d). There were several contributors and collaborations for the project, involving KB Home builder, Kingspan, and Entekra for the manufacturing and construction process. For the project to achieve its thermal and overall performance targets it became evident that high-performance insulation was required. Kingspan is a product manufacturer providing sustainable building solutions and new innovative technologies. Kingspan's Kooltherm K12 framing board was used to achieve high thermal efficiency (Kingspan Group, n.d).

Entekra a design, engineering, and manufacturing company presented a new process called fully integrated off-site solution for residential and commercial projects (Entekra, 2019). They streamlined the construction process leveraging the integration and application of software, engineering, technology, and modern methods of construction (Entekra, 2019). For the KB Home ProjeKt, they collaborated with Kingspan to prepare Kingspan's Kooltherm product to be factory fitted to fabricate the KB Home projeKt wall panels (Kingspan Group, n.d). The insulation boards were added at Entekra's factory adding value to the wall panels before being shipped to the site for assembly. Entekra's system has less material waste, reduced need for skilled labour, and more customised experience for the client compared to traditional processes (Kingspan Group, 2019). 


\section{Mt. Pleasant Community Centre}

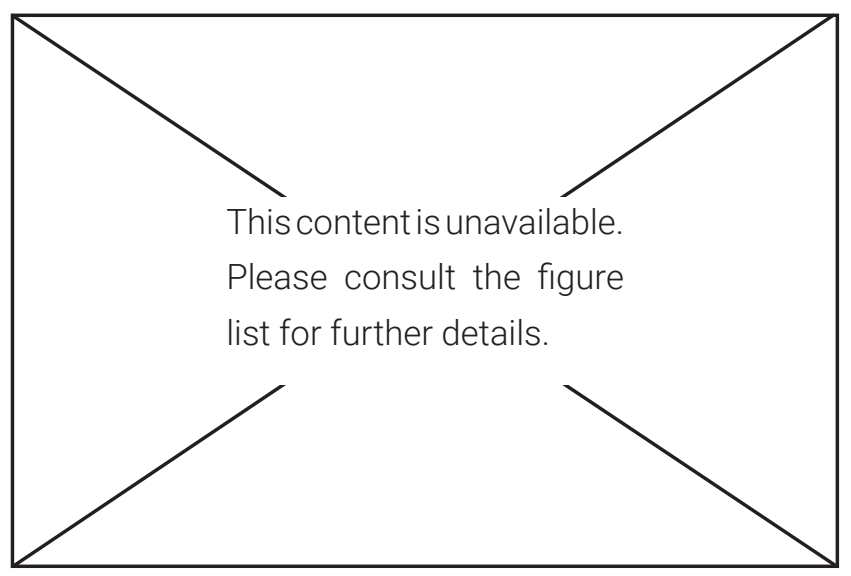

FIGURE 2.10. MT. PLEASANT COMMUNITY CENTRE

Project: Mt. Pleasant Community Centre

Location: Christchurch, New Zealand

Architect: Chris Moller Architecture + Urbanism

The Mt. Pleasant Community Centre located in Christchurch represents a successful approach to addressing the file-to-factory process and fabrication techniques. This project is one of the first in New Zealand to take a 3D BIM model directly to manufacture. The centre involved the prefabricated construction process, design-fabricateassemble having the design go straight to CNC milling (CMA + U, 2013). The project is made out of Laminated veneer lumber (LVL) timber panels that are fixed together rigidly with an array of both steel and timber joiners at the edges, screw-fixed in two directions (CMA $+U, 2013)$. The only reason this was possible was because the architect on the project took the risk and responsibility, and collaborated with the fabricator for the project. 


\subsubsection{DfMA CASE STUDY}

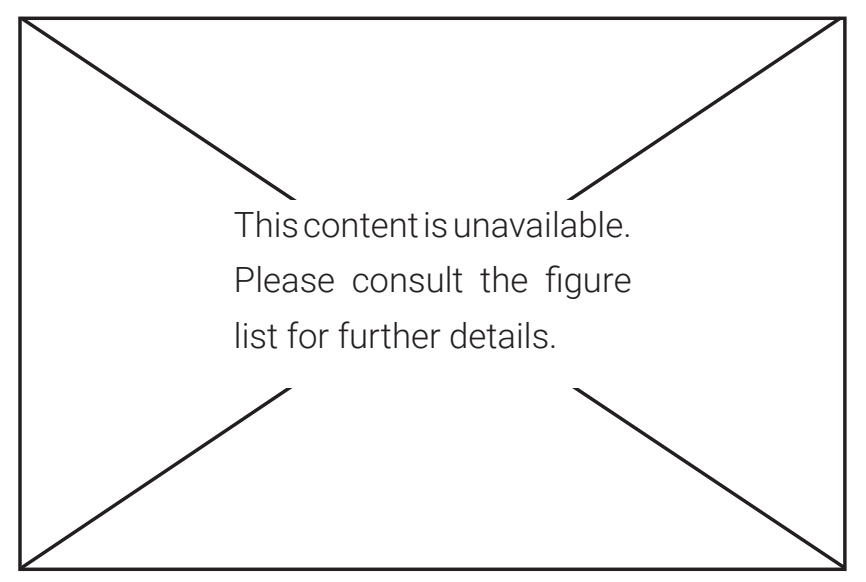

FIGURE 2.11. EXPLORE INDUSTRIAL PARK

Factory: Explore Industrial Park

Construction Company and factory owner:

Laing O'Rourke

This company aims to utilise technology to overcome long established barriers. Automation is increasingly becoming more popular with benefits such as increasing the productivity on production lines. Explore Industrial Park is beginning to shift the construction process to use more approaches similar to those used in the manufacturing sector. DfMA has been implemented into their daily practice improving their quality and their delivery of projects (Laing O'Rourke, 2013). They are one of the only factories that provides the most automated concrete products in Europe. The Laing O'Rourke group is in control of its own supply chain which is a key factor, allowing them to react quickly to any changes or requirements to site while utilising their automation and advanced software tools (Mills, 2019). Solibri office a digital software has been utilised to validate the contents and created a federated information model being able to check the quality of the data. Solibri also allows stakeholders to view the design while on site enhancing the workflow and minimising cost and time creating an automated process (Mills, 2019). From implementing DfMA, the factory has managed to move $70 \%$ of the onsite manufacturing offsite increasing productivity by 60\% and improving the delivery accuracy (Laing O’Rourke, 2013; Mills, 2019). 


\subsubsection{IPD PRECEDENTS}

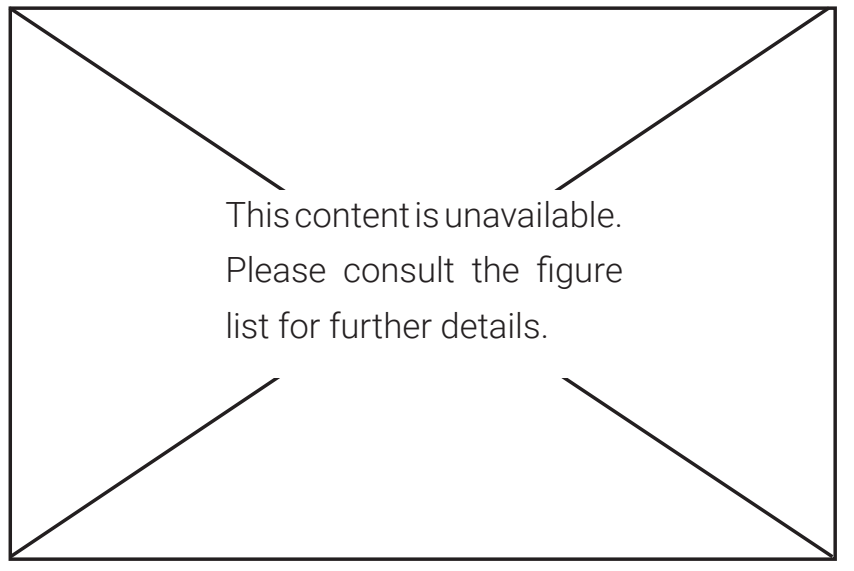

FIGURE 2.12.PROJECT: SUTTER HEALTH EDEN MEDICAL CENTRE

Location: Castro Valley, California

Architect: Devenney Group

Year of Completion: 2012

\section{Successful //}

- Delivered ahead of schedule

- $\quad$ Met \$32 Million target cost

- $\quad$ Achieved LEED certification

- Team delivered complete designs 15.5 months
Team Implementation

Team Formation

Goals

Cost and Decision

Project Management

BIM

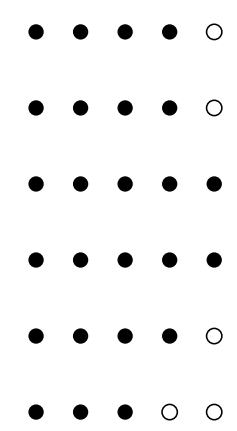

\section{Challenges //}

Close to Hayward fault with a seismic category $F$ resulting in a seismic factor $1=1.5$

Engineer had to design structure under restricted requirements

Exterior complex glass curtain wall - analysis of interaction between structure and skin 


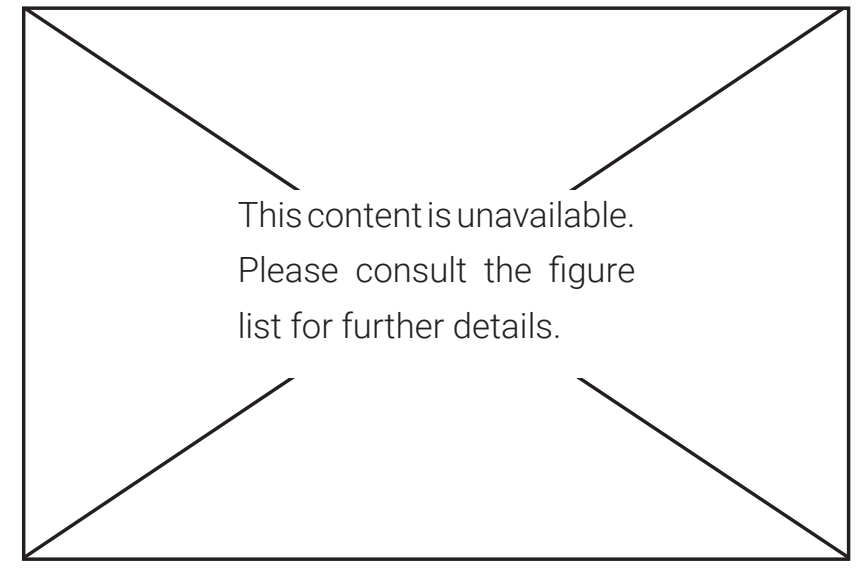

FIGURE 2.13.PROJECT: QUAIL RUN BEHAVIOURAL HEALTH HOSPITAL

Location: Phoenix, Arizona

Architect: Devenney Group

Year of Completion: 2014

\section{Successful //}

- Most partner offices were close by, no need for a co-location. Virtual meetings with screen sharing was very effective.

- $\$ 3.5 \mathrm{M}$ in savings from the team's original construction estimate.

- The contractor was able to provide timely updates on the project budget.
Team Implementation

Team Formation

Goals

Cost and Decision

Project Management

BIM

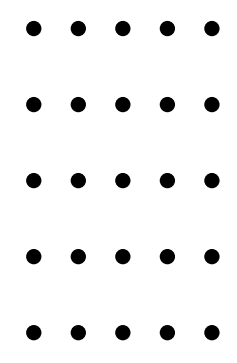

- 100

\section{Challenges //}

- Tension with architects due to the amount of time taken to complete design and produce full documentation

- Developing all of the appendices for cost, and budget, and those expectations

- Constructor partners thought design was further along and didn't understand they were invited to the very beginning of the design 


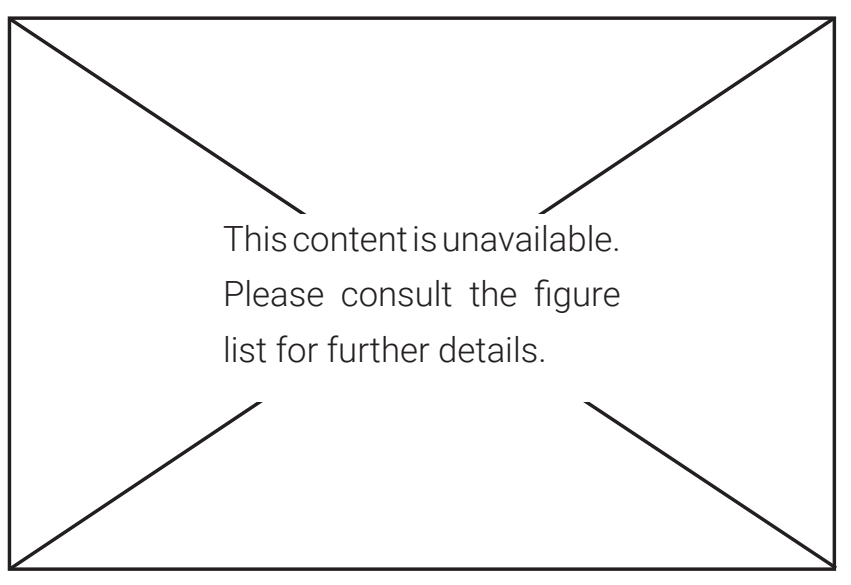

FIGURE 2.14.PROJECT: MOSAIC CENTRE FOR CONSCIOUS COMMUNITY AND COMMERCE

Location: Edmonton, Canada

Architect: Manasc Isaac Architects

Year of Completion: 2015

\section{Successful //}

- $25 \%$ faster than original schedule of fifteen months (based on typical delivery for a project of this size and scope

- First LEED Platinum rating and the first Living Building Challenge Petal Certification for the city of Edmonton and the first net-zero office building
Team Implementation

Team Formation

Goals

Cost and Decision

Project Management

BIM

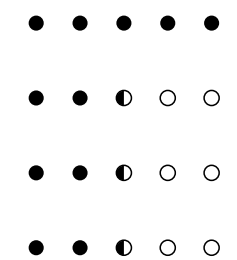

- 100

\section{Challenges //}

- The team was less successful meeting schedule goals, mostly due delays from the city.

- Major schedule challenges, however by using IPD this helped overcome these 


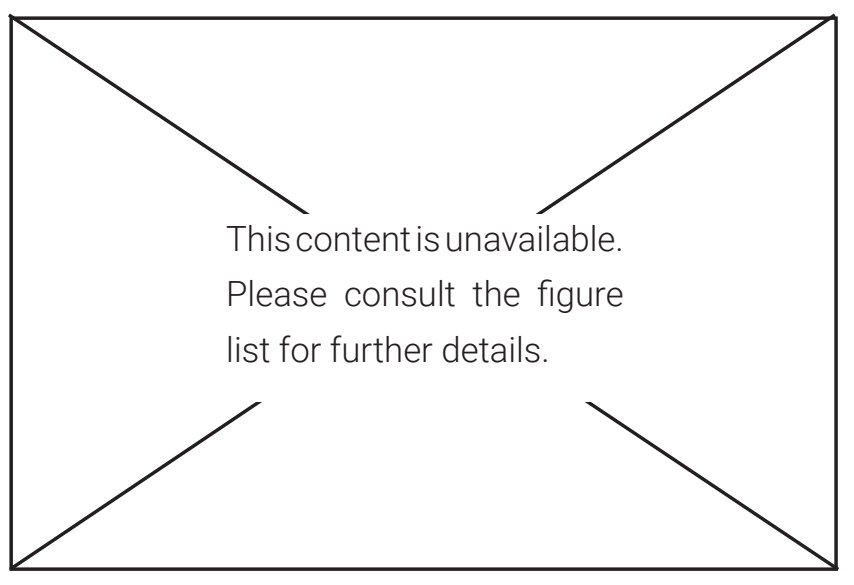

FIGURE 2.15.PROJECT: ROCKY MOUNTAIN INSTITUTE INNOVATION CENTRE

Location: Basalt, Colorado

Architect: ZGF Architects

Year of Completion: 2015

\section{Successful //}

- Team successfully mitigated a two-month delay in the windows delivery. Overall project schedule was not affected

- Passive house standards met and exceeded

- Achieved LEED Platinum
Team Implementation

Team Formation

Goals

Cost and Decision

Project Management

BIM

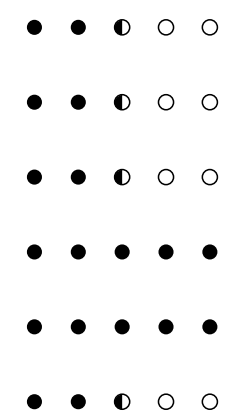

Challenges //

- Applying passive house strategies to a commercial program

- Remote location

- Challenges communicating with contractor

- Combining the real cost [limitations] was a true challenge

- Aspiration for a high performance building 


\section{FINDINGS FROM CASE STUDIES AND PRECEDENTS}

\section{File-to-Factory}

These case studies were chosen because of the improvements towards the file-to-factory process and ability to streamline the framing process for construction and assembly. This was demonstrated through the utilisation of current digital tools, fabrication techniques and creative use of timber.

$\mathrm{K} 90$ is an example of this, providing a clear and efficient manufacturing and assembly process through the utilisation of technology and the use of kit set parts. Katerra established the influence having a collaborative fully integrated team can have on the design-to-construction process. The other main emphasis was on having a manufacturing mindset being able to optimise the design and building processes. Their use of kit sets and panelisation process allowed for a more streamlined onsite assembly creating an effective smooth workflow. BIM was utilised and implemented well into the project.

ETH Zurich successfully created a new way of constructing timber frames and pushes the design potential of these through the utilisation of robotic fabrication and technologies. CAM software was utilised to program the robots to be spatially aware of the current building stage. By utilising this software if any changes are made, the computer model can be adjusted. This new way of constructing timber frames closed the gap between design, planning and execution through the integration of digital processes.

Through their fully integrated off-site solution, Entekra provides a smooth transfer through leveraging technology, engineering and building methods. This is an excellent demonstration of how an efficient workflow could be created. The ability to manufacture the wall panels off-site was beneficial, reducing on-site time and increased the labour savings. Entekra's building solution focussed on the modular aspect specifically looking at prefabrication, panelisation, and components demonstrating the ability to create a streamlined construction process.

The Mt. Pleasant Community Centre is an excellent example of how important it is to have a smooth transfer of data when going from design to manufacture. The way projects are designed more often than not is based off of the design intent. The way projects are delivered in New Zealand, they focus on the design intent due to the nature of the traditional delivery separating design from construction. Typically, architects also are reluctant to want to take responsibility for the construction of their design, and thus do not directly work with their designs through to completion. In this project, the architect took full responsibility directly taking a 3D model to manufacture fully utilising the power of BIM. 
Laing O'Rourke have demonstrated how DFMA and BIM tools can create a successful workflow improving the construction productivity at their factory. Nearly their entire process is automated enabling them to deliver concrete products efficiently, minimising cost, and time. By utilising BIM tools, managing their own supply chain and implementing DfMA principles, if there are any changes to the design or site requirements, Laing O'Rourke is able to react quickly to resolve these. Their factory Explore Industrial Park utilises the digital tools and machinery for the ultimate use of automation allowing the factory to continually evolve.

Overall the primary finding from these case studies was that other parts of the world in particular the US, Switzerland and the UK are taking steps towards improving the design-to-construction process. The utilisation of digital tools, building methods, workflow processes, or a combination of these have provided these manufacturing and construction companies to begin to move towards streamlining and creating a more automated construction process. New Zealand is making steps towards improving the design-to-construction process, however, this is still lacking.

\section{IPD Precedents}

The majority of the case studies didn't utilise BIM very well. Each was rated out of 5 for how well BIM was utilised. For all of the case studies this was only 2.5 - 3 and was not a key factor to the success of the project. Implementing IPD improved the team implementation and communication between the different disciplines reasonably well. The main exception was the Rocky Mountain Institute Innovation Centre (see Figure 2.15), where the team and goals were lacking. However, this project excelled with the cost and the project management of the overall project. Quail Run Behavioural Health Hospital was a project that stood out being successful in all of the key factors mentioned previously, apart from the utilisation of BIM.

While the implementation of IPD was reasonably successful in improving and creating a more collaborative process, the utilisation of BIM was lacking. IPD is typically used for large scale projects which is relevant to all of these case studies. The main reason IPD was implemented into these projects was due to it being efficient and cost effective. New Zealand primarily consists of small to medium enterprises which could be the reason IPD processes have not really been implemented. DfMA is considerably more promising when it comes to implementing a more collaborative process when moving from design-to-construction. 


\section{SUMMARY}

The current literature work that has been done to achieve a direct link for file-to-factory processes mainly involves establishing a platform or algorithm that works for the software to be read and ready for digital fabrication. Currently the way we deliver projects within New Zealand is using the traditional design-bid-build procurement process. This process while widely understood is inefficient when it comes to file-to-factory in particular for timber framing going from design to manufacture.

While BIM is becoming more commonly used throughout the architecture and building industry, it is not being utilised to its full potential. From the case studies, this potential has already largely been achieved in countries overseas such as the United States and Sweden. As a country, New Zealand needs to catch up to move forward with the shift towards a more efficient system of project delivery and improve the flow of information.

This thesis explores the opportunity to utilise BIM tools to their full potential combined with design for manufacture and assembly process to create a collaborative and new file-to-factory workflow to improve the way we deliver projects. Being able to take a BIM model straight to manufacture will allow us to leverage the information. A series of interviews was subsequently conducted with industry professionals in New Zealand to see what specific issues are currently being faced in the design-to-construction process. 


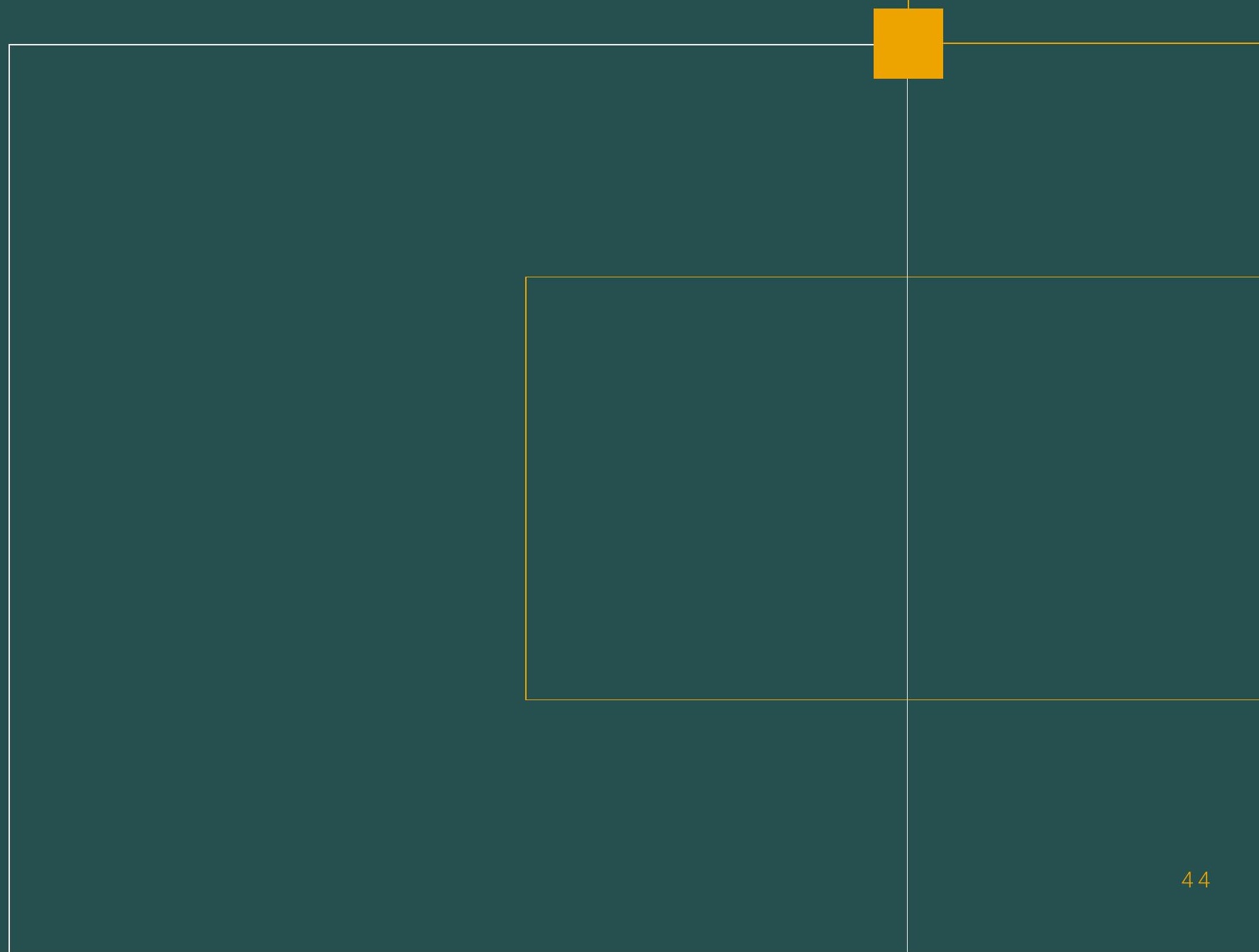




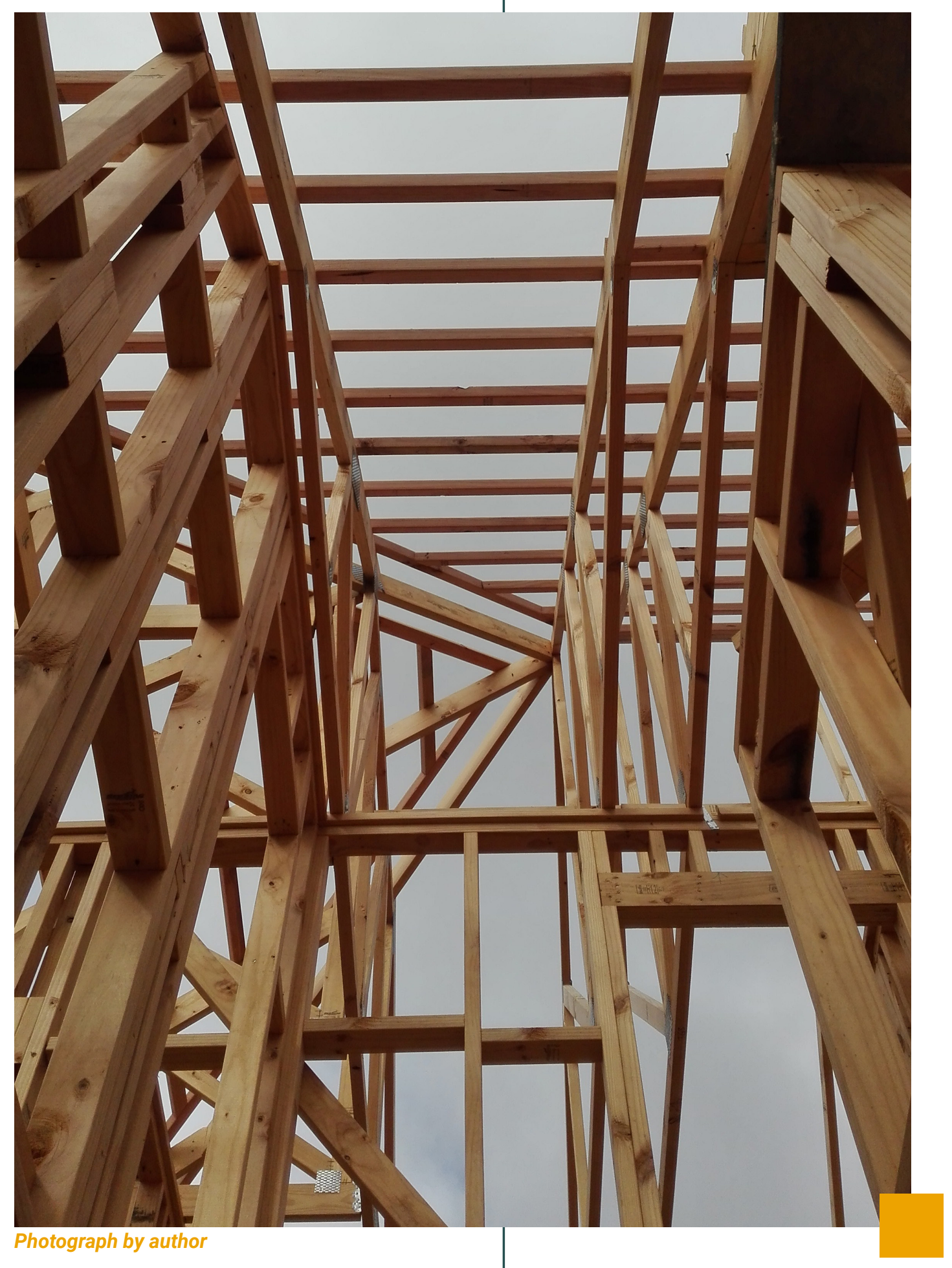



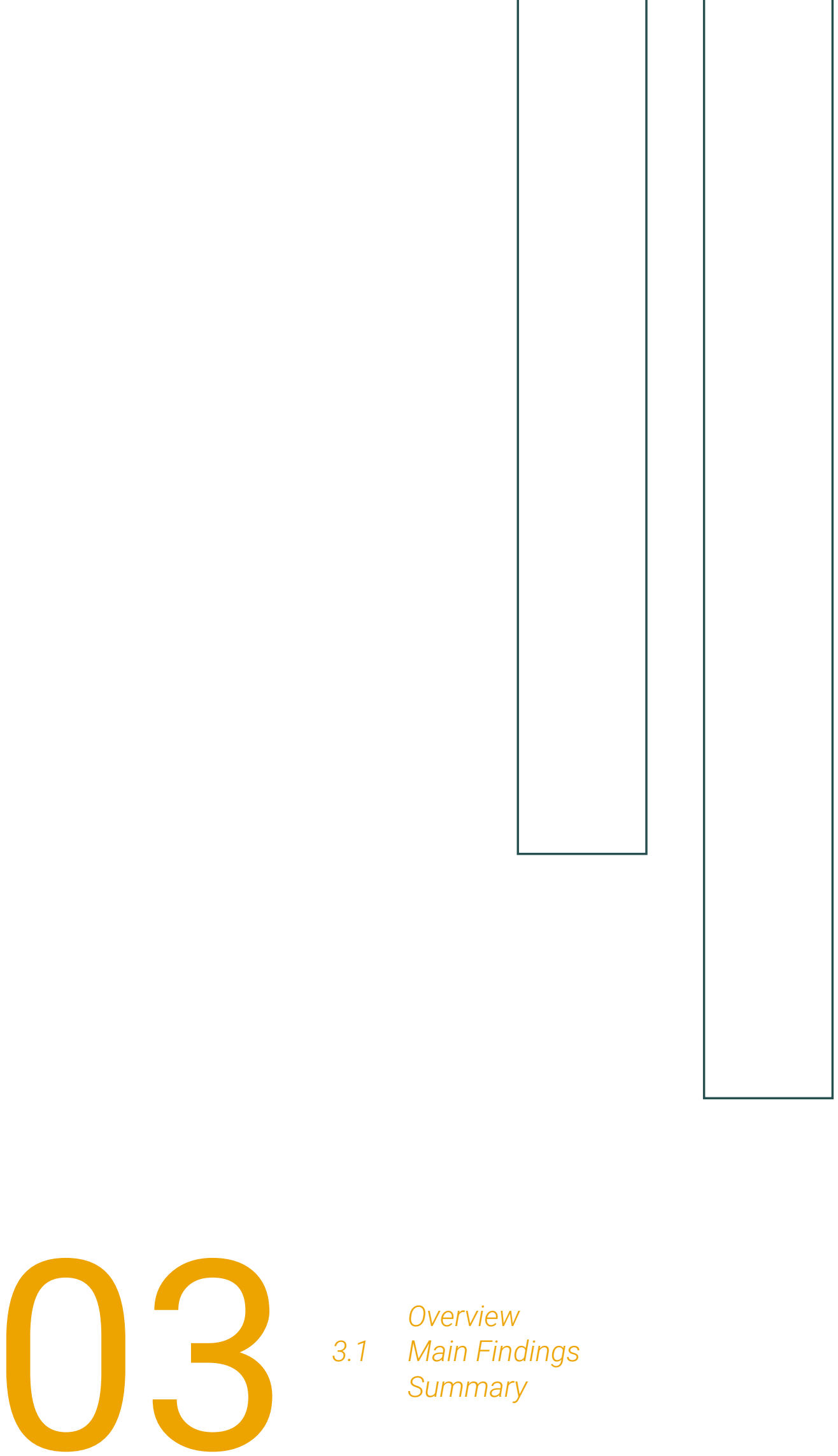

\section{Overview \\ 3.1 Main Findings \\ Summary}

DATA COLLECTION 


\section{O VER VIE W}

Many issues were identified from conducting five interviews with different professionals within the architecture and building industry. A variety of different industry professionals were chosen to be interviewed to gain a wide knowledge of the file-to-factory process. The interviewees include an automation research lead and production assistant, technical sales manager, director of a design, modelling, and engineering office, an individual running an industry association for prefab, and a manager from a frame and truss company. Each interviewee demonstrated expertise across the design to manufacture spectrum. 


\section{1 MAIN FINDINGS}

The key themes that emerged from conducting the interviews were: remodelling of completed work, problems with the building delivery process, and architects having a lack of understanding on manufacture and assembly processes.

Remodelling work that has already been done was primarily due to the disconnection between BIM and CAM software. This caused a disconnect between the different disciplines in the architecture and building industry. The disconnect between BIM and CAM is especially problematic when it comes to the shop drawing process creating a translation stage. When the design is modelled using BIM software, this then gets remodelled into CAM software to be detailed and prepared for manufacture. Due to the different software used by each party, errors such as omissions and uncertainties arose.

The traditional construction procurement process in New Zealand separates (by contract) design from construction. The same way digital tools have been used to advance the designing process; digital fabrication has allowed for the advancement of manufacturing those design elements through CNC machines. Despite these advancements a huge challenge remains. Although there is a new way of building, contractors are still trying to procure it the traditional way. Consequently, this is inefficient. The lack of early contractor involvement is another issue. The construction phase of the building is not able to inform the design. Often by the time a contractor or consultant becomes involved in the project it is too late for the design to benefit from their input and have/provide both manufacturing and construction efficiency. In particular this predominately affects projects that are intended to be prefabricated. The prefabrication and assembly processes are considered too late to influence the design.

The final key general consensus was that architects have limited knowledge or understanding of how their designs will be manufactured and assembled. There is little consideration and inclusion of this in their drawings, especially when it comes to using prefabricated methods and assembly processes. It all comes down to the project delivery process, communication, and skill. According to one interviewee, there is a dramatic skill shortage in New Zealand of fabrication modellers and machine operators. There is also an issue with architects not understanding DfMA. These specialised skills are difficult to find and because the industry is reliant on skilled workers, this is a big constraint on the industry.

Design for manufacture and assembly is a collaborative and integrated approach that strives to bring design and construction together. The process facilitates the interaction between all stakeholders of a project team, including client, designers, contractor, key suppliers, BCA (Building Consent Authorities) and more. Many of the interviewees discussed this process as a solution to allow for early contractor involvement, allow architects to better understand how their designs will be manufactured and assembled. This process will also improve the way projects are procured and the amount of remodelling/re-work that is required. DfMA's build methodology will be able to influence and inform the design rather than this being an afterthought once the design has been finalised. Implementing design for manufacture and assembly would improve the manufacturing and construction efficiency, reduce errors, and cost. 


\section{S U M M A R Y}

From the interviews with industry professionals, the key themes that emerged was the remodelling of completed work, problems with the building delivery process, and architect's having a lack of understanding on how their designs will be manufactured and assembled. An initial testing phase utilising digital tools will be undertaken to test the limitations and opportunities on how this could affect the way architecture projects are designed and constructed. 


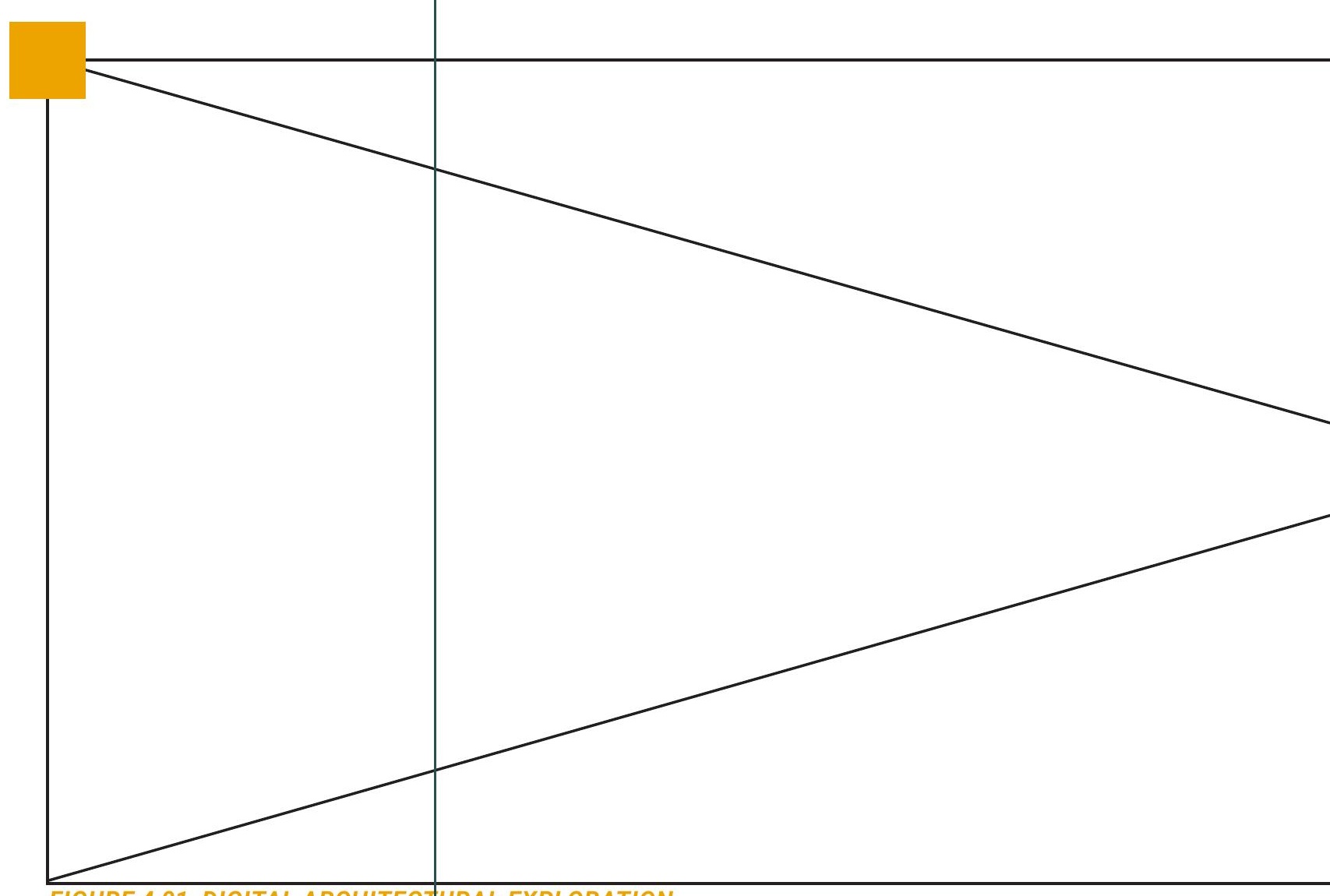

FIGURE 4.01. DIGITAL ARCHITECIURAL EXPLORATION

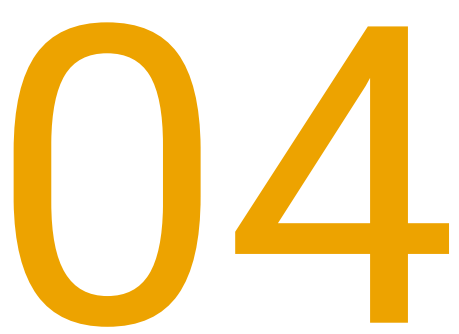

Overview

4.1 Software plugins for Revit

4.2 MWF Pro Wood

4.3 Hut Series

4.4 Early Testing

Summary

INITIAL TESTING 
This content is unavailable.

Please consult the figure

list for further details.

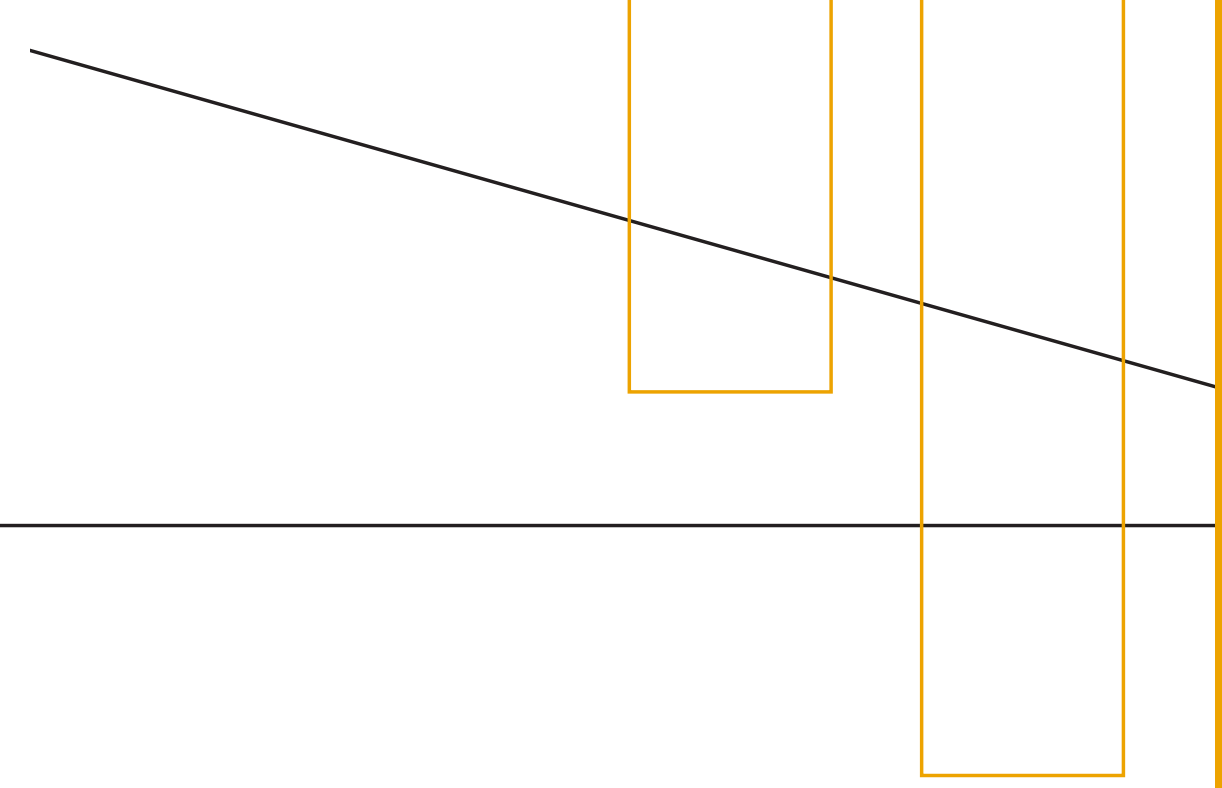




\section{O VER VIEW}

This initial testing phase focuses on how utilising digital tools can affect and influence the design-to-construction process. Accordingly, Revit is one of the most commonly used BIM modelling software in the architecture and building industry. This chapter discusses the available timber framing plugin options available for Revit. A series of small hut designs was used to explore the limitations and opportunities through the use of digital tools. The main timber framing plugin that has been looked into extensively is MWF Pro Wood. This software allows for automatic framing for walls, roofs, floors, and trusses with a click of a button. 


\subsection{SOFTWARE PLUGINS FOR REVIT}

There are several different timber framing plugin options available for Revit. Three main ones stood out as being the most useful when it comes to generating framing for projects; hsbCAD, AGACAD, and MWF Pro Wood. The primary finding when comparing these plugins was that MWF Pro Wood and AGACAD are similar both able to generate timber framing through the use of rule sets and customisable templates. MWF Pro Wood allows for an extremely large number of wall framing possibilities that can be created and customised. HsbCAD is slightly different, focusing on the joinery of timber framing. HsbCAD is able to generate and cut timber to create parametric joins and customisable slot joinery. The main drawback of hsbCAD is that there are not many options for customisability nor templates to create rule sets for timber wall framing.

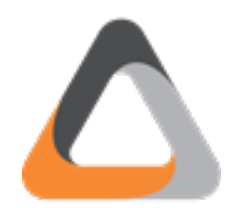

MWF Pro Wood

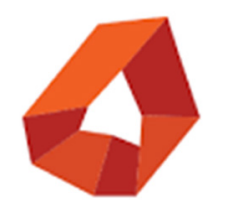

Hsb Timber

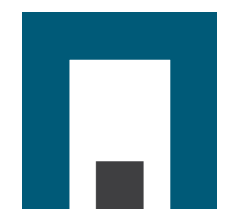

AGACAD 


\subsection{MWF PRO WOOD}

MWF Pro Wood, by StrucSoft Solutions, is an add-on (plugin) for Revit capable of framing small single-family homes up to large scale multi-family structures. This digital tool was created for framing subcontractors and is not typically used by architecture firms. MWF Pro Wood can be implemented to improve the transition from design to manufacture during the shop drawing phase and has the ability to automate everything from structural framing, joins, clapboard, and sheathing. Not only does the plugin automatically generate framing, but it also has the ability to specify joints, for example where two walls will intersect. Rule sets and templates can be created for set conditions that will generate the framing or join required when those conditions are met. The way these have been set up has been detailed in the Appendices C \& D. 


\subsection{HUT SERIES}
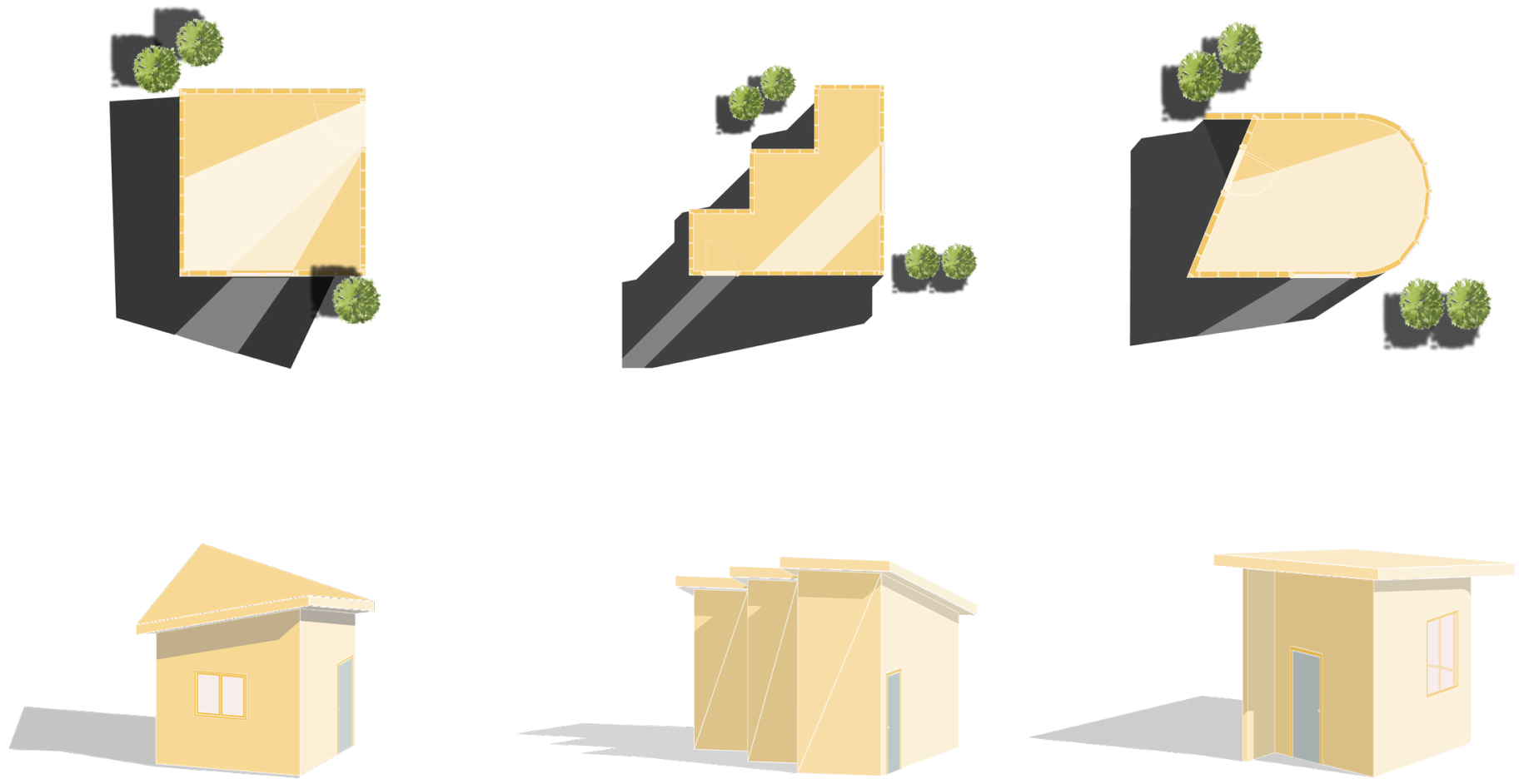

FIGURE 4.02. HUT SERIES 

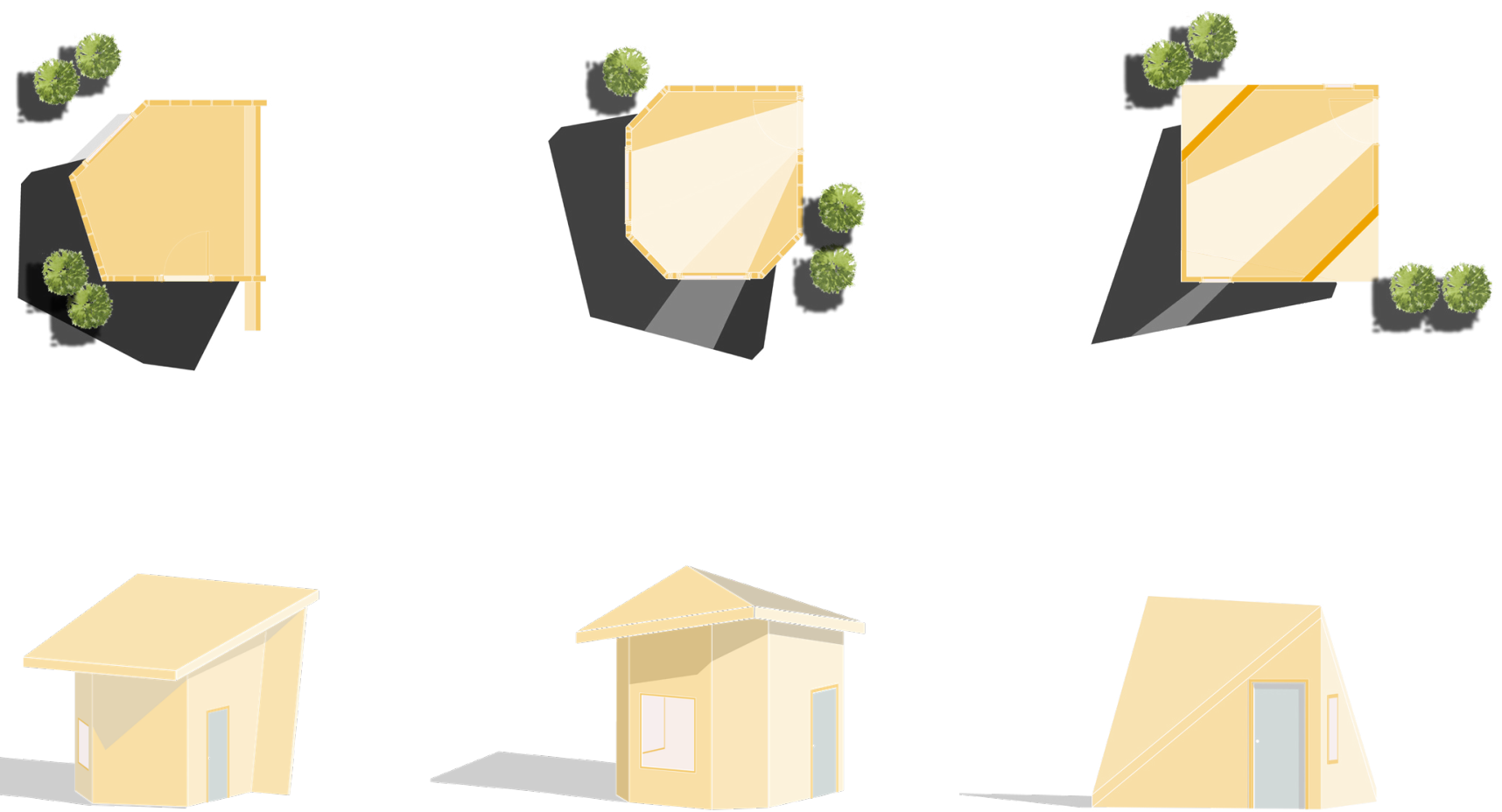


\subsection{EARLY TESTING}

An initial testing phase was conducted to characterise the capabilities of MWF Pro Wood. This testing was executed through a series of small $10 \mathrm{~m}^{2}$ huts designed to test the plugin by taking different shapes and forms (see Figure 4.02). Initially, the huts were modelled into Revit and then automatically framed using MWF Pro Wood. By completing the series of tests, several limitations and opportunities of the digital tools emerged.

To begin this investigation, two basic huts were modelled and framed in Revit using MWF Pro Wood. One with a square base (A) (see Figure 4.03) and the other triangular (B) (see Figure 4.04). These were used to test the initial output of the framing before creating other small huts to test the limitations and opportunities.
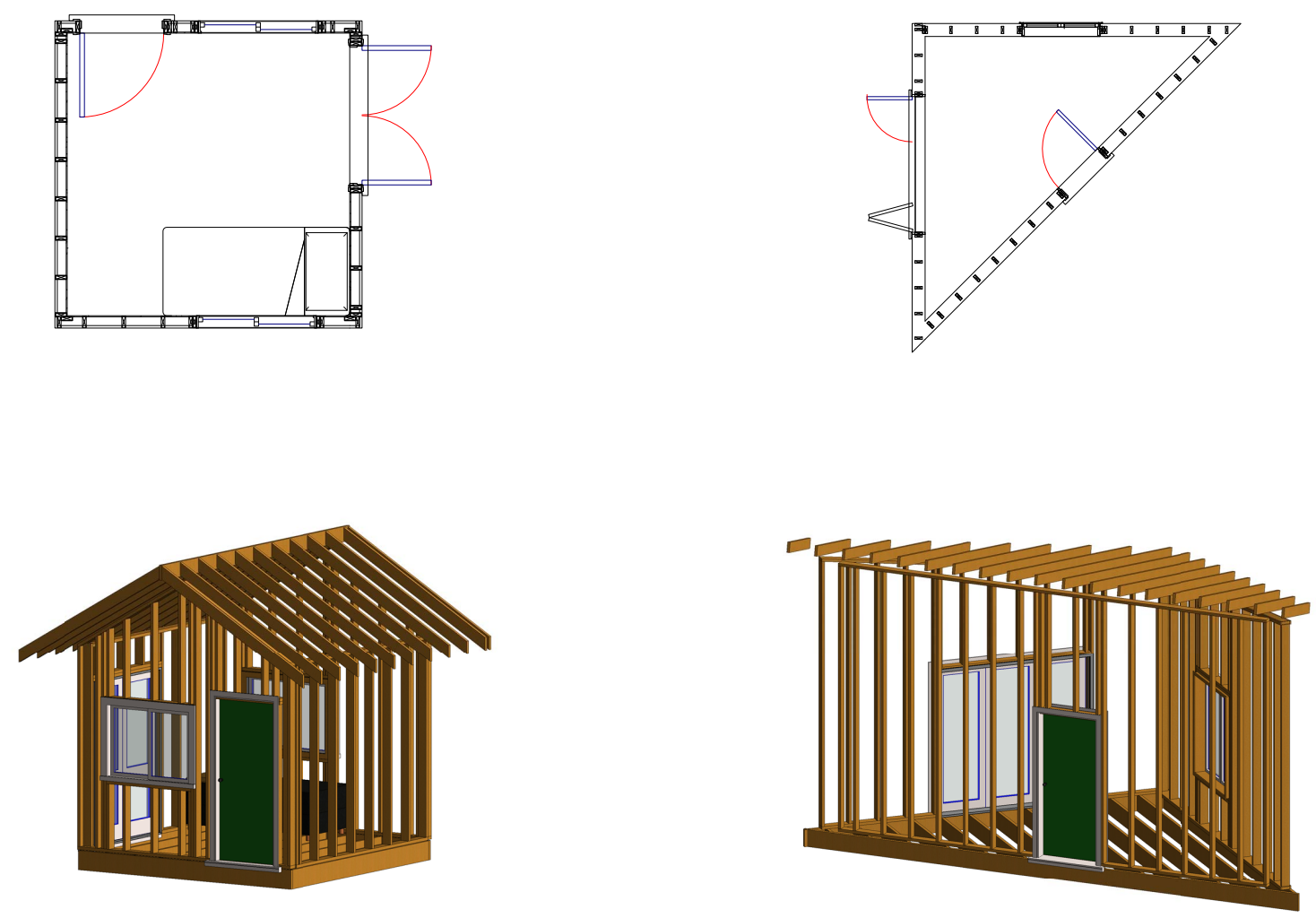
Huts $\mathrm{C}-\mathrm{H}$ were designed to challenge the external form through simple spatial changes to test the framing output. MWF Pro Wood provides the opportunity to easily create different designs. Examples are shown in Huts C and D. By simply changing the arrangement of the roof this creates a butterfly roof that aligns with the corner edge of the hut. Hut $\mathrm{C}$ was able to automatically generate framing for the roof and walls relatively easily (see Figure 4.05). The same can be said for Hut D which explores multiple and various edges. The framing capability worked well and joined up to the roof with ease (see Figure 4.06). For Revit, the limitations revolved around the system and what types of designs that were supported within the software. The limitations of MWF Pro Wood are similar to the Revit because it is linked with Revit's wall, floor and roof components. Consequently, since Revit works extremely well with simplistic designs the same can be said for MWF Pro Wood.
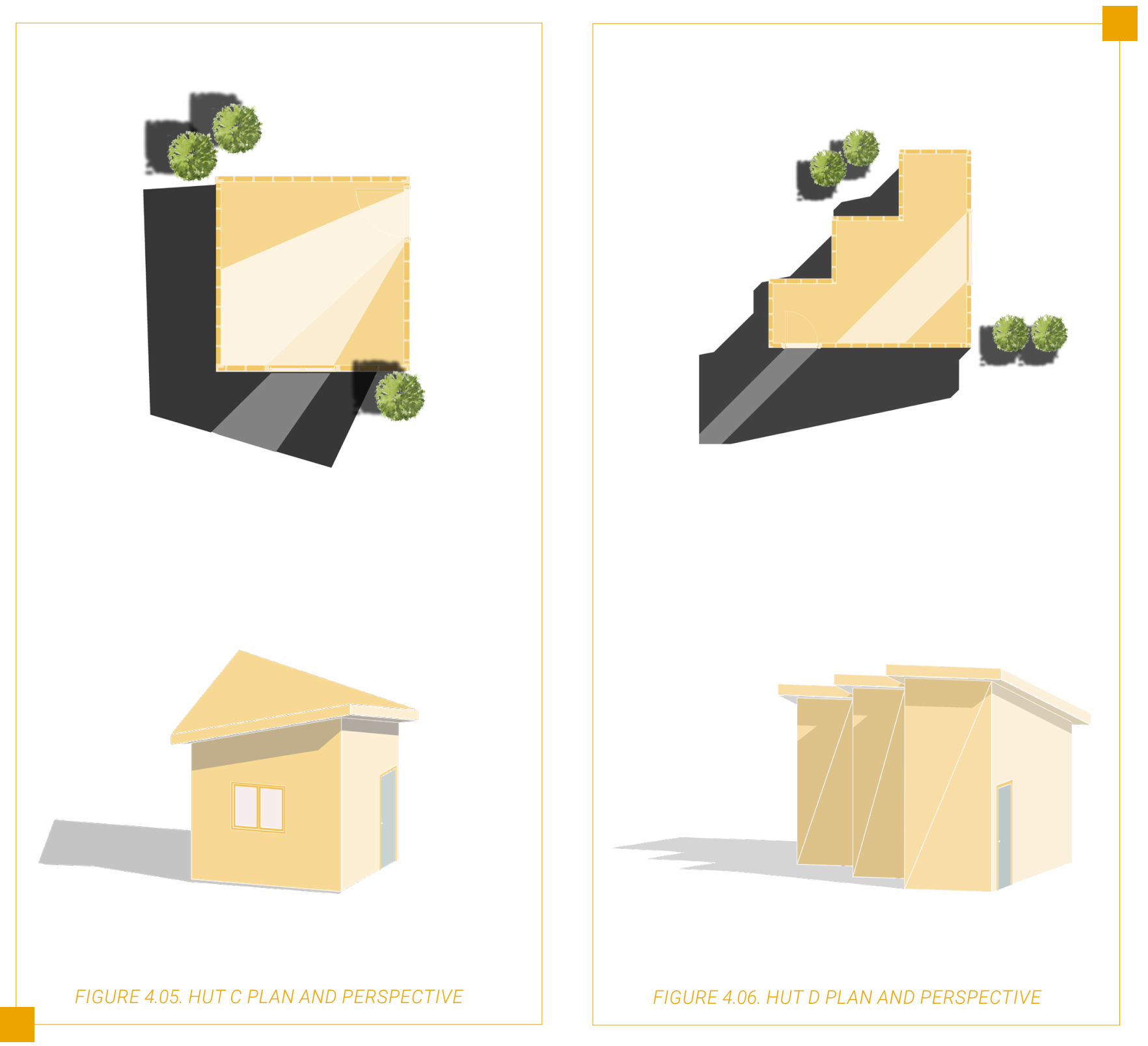
Limitations of MWF Pro Wood became apparent in more complex roofs. Hut G demonstrated joining issues with the roof and walls because of the unique shape and alignment of the roof. This created some difficulties in the joins that could be created at the corners and connecting the two together (see Figure 4.07). Another hut that had difficulties with the roof was Hut H. Since the roof extended to the ground this consequently cause MWF Pro Wood to be unable to generate the roof framing. This was due to the parameters of the roof and because of the thickness as well as length to the ground (see Figure 4.08).
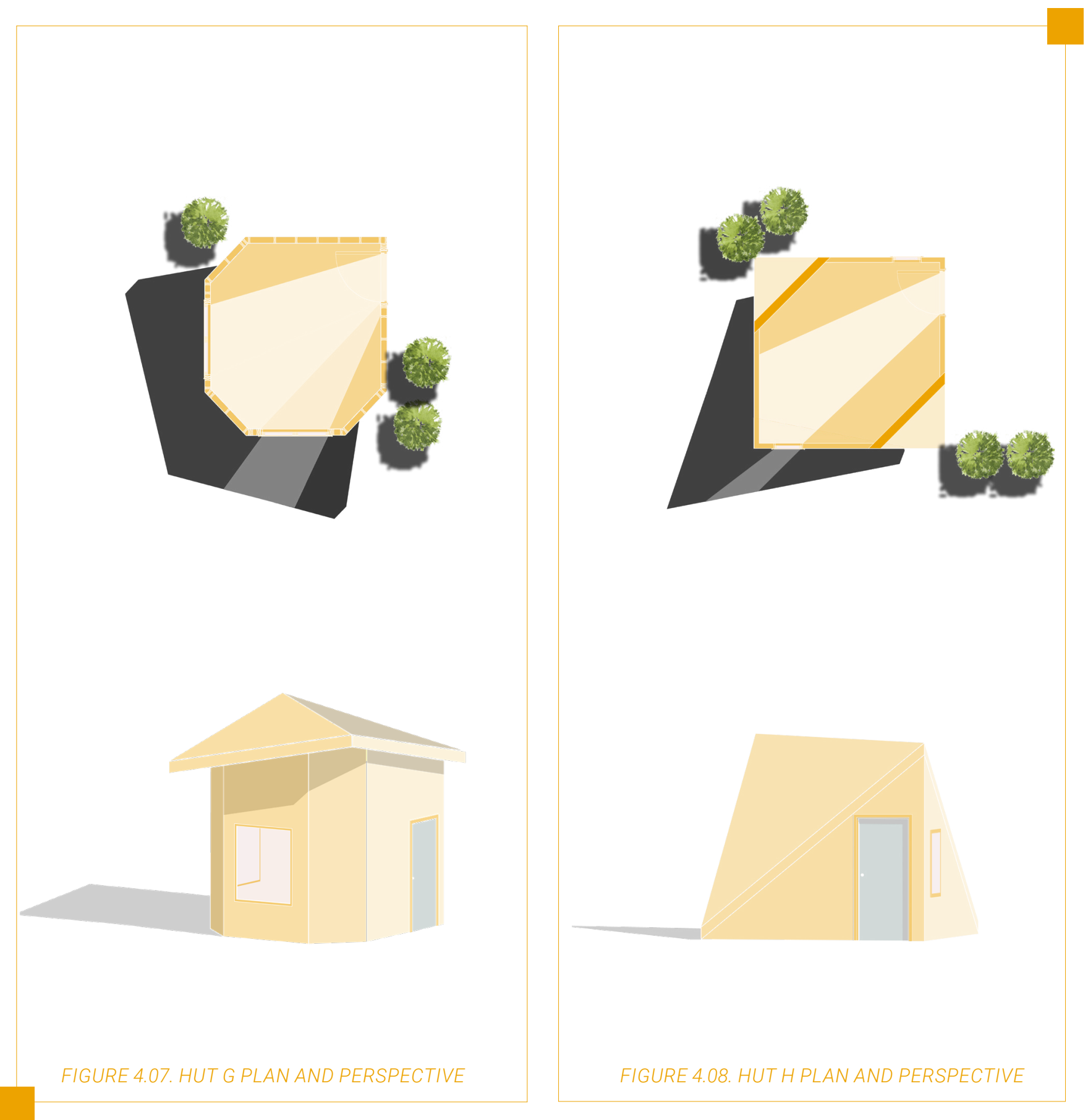
The key issues with modelling the huts in Revit are directly relevant to Huts $E$ and $F$. The primary difficulty was the ability to model unique or different exterior forms. The difficulty with hut E was due to the rounded curve of the wall at one end (see Figure 4.09). Although this was modelled as a wall, there were issues with MWF Pro and no framing would generate. As a better understanding of the plugin was gained, it became apparent the only way for this to be able to be framed was to first outline the curve in AutoCAD and link it into the Revit file. By doing this a wall could be created using the pick lines option creating wall segments around the circumference of the circle. Only then would MWF Pro Wood be able to automatically generate the framing around the exterior. For Hut $F$ there were limitations with both Revit and MWF Pro Wood. Initially the modelling of the slanted wall presented an issue in Revit and had to be modelled as a component rather than a 'wall'. This in itself created an issue and limitation for MWF Pro Wood since the framing will only generate for walls that have been used in Revit (see Figure 4.10).

Although several of the Huts (E, F) could be modelled in a different software such as Rhino and then imported into Revit to be framed this would be problematic. These would first need to be redrawn once imported into Revit defeating the entire purpose of modelling it in the other software. Other issues would also occur due to limited interoperability between software programs and the editing allowed once the design has been imported.

In testing the limitations and opportunities for MWF Pro Wood it was interesting to see that the main limitations came from Revit rather than the plugin itself. While there were some issues with the joining and framing of the plugin, many of these were resolved later on once a better understanding of the plugin had been gained. Revit works well for most architectural designs; however, it does not work particularly well for parametric or 'nonstandard' architecture. 

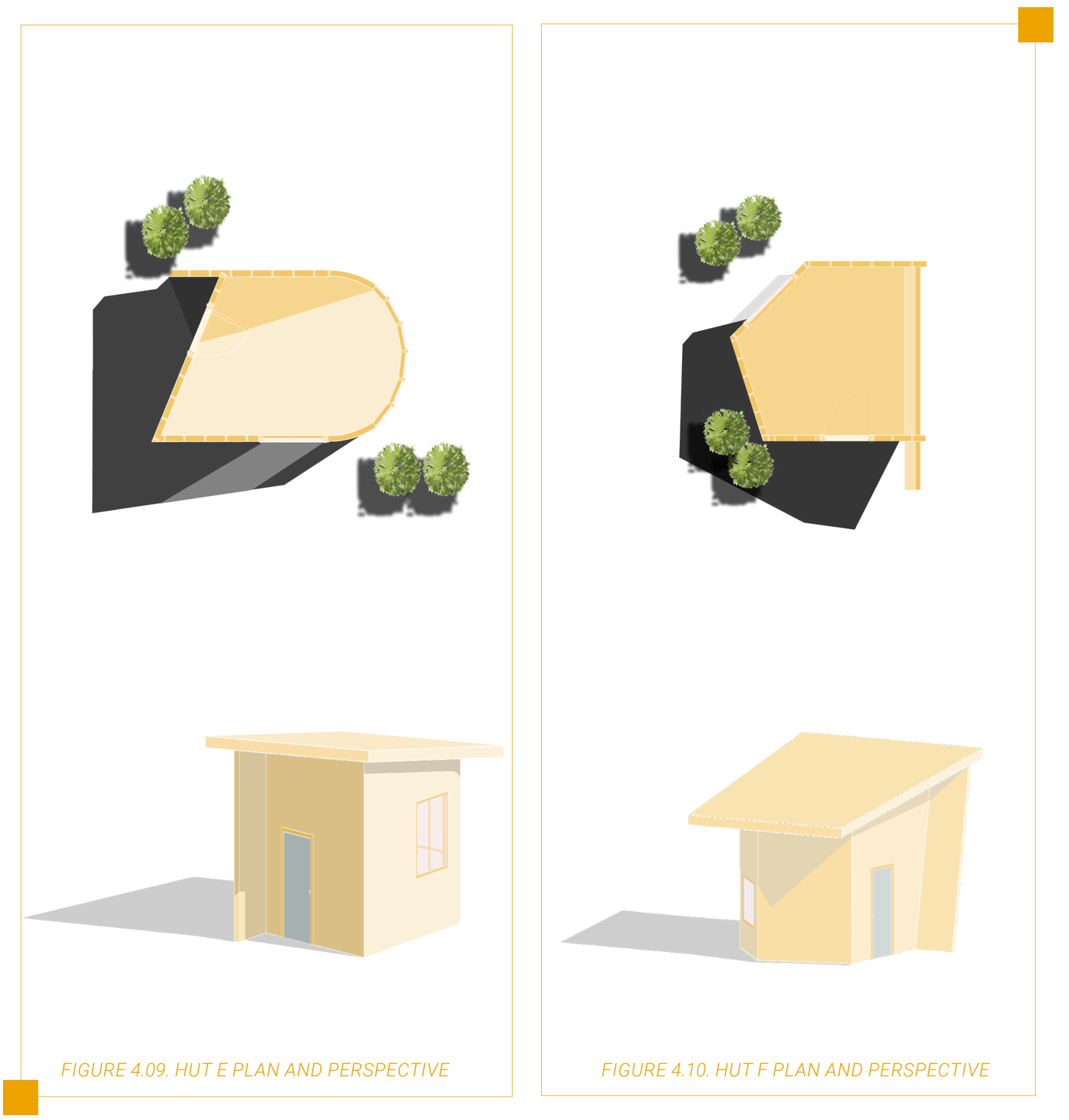


\section{S U M M A R Y}

The initial testing of the MWF Pro Wood plugin demonstrated the inability to frame certain elements due to the capabilities and limitations of Revit itself. Because the two are linked together, if the design included elements such as a slanted wall modelled using a mass this caused issues with the framing since the plugin could not recognise the mass as a wall. Other limitations revolved around the roof alignment with the walls and the ridgeline. However, these issues could be reported to the developer for improvements to the plugin. There were some joining issues. However, these were mainly due to the learning curve of the software. These were resolved later on. This initial testing phase tested the basic limitations and opportunities of the software. However, it used the default settings for templates and rule sets. Due to the opportunities available with simplistic and rectangular designs which Revit supports this affected the next testing phase. The next phase further tested the MWF Pro Wood plugin bringing it back to New Zealand context by programming the plugin to be suitable for NZ building standards, based off of NZS 3604 as a proof of concept. 


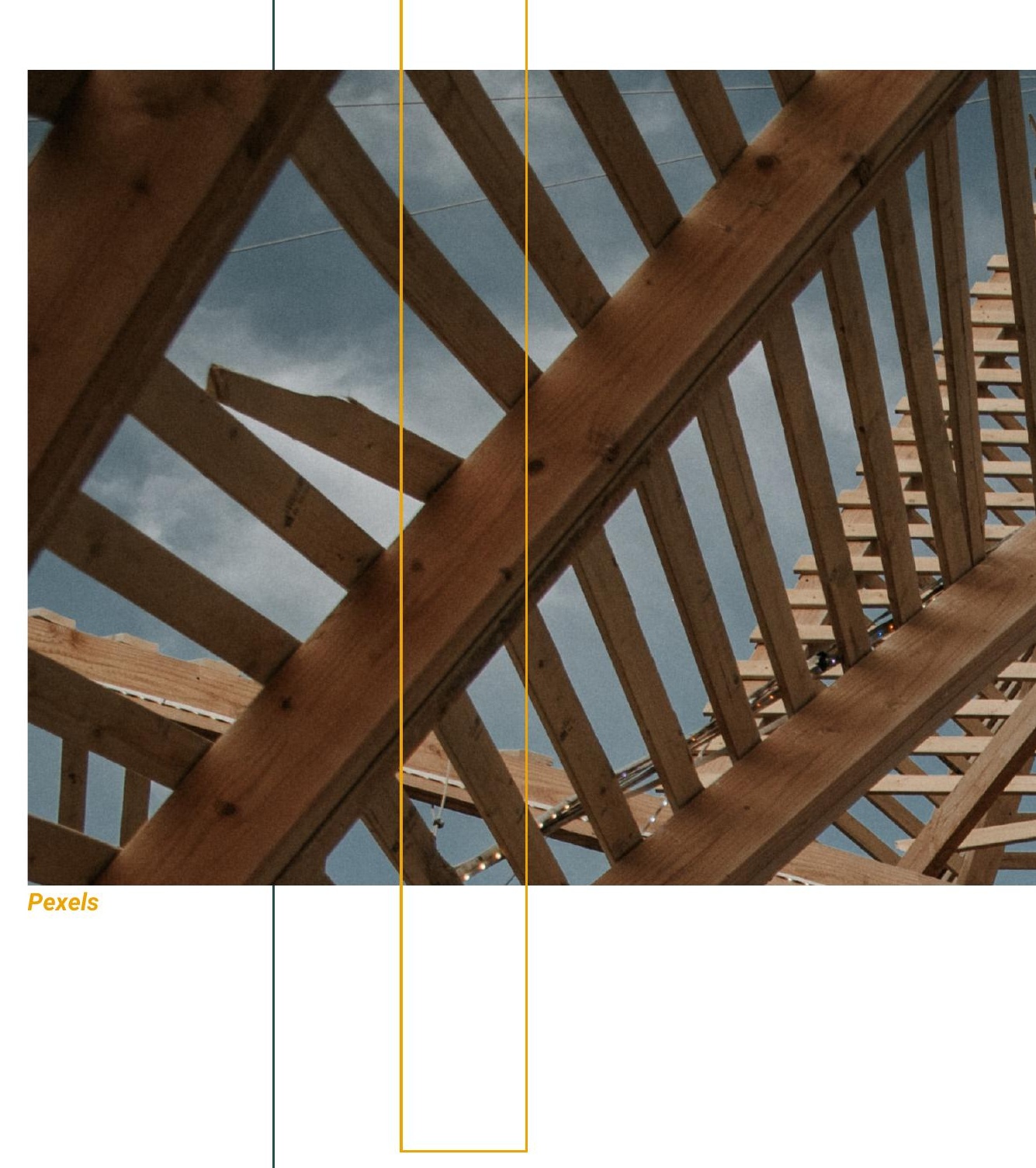



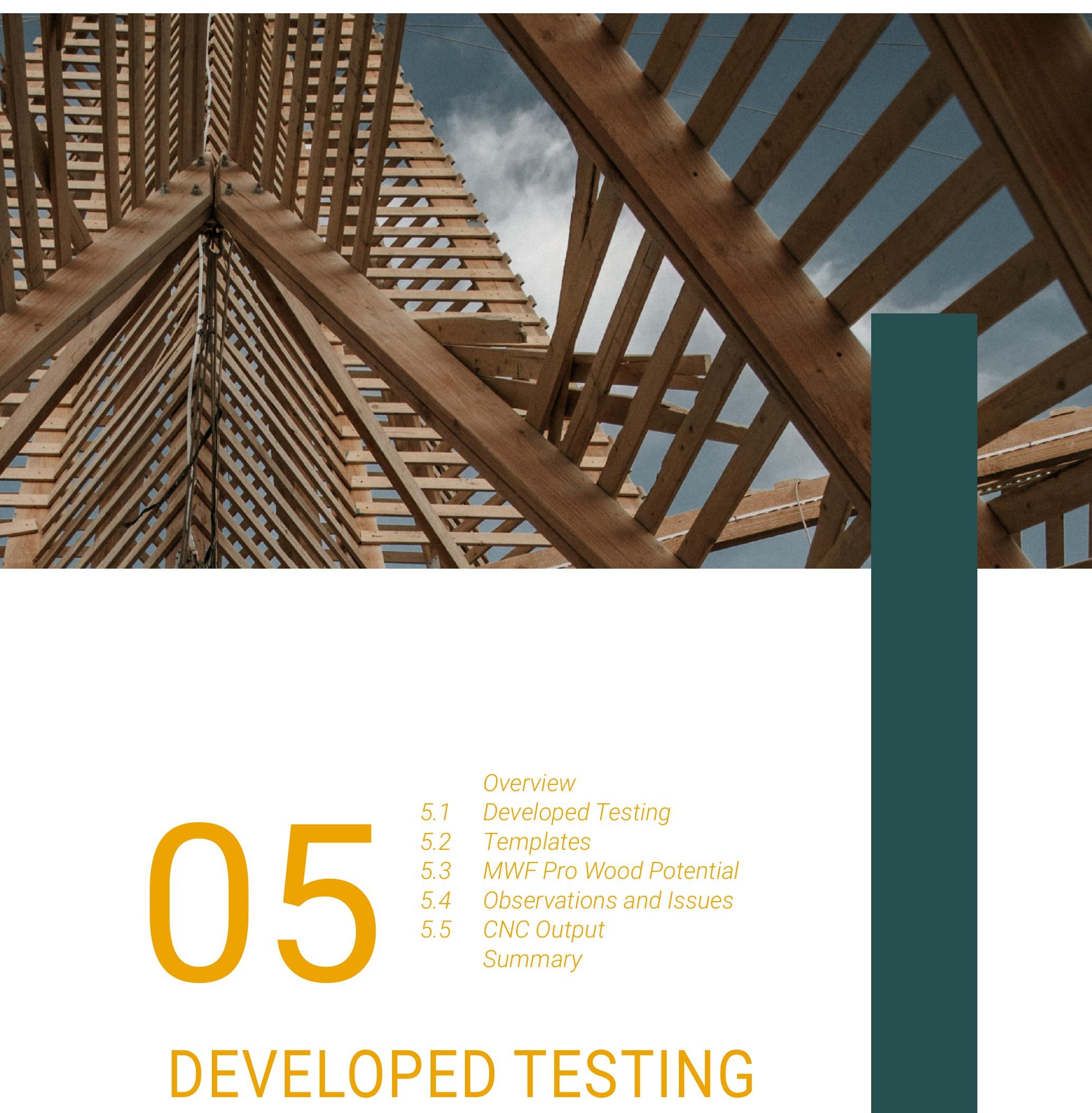

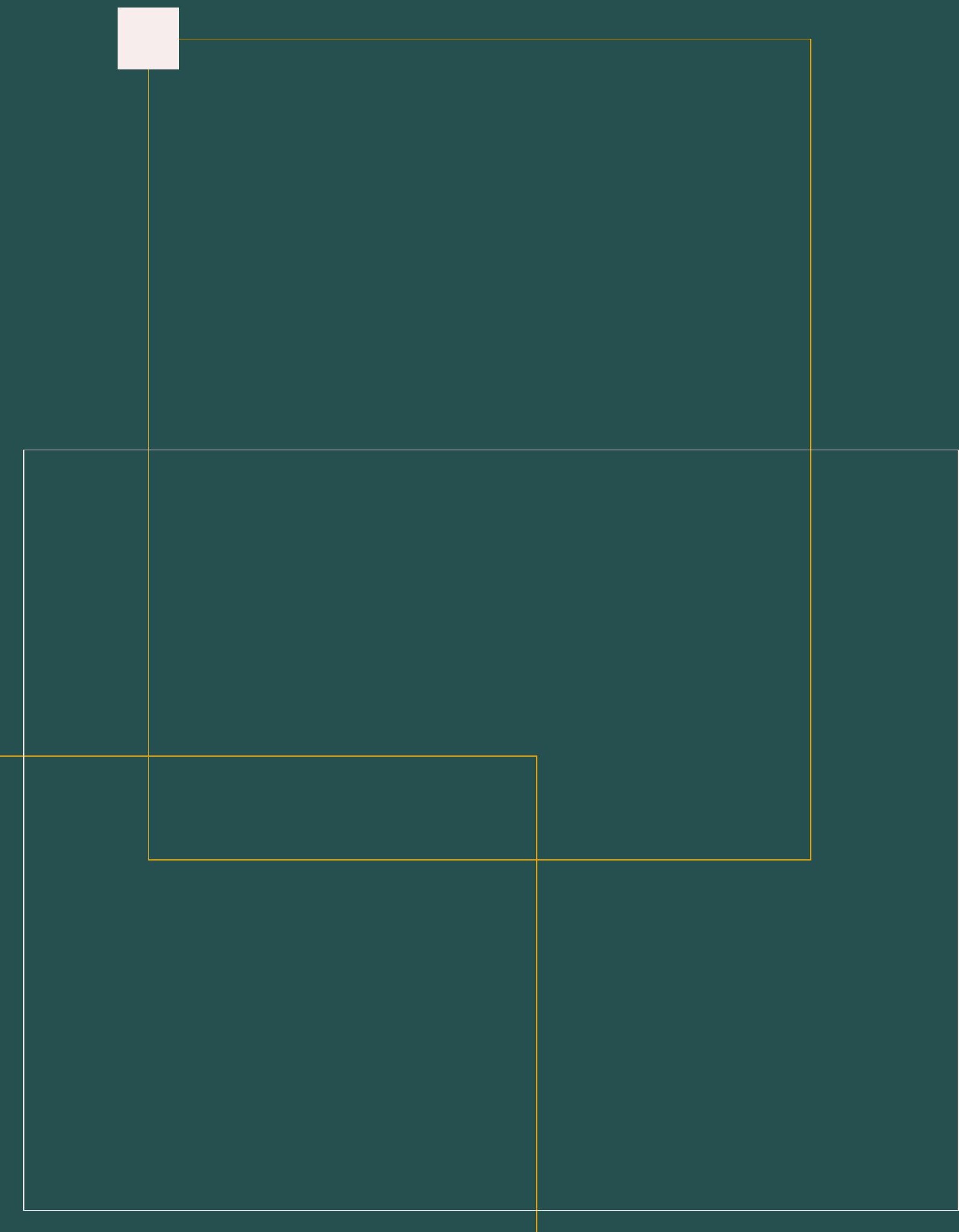


\section{O VER VIEW}

This chapter focuses on utilising digital tools, in this case MWF Pro Wood. Next, the plugin was applied to the New Zealand context. This developed testing looks at how designers can include manufacturing and assembly data into their designs focusing on the file-to-factory shop drawing process for timber framing. The chapter explores the potential of programming the plugin to New Zealand timber sizes and building code. By using the building code NZS 3604 and rule sets, templates have been successfully created based off of different set conditions and parameters to test the limits of the program. This chapter also discusses the observations and issues that were faced when creating these templates and the CNC output opportunities. 


\subsection{DEVELOPED TESTING}

A developed testing phase was conducted to test the ability of the plugin and to see whether it could be programmed and applied to New Zealand building standards. The framing templates and rule sets were created based off of the New Zealand Building Code NZS 3604. This building standard provides the sizing and structural information of timber members based off of the span, lengths, wind zone, and height of the storey.

In MWF Pro Wood, customisable templates can be set up according to the particular settings that are desired for spacing, sizing, tracks, dwangs (horizontals), and opening of the framing for the wall. Each template can be saved individually into the project or onto the disk drive and available for future use and other projects.

For this investigation, three different sets were created with distinctive conditions and parameters taken from NZS 3604. The first set's basic conditions consisted of a maximum wall height of $2700 \mathrm{~mm}$ with a stud spacing of $400 \mathrm{~mm}$ that was single storey. In this set three different templates were programmed into the plugin based on the wind zones Low, High and Extra High. Once these conditions were identified this determined the size of the timber framing required.

New beams and columns were created based on the NZS 3604 sizing and applied to the templates. A second and third set were created each single storey and each had templates addressing the multiple wind zones Low, High and Extra High. The second set conditions had a maximum wall height of $3000 \mathrm{~mm}$ with a stud spacing of $600 \mathrm{~mm}$ while the third consisted of a maximum wall height of $4200 \mathrm{~mm}$ with a stud spacing of $600 \mathrm{~mm}$. A table of these conditions determining the sizing of the framing has been compiled (see Figure 5.01). A total of nine templates were created and the creation of these has been detailed in Appendix C. The names of the templates were created based on their parameters. LS2700_400_90x35 in this template, the L stands for the wind zone Low, S for single storey with walls that are maximum $2700 \mathrm{~mm}$ high, and has a stud spacing of $400 \mathrm{~mm}$. Referring to NZS 3604 these conditions mean that the stud size will be $90 \times 35 \mathrm{~mm}$. 


\subsection{TEMPLATES}

Set 1 - Maximum wall height 2700 mm, 400 mm stud spacing, single storey

\begin{tabular}{|c|c|c|}
\hline Wind Zone & Stud size & Template Name (in plugin) \\
\hline Low & $90 \times 35 \mathrm{~mm}$ & LS2700_400_90x35 \\
\hline High & $90 \times 45 \mathrm{~mm}$ & HS2700_400_90x45 \\
\hline Extra High & $90 \times 70 \mathrm{~mm}$ & EHS2700_400_90x70 \\
\hline
\end{tabular}

Set 2 - Maximum wall height 3000 mm, 600 mm stud spacing, single storey

\begin{tabular}{|c|c|c|}
\hline Wind Zone & Stud size & Template Name (in plugin) \\
\hline Low & $90 \times 45 \mathrm{~mm}$ & LS3000_600_90x45 \\
\hline High & $90 \times 70 \mathrm{~mm}$ & HS3000_600_90x70 \\
\hline Extra High & $140 \times 45 \mathrm{~mm}$ & EHS3000_600_140x45 \\
\hline
\end{tabular}

Set 3 - Maximum wall height 4200 mm, 600 mm stud spacing, single storey

\begin{tabular}{|c|c|c|}
\hline Wind Zone & Stud size & Template Name (in plugin) \\
\hline Low & $140 \times 45 \mathrm{~mm}$ & LS4200_600_140x45 \\
\hline High & $140 \times 90 \mathrm{~mm}$ & HS4200_600_140x90 \\
\hline Extra High & $190 \times 45 \mathrm{~mm}$ & EHS4200_600_190x45 \\
\hline
\end{tabular}


Template LS2700_400_90x35

Maximum Wall Height: 2700mm

Wind: Low

Stud size: $90 \times 35$

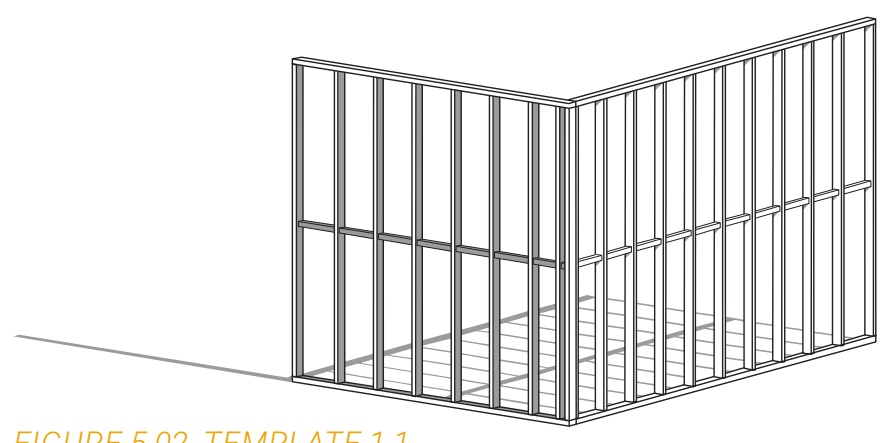

FIGURE 5.02. TEMPLATE 1.1

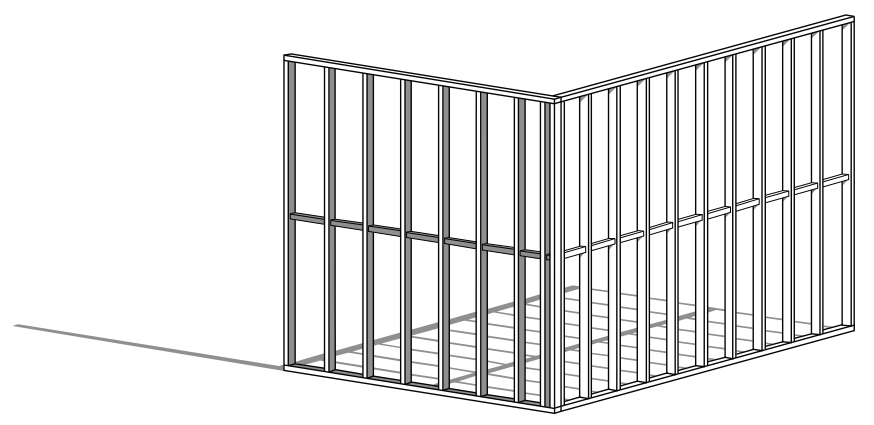

FIGURE 5.03. TEMPLATE 1.2

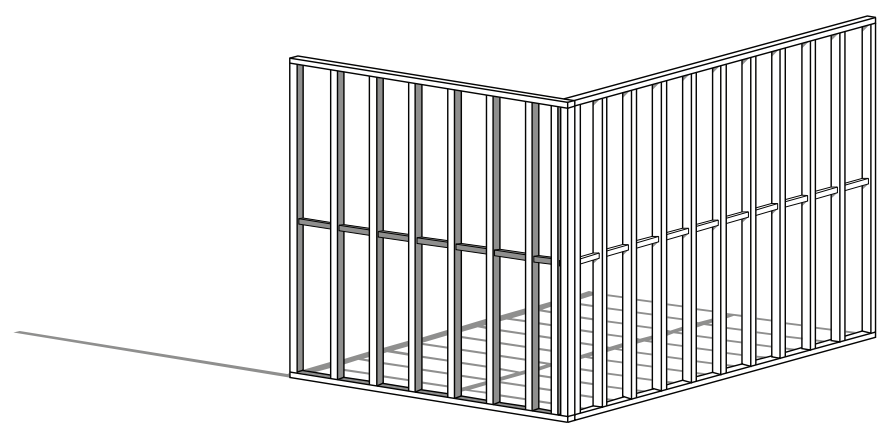

FIGURE 5.04. TEMPLATE 1.3

Template EHS2700_400_90x70 Maximum Wall Height: 2700mm Wind: Extra High

Stud size: 90x70

Template HS2700_400_90x45 Maximum Wall Height: 2700mm Wind: High

Stud size: $90 \times 45$

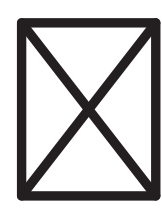




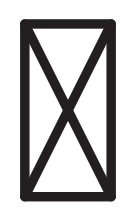

Template LS3000_600_90x45

Maximum Wall Height: $3000 \mathrm{~mm}$

Wind: Low

Stud size: $90 \times 45$

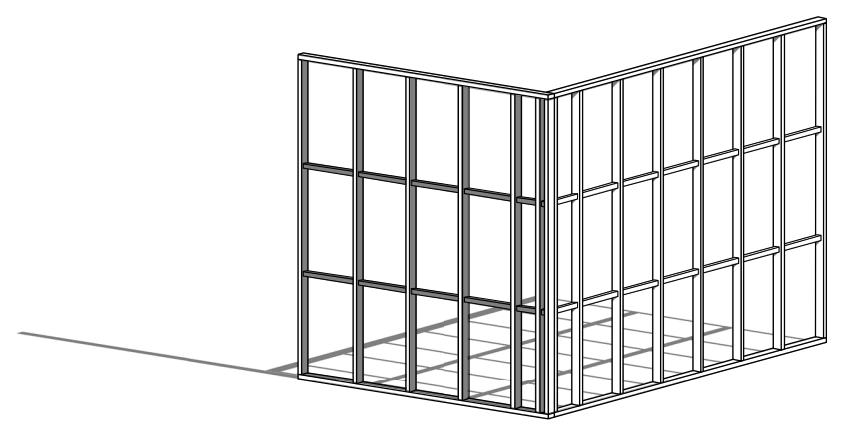

FIGURE 5.05. TEMPLATE 2.1

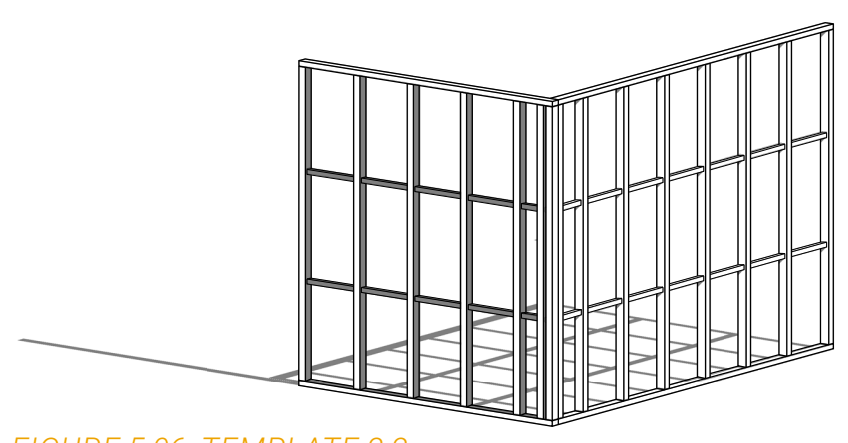

FIGURE 5.06. TEMPLATE 2.2

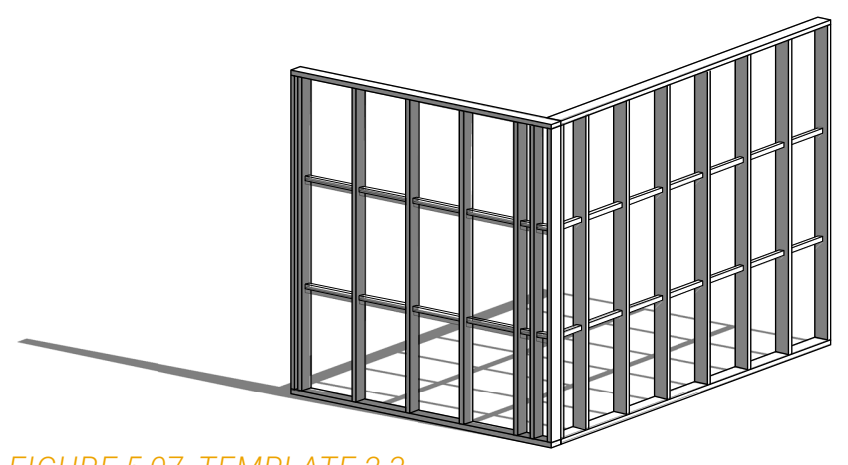

FIGURE 5.07. TEMPLATE 2.3

Template EHS3000_600_140×45

Maximum Wall Height: $3000 \mathrm{~mm}$ Wind: Extra High

Stud size: 140x45

Template HS3000_600_90x70

mum Wall Height: $3000 \mathrm{~mm}$

Wind: High

Stud size: $90 \times 70$ 


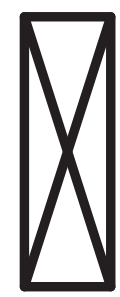

Template LS4200_600_140x45

Maximum Wall Height: $4200 \mathrm{~mm}$

Wind: Low

Stud size: $140 \times 45$

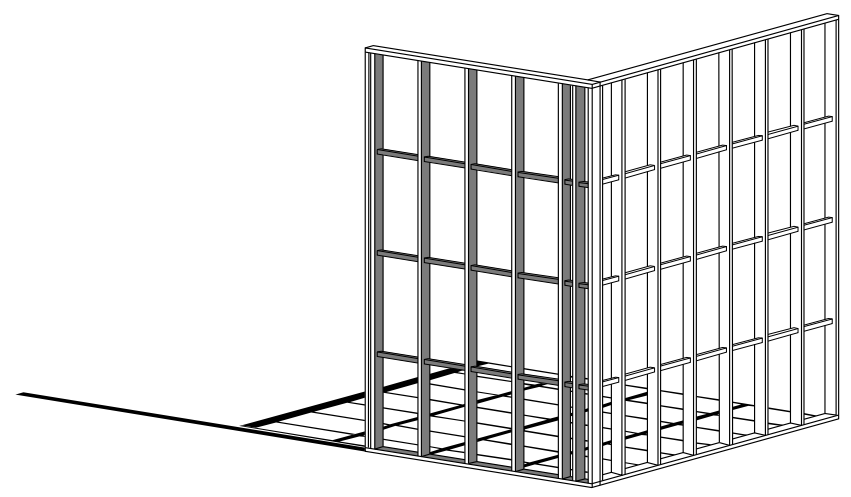

FIGURE 5.08. TEMPLATE 3.1

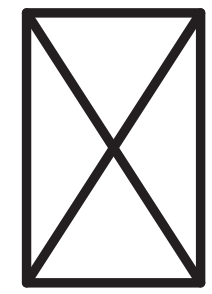

Template HS4200_600_140x90 Maximum Wall Height: $4200 \mathrm{~mm}$ Wind: High

Stud size: $140 \times 90$
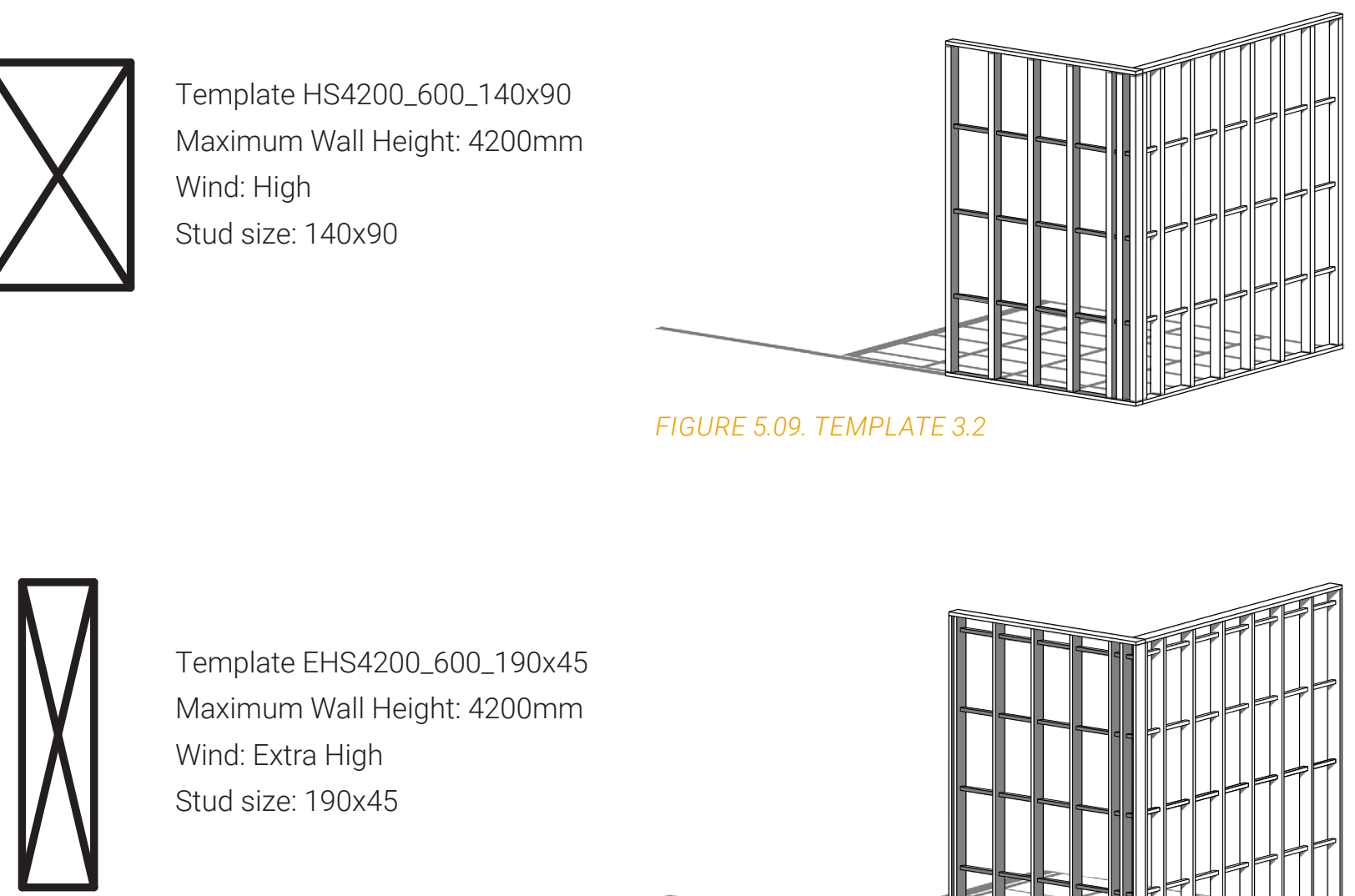

Template EHS4200_600_190x45 Maximum Wall Height: $4200 \mathrm{~mm}$ Wind: Extra High Stud size: 190x45

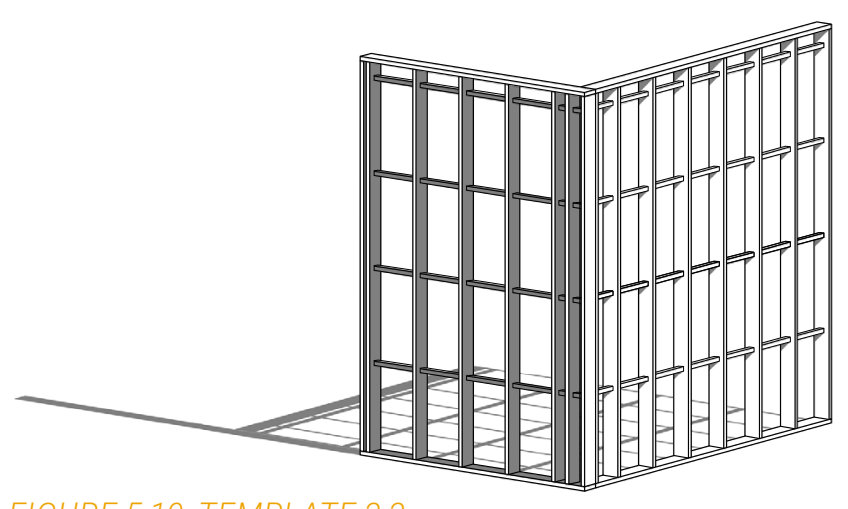

FIGURE 5.10. TEMPLATE 3.3 


\subsection{MWF PRO WOOD POTENTIAL}

To test the potential of MWF Pro Wood, an existing house design was modelled into Revit and timber framing was automatically generated for the walls, and roof. The framing for this existing house design has been demonstrated in Figure $5.11 \sim$ Figure 5.13. The sizing of the frames was all to the New Zealand Building Code Standards. By exploring the opportunities of using this plugin on residential projects and from the initial testing phase, the issue of joining two walls emerged. An Auto Join Rule was created to automatically generate a join for certain wall and framing conditions. This has been detailed further in Appendix D.

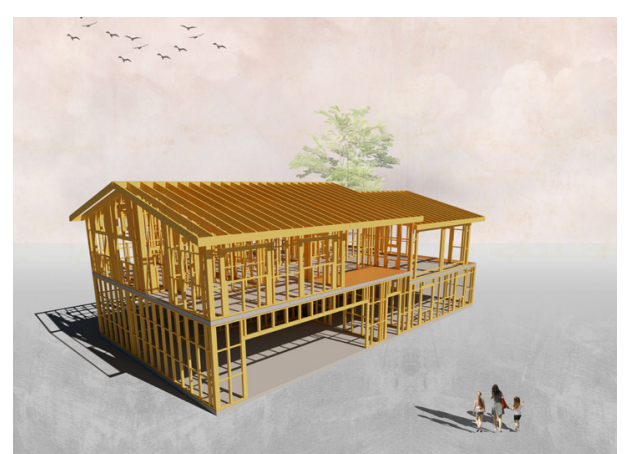

FIGURE 5.11. FRONT ENTRANCE

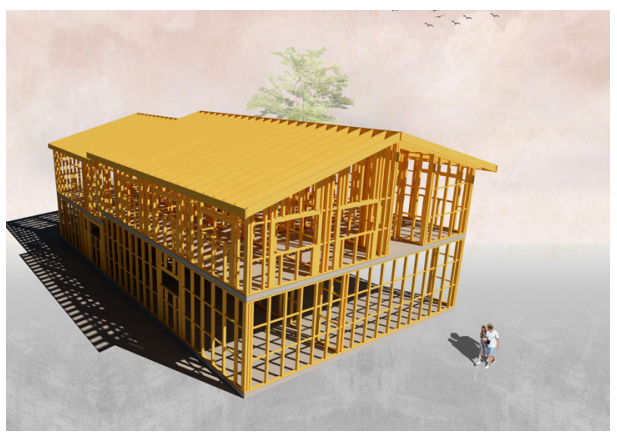

FIGURE 5.12. BACK VIEW OF HOUSE

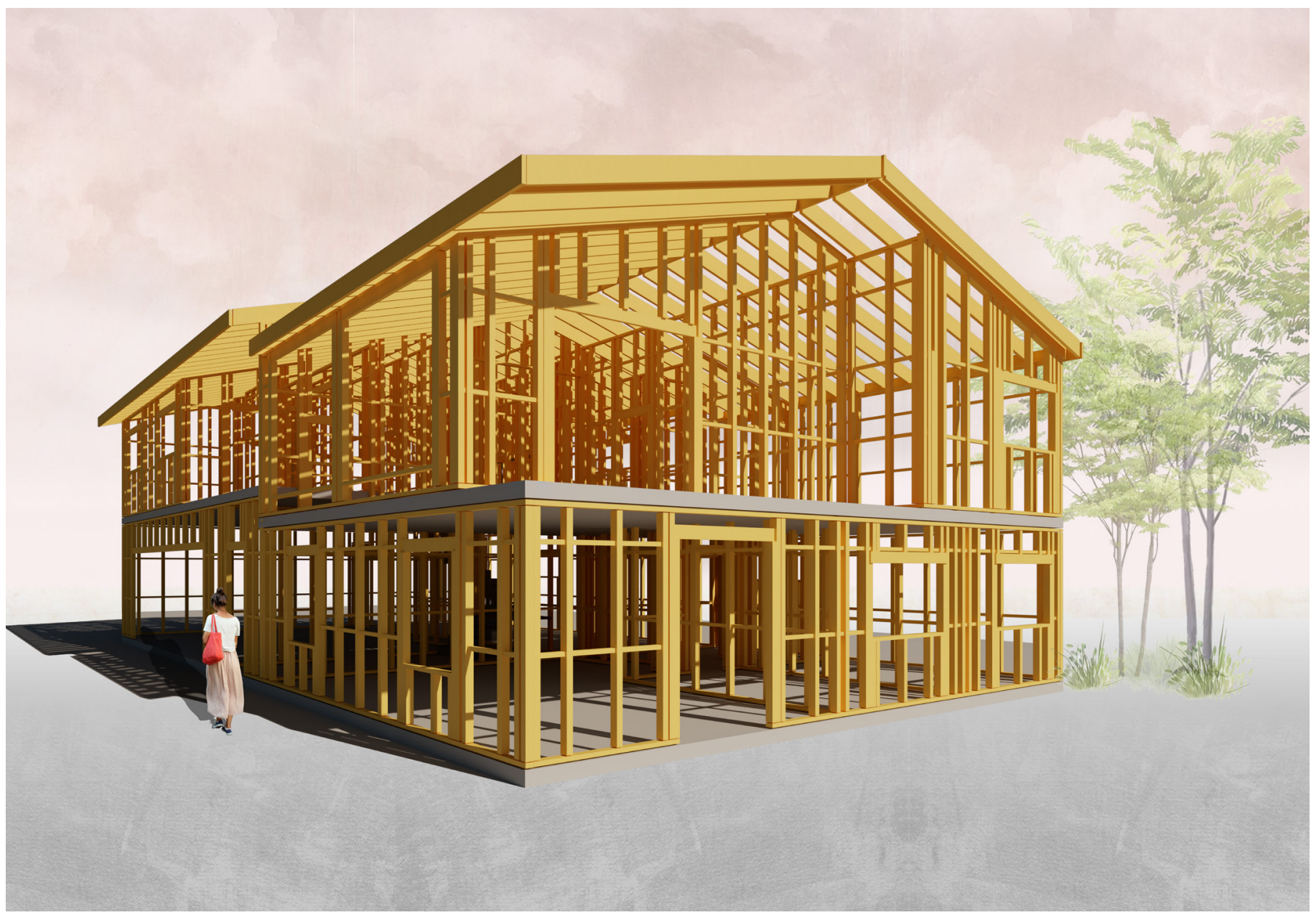




\subsection{OBSERVATIONS AND ISSUES}

When it came to creating the templates and rule sets the first step was to load data so that existing pre-sets, joins, and framing conditions could be created. The primary issue that was faced when setting up the templates was related to the horizontals and openings. Initially the lintels (headers) sometimes would align with the horizontals at the window and door openings creating unnecessary framing. However, this was easily fixable by editing the horizontals settings and checking the box that says 'stop at kings'. This variable prevented the horizontals from appearing in the openings.

Another issue was setting up the templates for the shop drawings. The default sheet template was an A4 landscape. A copy of the template adjusting the size, company boarder, and 'zones' where the different views such as 3D, elevation, etc. were placed was customised. The template provided in-depth customisable settings and ultimately the template needed to be named or include MWF to appear and be recognised by the plugin.

Panel 'split wall' optimisation was another option that was identified. This setting is particularly relevant and useful for the manufacturing of elements. Some manufacturers have a specific maximum length the framing panel can be, based on what their machines are able to manufacture. The panel 'split wall' sets a maximum length before the framing automatically creates a second wall panel.

These issues and observations were a learning curve to the software but were easily solvable. Overall the programming of the plugin to suit New Zealand building standards was successful, allowing walls to be framed based off of conditions from NZS 3604.

The plugin itself was designed for framing subcontractors and is not generally used by architecture firms. Despite this, the software is relatively easy to learn and enables the designer to consider the manufacturing and assembly requirements of their design.

Not only is this digital tool user friendly and can easily automatically generating timber framing, it is also a step towards being able to take a model directly to manufacture. This would eliminate the need for a translation stage, reducing expensive remodelling. It is also a step towards streamlining the design-to-construction process and improving productivity. 


\subsection{CNC OUTPUT}

To test the CNC output of the plugin, a meeting with a truss and frame manufacturing company was set up to see if it would be possible to collaborate with them and test the BIM tool potential. The truss and frame manager was interested to see the output and potential impact utilising these BIM tools could have on their manufacturing processes. However, due to the high capacity of projects they were currently working on this was not deemed to be feasible.

Another limitation to the testing of the CNC output was due to this being a feature only available to those who bought the licensing. Although this output was not available for testing, several example files of what could be exported was supplied by a support person at Strucsoft the company who designed the plugin. These files were BTL files (see Figure 5.14 and Figure 5.15). The BTL file provides a complete description of the format and processing which can be read by several different CNC machines. It is a free standard that suits most design software and machines. These files can be arranged and shown by individual components, display manufacturing details, and provide a 3D view of the component. Material type, grade, length, quality, assembly number and other manufacturing information can be generated. Figure 5.15 demonstrates the ability to show components of the frame, with its individual manufacturing details. The BTL file generates G-code for the timber frames to be fabricated on a CNC machine. This output option provided several different CNC modules specific to the machine it needed to be output to. Tutorials from the developer's YouTube channel suggests the options of the CNC output were customisable based on the specific requirements needed for the CNC operations and tools.

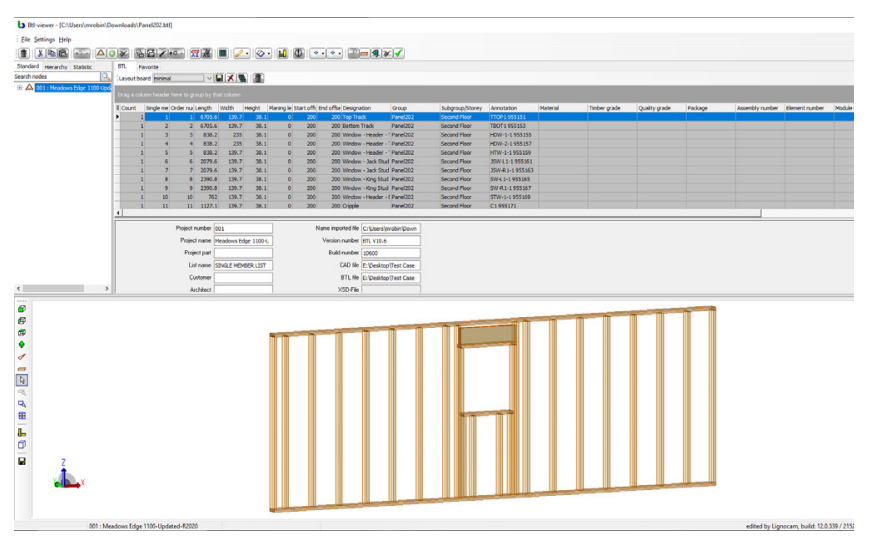

FIGURE 5.14. 3D VIEW OF WALL FRAME

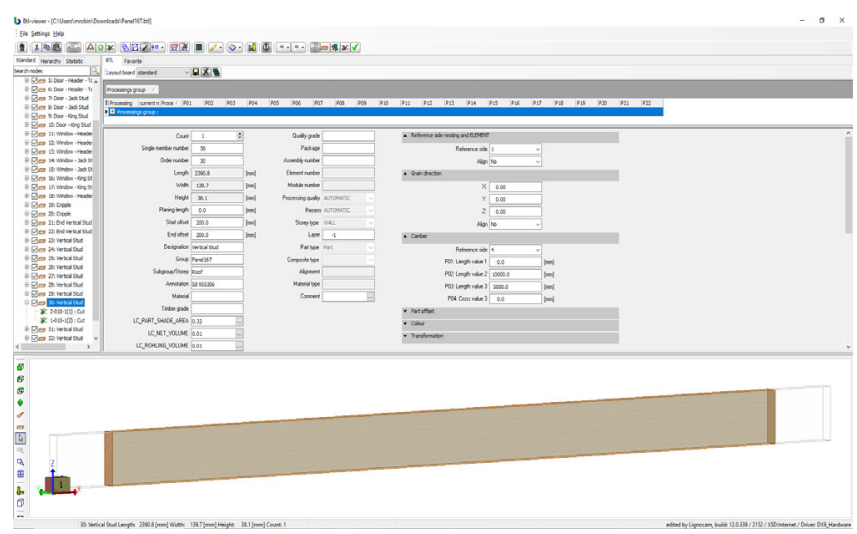

FIGURE 5.15. COMPONENT DETAILED INFORMATION 


\section{SUMMARY}

The findings from the developed testing phase were significant, confirming the potential of programming the plugin to New Zealand timber sizes and building code. Rule sets and templates based on NZS 3604 were able to be created based on set conditions. Many observations and issues were discussed, however, most of these were due to the software's learning curve. The ability to automatically generate timber framing easily allows architects to consider how their designs will be manufactured and assembled. This digital tool can improve and impact the way architectural projects are designed and constructed. By beginning to streamline the design-to-construction process, not only could this increase productivity on production lines but also reduce the need for specialist technicians and the need for remodelling. Although the CNC output was unable to be tested this could be future research to verify the CNC opportunities of MWF Pro Wood. 


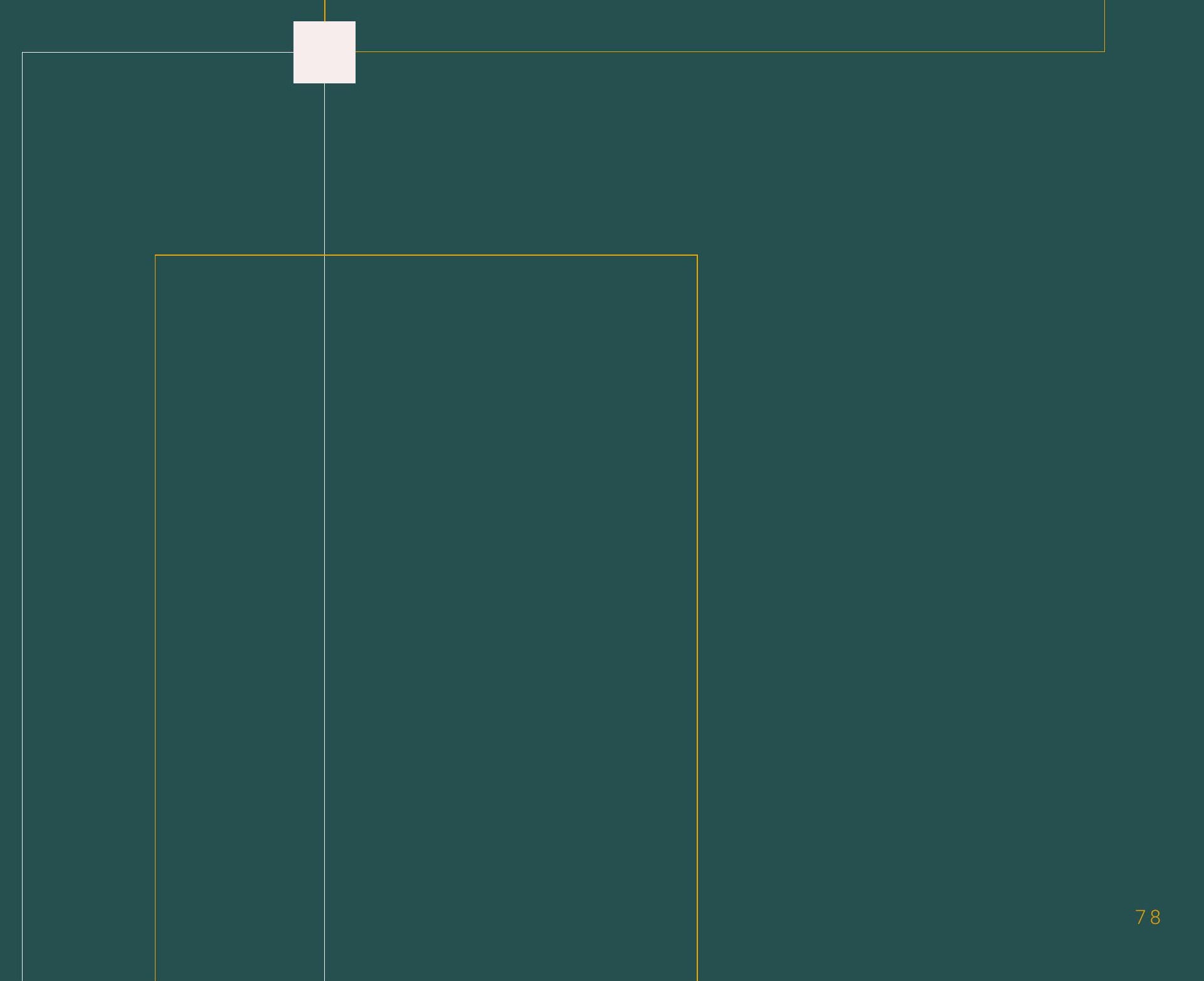




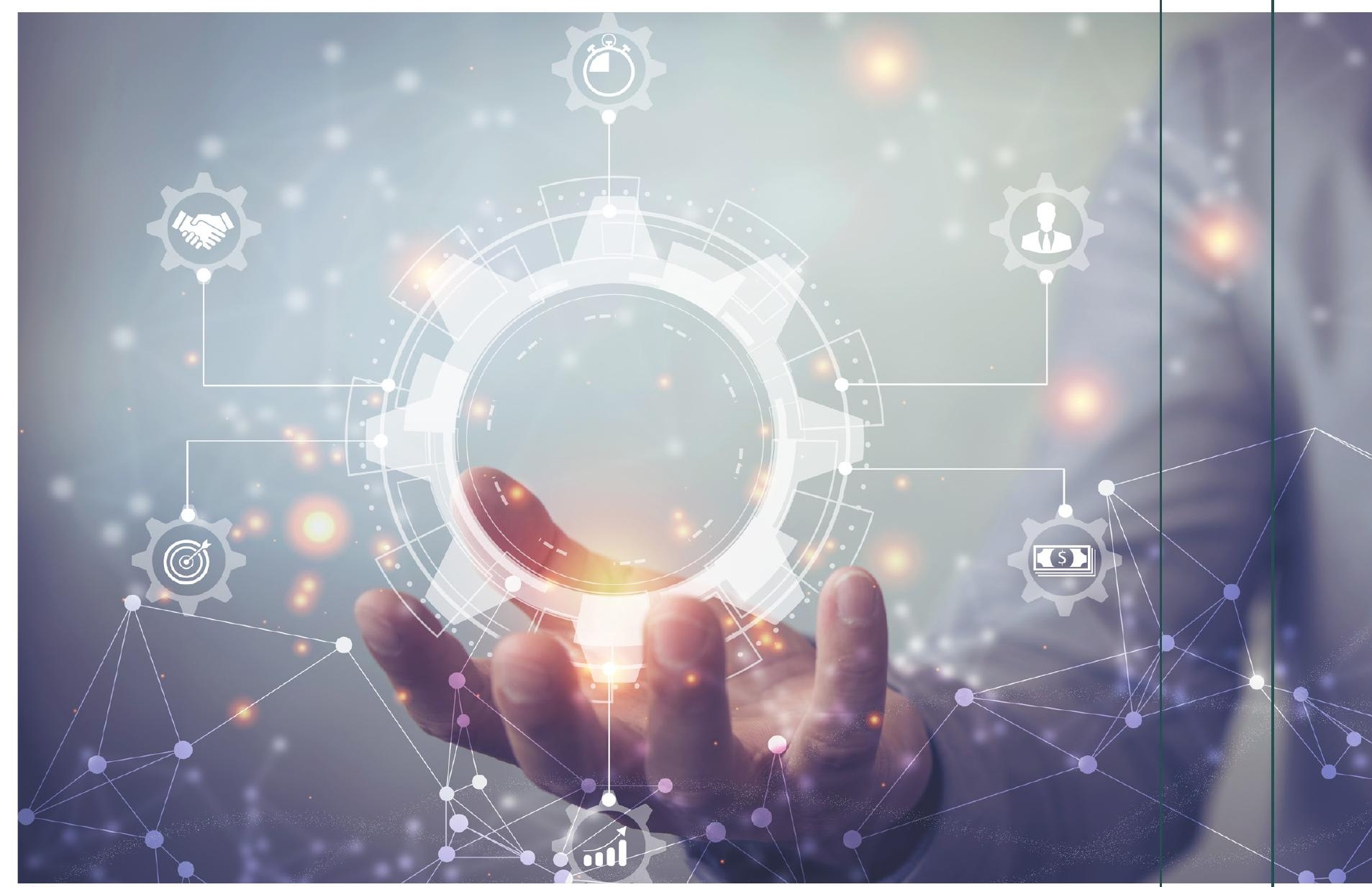

() [Looker_Studio] / Adobe Stock

Proposed Workflow

6.1 What was learnt?

6.2 Limitations

6.3 What does it mean for the industry?

Future Work

DISCUSSION AND OUTCOMES 


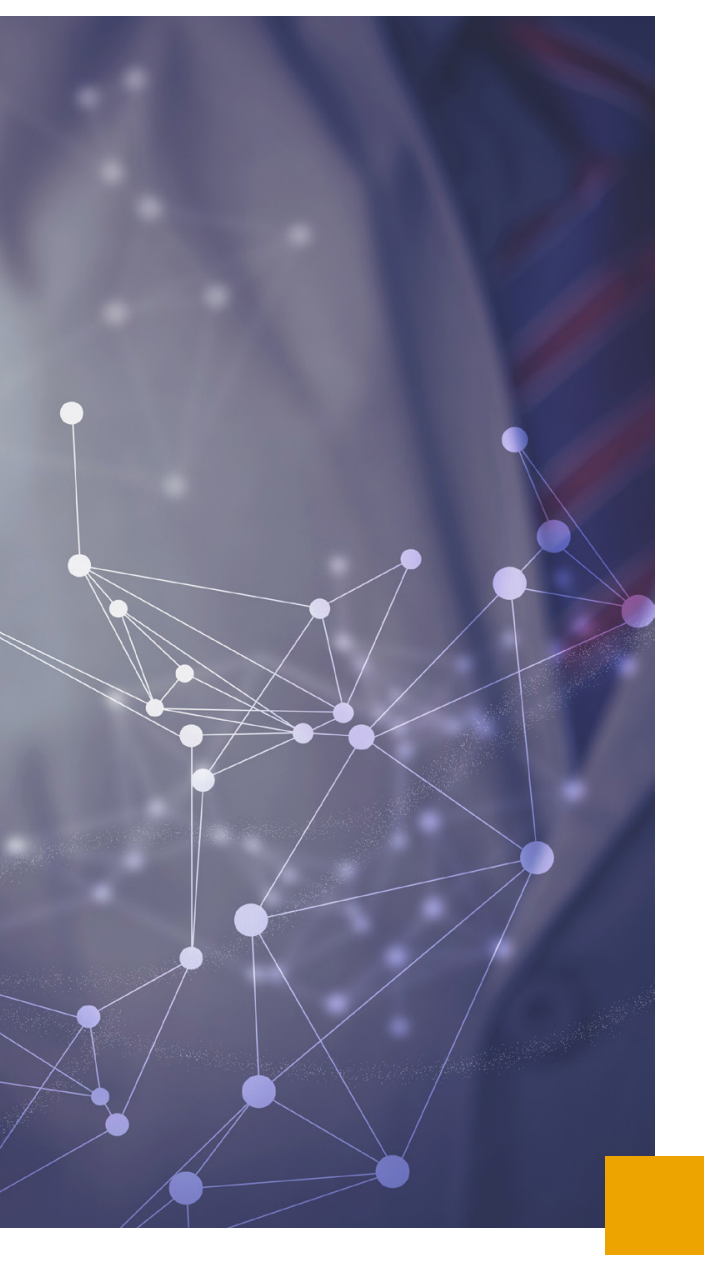




\section{PROPOSED WORKFLOW}

The following chapter assesses the newly established workflow, defining and evaluating the performance of the workflow through the testing of timber framing meeting New Zealand building code NZS 3604. The workflow has been developed for particular outputs and conditions, however, could be applied to elements other than framing in the future.

This workflow process focuses on two main components. Design for Manufacture and Assembly guidelines and principles and BIM processes/tools for Revit. This thesis presents a new file-to-factory workflow aiming to bring design and construction together and begin to streamline the design to manufacture process.

It aims to assess the impact a file-to-factory workflow could have on the way architecture projects are designed and constructed in New Zealand. Through the accumulation of the results from interviews, literature review, case studies, and initial and developed testing of BIM tools, a new shopdrawing process (see Figure 6.02) and file-tofactory workflow has been presented (see Figure 6.04). The impact DfMA and BIM tools can have throughout the design-to-construction process has been diagrammed in Figure 6.03. The red arrows indicate the importance of DfMA being implemented early on in the design process. As the design-to-construction process progresses, the impact on the project increases. It is important to note these processes and tools are already existing but have not been utilised to their full potential in the architecture and building industry in New Zealand.

Risk

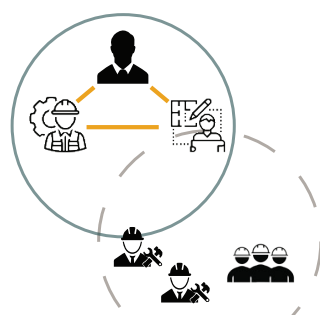

$\checkmark-$
People involved

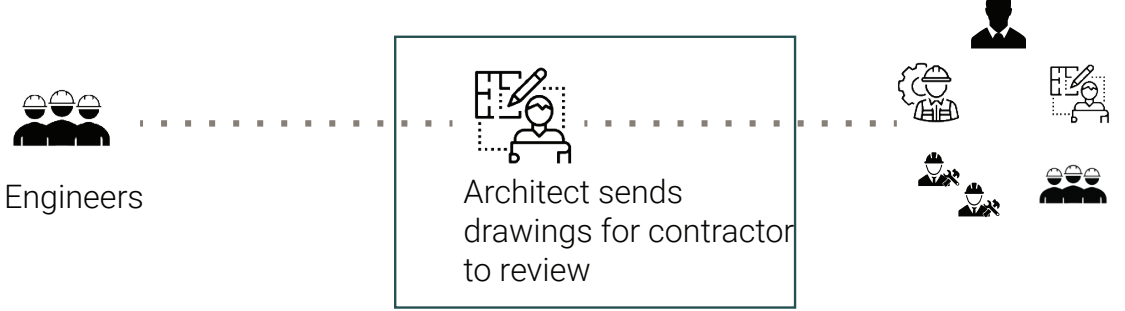



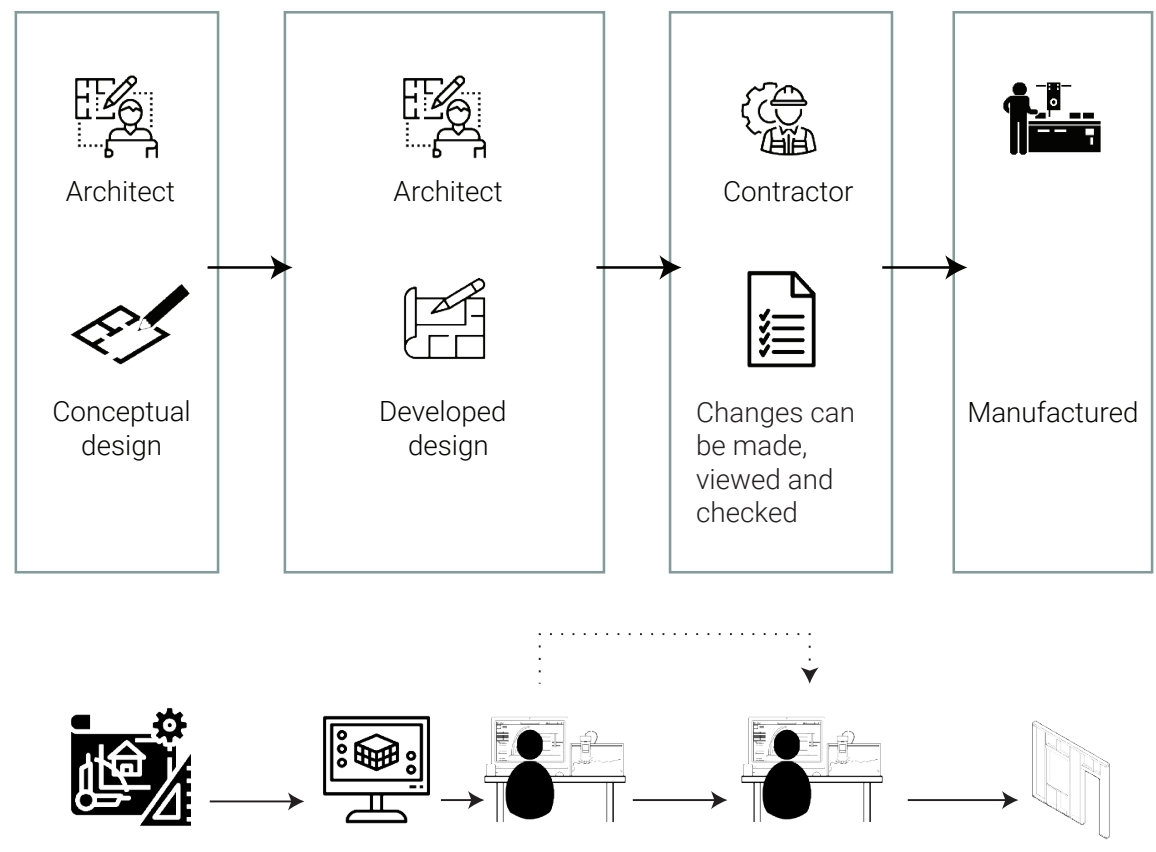

Sketching
Revit MWF Pro Wood Contractor can
or similar BIM make changes,
tool view and verify

$\mathrm{BIM} \quad \mathrm{BIM}$

FIGURE 6.02. PROPOSED SHOPDRAWING PROCESS

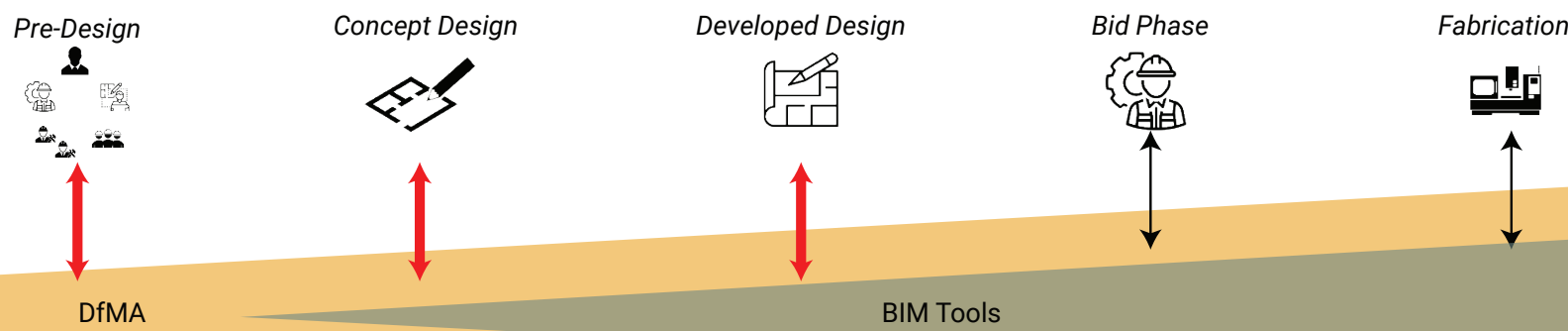


FIGURE 6.04. NEW FILE-TO-FACTORY WORKFLOW

Implementing DfMA and BIM

Tools into the Design-to-

Construction Process

Refine, reflect, and repeat until aimed results are achieved
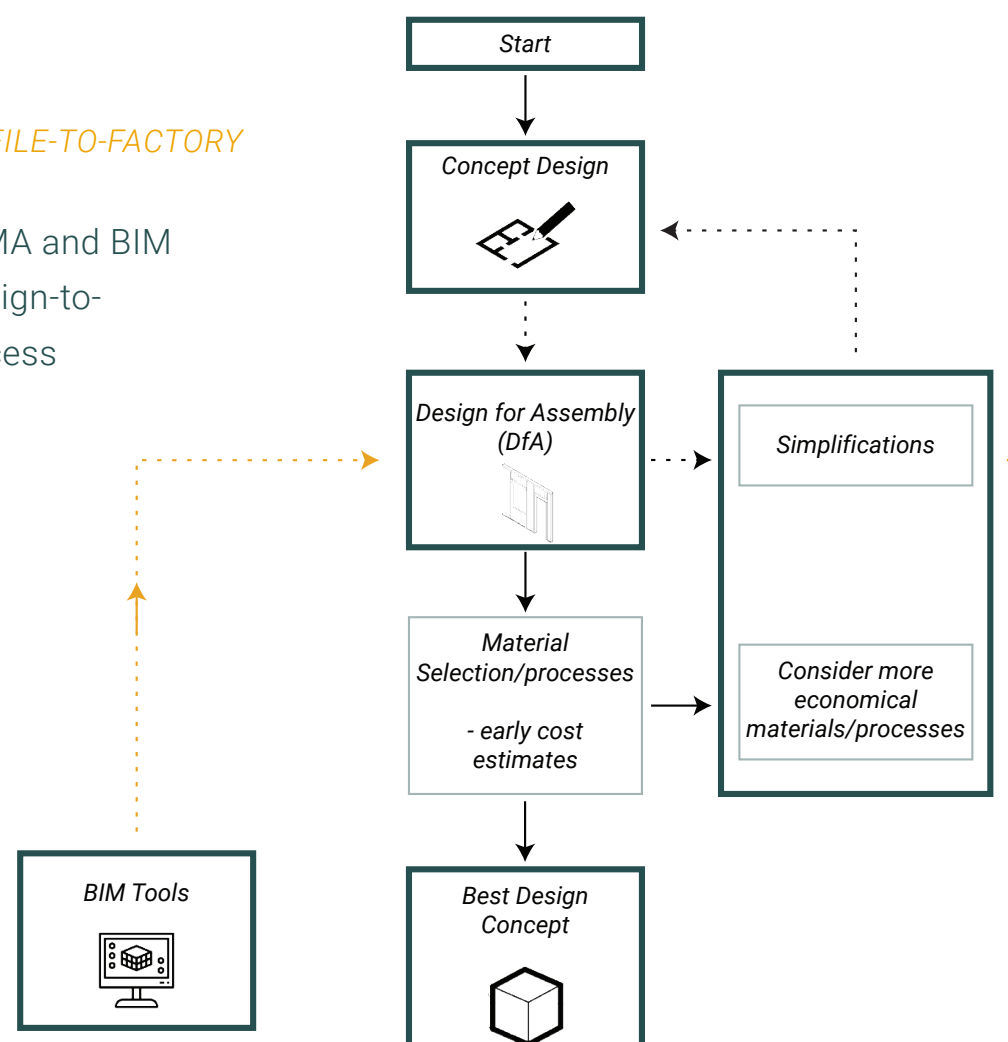

A

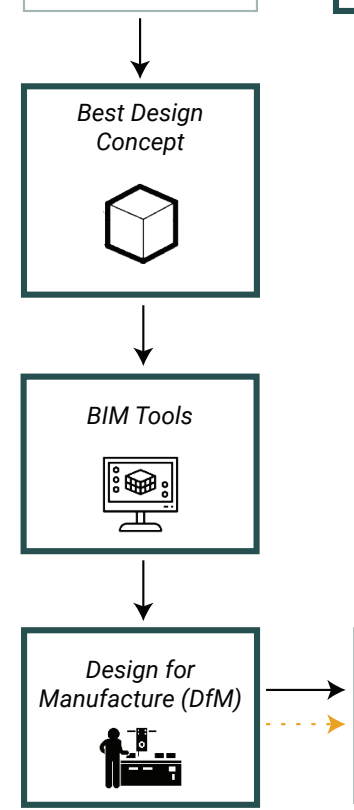

A
Detail Design

- minimum

manufacturing cost

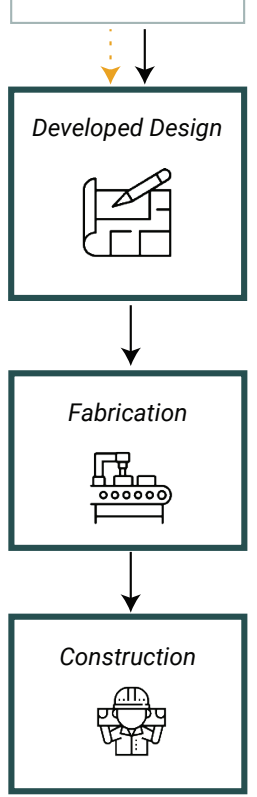




\section{1 WHAT WAS LEARNT?}

\section{What is the significance of the results?}

From Literature Review

The results tell us that there is still are still issues with the shop drawing file-to-factory process due to the traditional project delivery.

- Remodelling

- Design separated from construction

- Architects not designing for manufacture and assembly

As mentioned in the literature review (see Duro-Royo \& Oxman, 2015; Larsen \& Schindler, 2008), previous studies have demonstrated the importance of understanding the building processes and methods and tools for the fabrication/manufacturing process. The findings from the interview are similar to the research based on the main issues industry professionals are currently facing in regards to the design to manufacture process. There is currently a lack of understanding from architects and designers in the manufacturing and assembly process of their designs and therefore these processes are not considered early enough during the design process. This is especially relevant when prefabrication is involved. This finding was significant because as the industry continues to use new ways of building, it is key for architects and designers to begin to understand and consider manufacturing and assembly processes in their designs.

This finding is consistent with that of Pigram and McGee (2011) who mention the criticality of architects understanding the ultimate means of production as the formal and tectonic complexities grow. Typically, with the traditional design-bid-build delivery process, there is not enough early contractor involvement that allows the construction phase of the building to inform the design. In particular, with prefabrication this consequently causes prefabricated and assembly solutions to be considered too late in the design-to-construction process for them to fully impact/affect the design. It became clear through the interviews that one of the solutions towards solving these issues was by implementing a process called DfMA.

From the literature, there is currently no standard or streamlined approach towards the way architecture projects are designed and constructed. The fact that there is a range of different approaches demonstrates that there is still an issue with the design to production process due to the separation between design and construction in the traditional delivery process and software involved. However, none of the literature review approaches investigated the impact utilising BIM tools could have on the way architecture projects are designed and constructed.

An interesting finding from the initial testing phase was that many of the limitations came from Revit rather than 
the BIM tool plugin itself. Although many of these limitations were known initially, through the series of tests this was clarified. The limited interoperability between different design programs restrained what could be done with the design in regards to parametric elements. While there were some issues and challenges with automatically generating the framing and joinery for the series of huts, many of these were resolved later on once a better understanding of the plugin had been gained. This demonstrated the learning curve of the plugin and that many of the issues were easily resolvable once the plugin had been fully explored.

Oosterhuis et al. (2015), Larsson et al. (2012), and Pigram and McGee (2011) showed that, the utilisation of digital tools and/or creation of platforms and tools, can begin to establish a continuous digital workflow specifically relating to parametric design. However, the results from the initial and developed testing proved the creation of new platforms and tools is unnecessary when it comes to timber framing. It demonstrated the utilisation of BIM tools and the ability to create rule sets and templates for New Zealand building standards in a similar way to those determined in Duro-Royo and Oxman's (2015) work. The use of BIM and DfMA processes in combination with the use of BIM tools is significant due to the ability to leverage information from the BIM model and take this straight to manufacture. This eliminates the need for remodelling and begins to streamline the design-to-construction process through the automatic generation of timber framing based on set conditions. While these conditions have been set to suit New Zealand building standards, it is essential to note these could be programmed and altered to suit other types of building code or building systems other than NZS 3604. The results also do not indicate how this file-to-factory workflow might impact or push the design potential through the use of rule sets to influence the design and set conditions. However, this opportunity could be explored extensively in future studies.

\subsection{LIMITATIONS}

- The results can't tell us exactly how much time or cost will be saved since this was not thoroughly calculated or explored

- Also doesn't tell us the design potential of pushing the design and using rule sets to influence the design

- Cost for learning the software and training of it however beneficial for future use (easy once learned)

- Doesn't fully explore the CNC output due to not being able to fully access the software

However, the results from the interviews, initial and developed testing cannot give us quantitative data on exactly how much time or cost would potentially be saved. This was not part of the scope but is important information that would be necessary to calculate and explore to test whether the workflow would improve the overall project efficiency. The results also do not indicate how this file-to-factory workflow might impact or push the design potential through the use of rule sets to influence the design and set conditions. 


\subsection{WHAT DOES IT MEAN FOR THE INDUSTRY}

Productivity improved, quality enhanced, and increased productivity on production lines (automation)

- Lower costs

- Streamline processes and increase accuracy

- Reduces expensive remodelling

- More collaborative process

- Gives architects more control of the design

- Reduces human error

Through the utilisation of BIM tools and BIM processes and DfMA principles this has created a new file-to-factory workflow. This workflow is promising because it looks to improve the main issues with the current traditional designbid-build delivery process. Compared to the traditional design-bid-build process, this new workflow provides more benefits when it comes to the file-to-factory process. The collaborative workflow allows for contractor involvement and consideration of manufacturing and assembly processes early on in the design phase. It provides a different approach to designing and constructing architectural projects by applying a more focused mindset towards the technical feasibility of the design.

By implementing BIM processes and DfMA principles, design and construction are no longer contracted separately and the utilisation of BIM tools to their full potential eliminates the need for a translation stage between design and manufacture. The expensive remodelling, human errors, omissions, and uncertainties are reduced, thereby saving time and money. However, the results from the interviews and the initial and developed testing cannot give us quantitative data on exactly how much time or cost would potentially be saved. This was not part of the scope of this research but would be important information that would be necessary to determine whether the workflow would improve the overall project efficiency. The new workflow begins to streamline the manufacture of timber framing and increase the accuracy. Productivity on production lines could also be increased and improved while ensuring better quality.

The shift towards a new workflow would be challenging especially with the current reluctance towards change in the industry. The time taken to implement these processes, software and principles could be time consuming and costly. Although learning how to set up the rule sets and templates could take time, there are many long-term benefits. It would allow for anyone throughout the design to production process to utilise these BIM tools and provide architects with more control over their designs. Training could be provided initially to create awareness about the BIM tools essentially no longer requiring skilled fabrication modellers and machine operators. This is advantageous for the industry due to the current skill shortage in New Zealand as identified from the interviews. 


\section{FUTURE WORK}

To better understand the implications of these results, more research into other areas of this research could be undertaken. Investigations into the following areas could be beneficial for exploring and addressing the separation between design and construction.

- Partner with the construction industry to implement and use the workflow in a production environment to truly understand the impact the workflow can have on the way architecture projects are designed and constructed.

- Future studies could address applying the workflow of rule sets and templates towards other design opportunities and building systems other than NZS 3604. This will establish a greater reach and range of being able to automatically generate particular components under certain conditions.

- Research focusing more in depth about the CNC output and manufacturability opportunities of the plugin would be beneficial to understand the full capabilities of the BIM tools when going from design to manufacture. This research would further demonstrate the viability of this file-to-factory and verify its potential.

- Another avenue of research would be looking into creating a digital library to create kit set parts for the designto-construction process as a way to evaluate the design potential.

- An investigation into the realistic figures and quantitative data on how much time and cost this workflow would save would be extremely important to carry out and identify. This would also give an indication on whether the overall project efficiency was improved or not. 


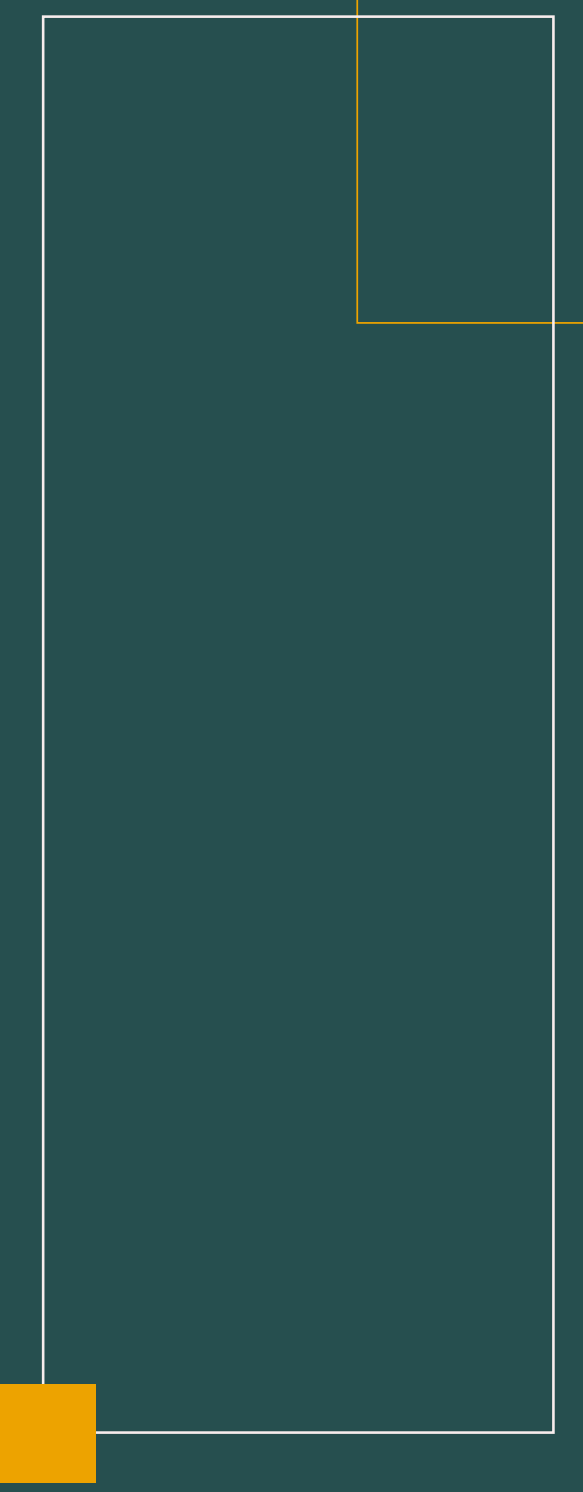




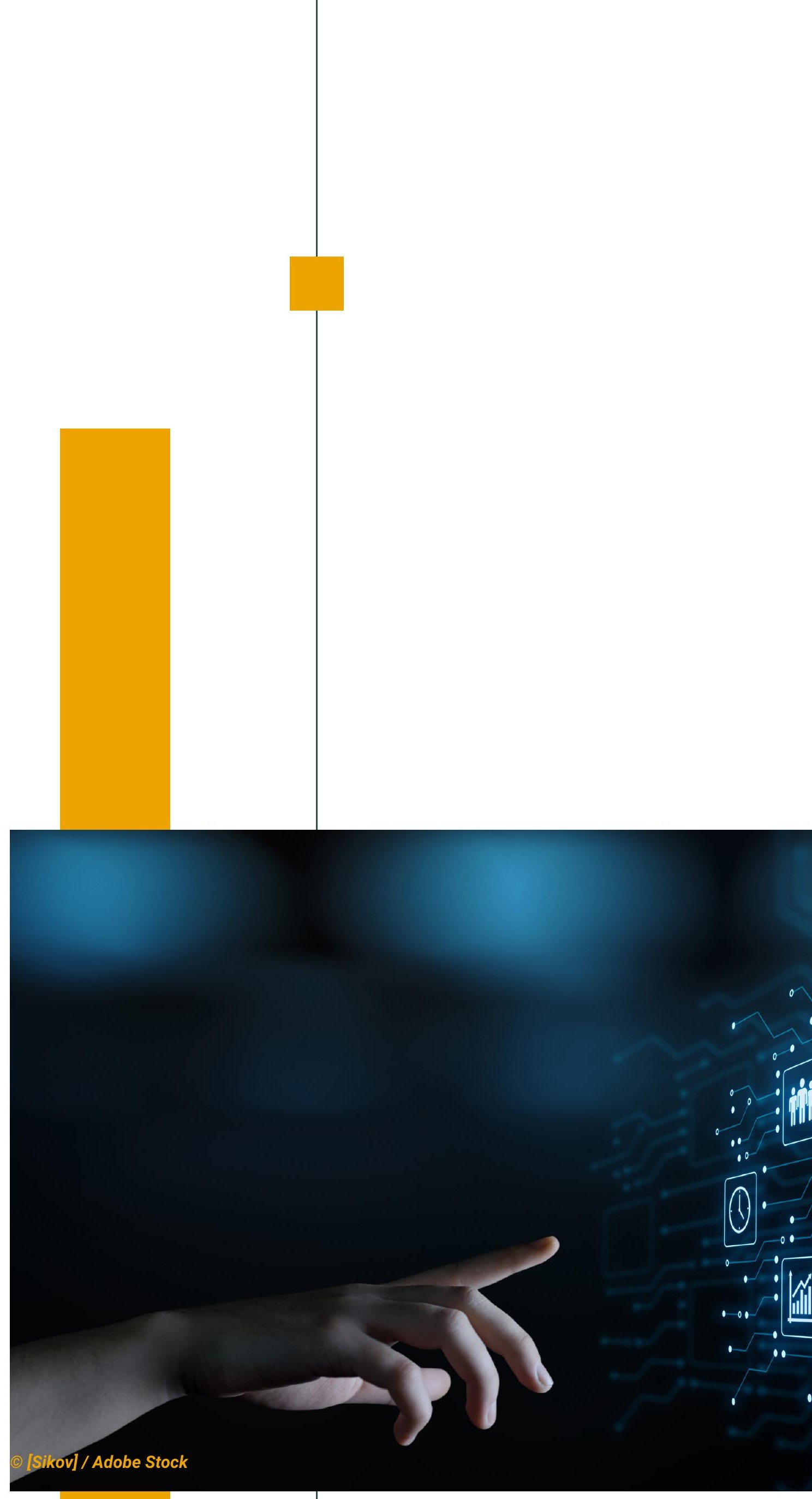



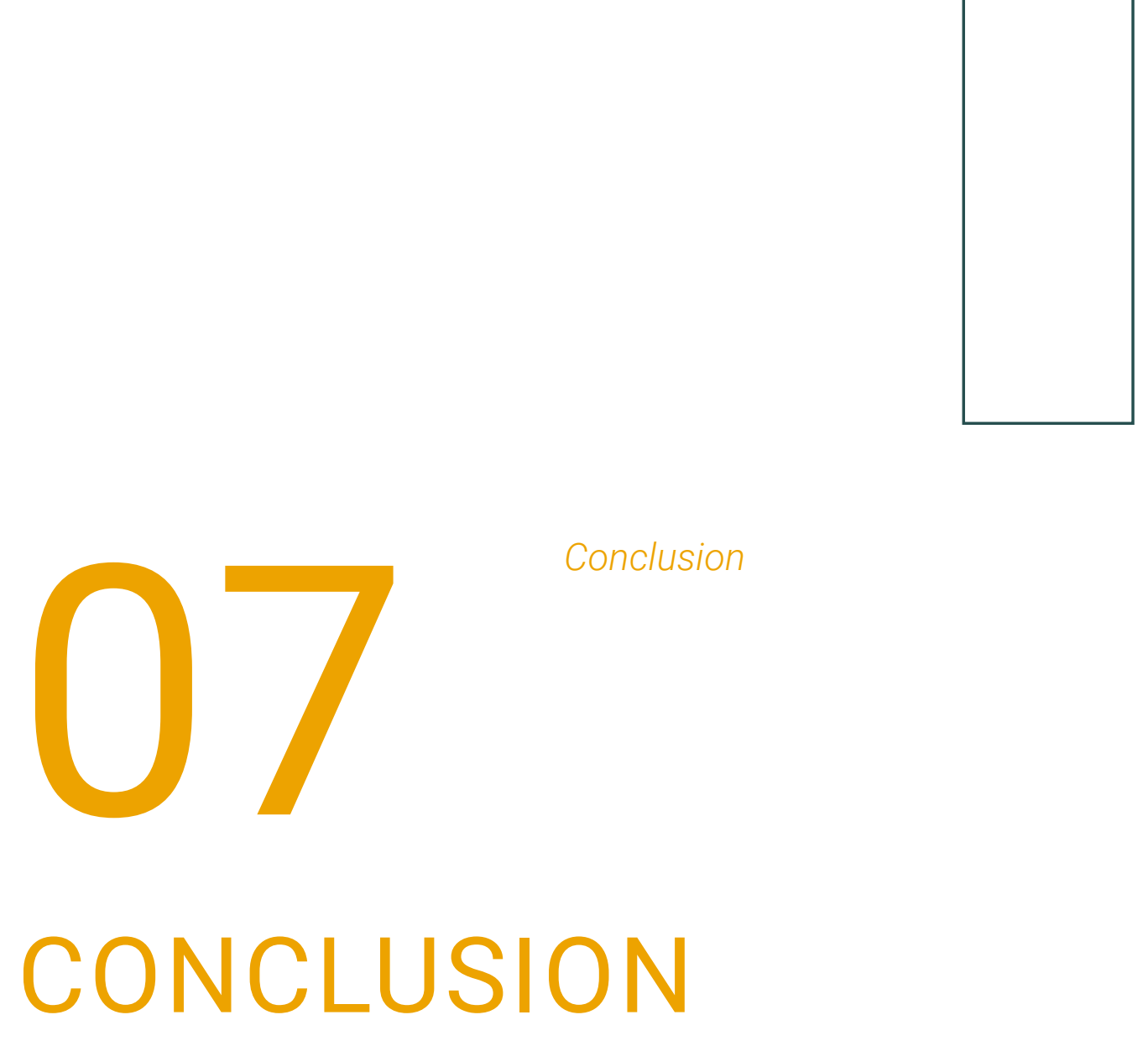

\section{0}

- 00

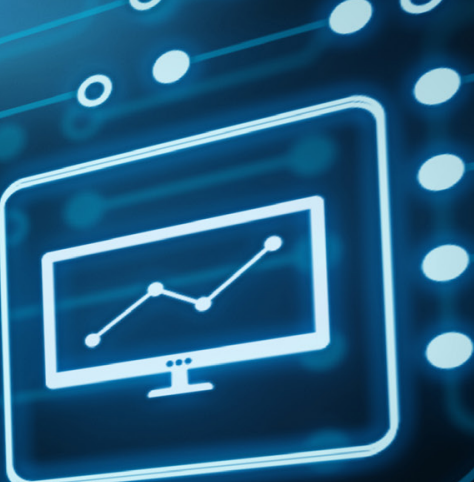

o

- 0

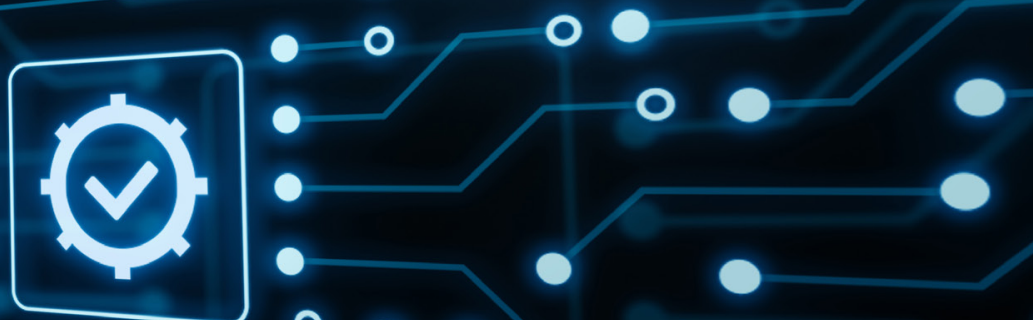

○

(

○

o 


\section{CONCLUSION}

This research aimed to identify what impact a file-to-factory workflow could have on the way architecture projects are designed and constructed in New Zealand. This workflow was created through the utilisation of BIM tools for Revit in combination with DfMA principles. By exploring and analysing the file-to-factory process through the utilisation of digital tools, this thesis demonstrates the implications the workflow that was created could have on the building industry.

From the qualitative interviews, it became clear that there are many issues in the building industry relating to the file-to-factory process. DfMA emerged as a main solution to begin to make improvements for the shop drawing process. This process would not only bring together design and construction but provide a more collaborative design process. The experimental tests completed in the initial testing demonstrated the opportunities of utilising digital tools while identifying limitations of MWF Pro Wood. The results identified the ability of the plugin to link with Revit and worked best with rectilinear forms. Although some challenges and issues were encountered, these were mostly due to the learning curve of the plugin and not the design itself. The results from the experimental developed tests revealed the ability to program NZS 3604 into the plugin and the creation of rule sets that allowed framing to be automatically generated.

This research contributes to and addresses the separation between design and production by bridging the gap through the creation of a new file-to-factory workflow. All of the manufacturing, assembly processes, and digital tools discussed are existing. The workflow couples the processes together seeking to bridge some of the technology together eliminating the need for remodelling and providing a more collaborative design to production process. In order for the industry to shift towards this new workflow all of the main stakeholders in the project need to be in agreement. However, there is currently a reluctance towards change. Compared to the traditional design-bid-build process, the risk in this collaborative workflow is shared rather than placed solely on the owner during the design phase and then contractor in the construction phase of the building process.

The utilisation of BIM tools and implementation of DFMA principles can have an impact on the the way architectural projects are designed and constructed in New Zealand. These processes and tools already exist, however are not currently being utilised to their full potential. Utilising the BIM tools to their full potential supports the industry since the tools are relatively easy to learn. This reduces the need for specialist technicians. This collaborative workflow enables designers and architects to work towards understanding how their designs will be manufactured and constructed. The new file-to-factory workflow is significant to the industry because it begins to streamline the design-to-construction process and allows for the industry to grow, advance, and increase productivity. 


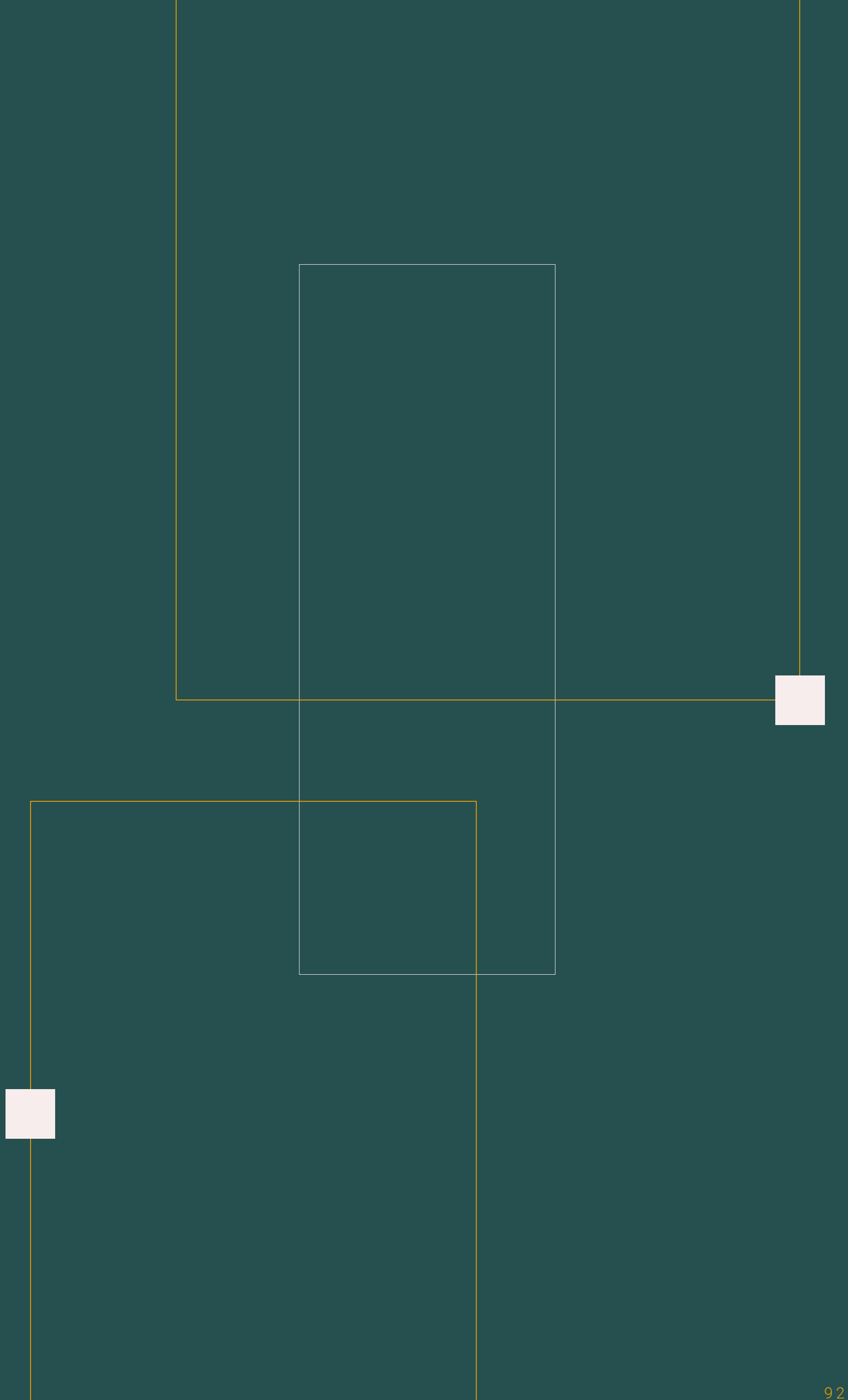


BAC. (2019). The New Zealand BIM Handbook: A Guide to Enabling BIM on Built Assets (Third). BIM Acceleration Committee.

Bascand, G. (2011, March 25). Manufacturing and construction pull down productivity growth [New Zealand Government]. Retrieved September 24, 2019, from Stats NZ website:

http://archive.stats.govt.nz/browse_for_stats/economic_indicators/productivity/IndustryProductivityStatistics_MR19782009.aspx

Bogue, R. (2012). Design for manufacture and assembly: Background, capabilities and applications. Assembly Automation, 32(2), 112-118.

https://doi.org/10.1108/01445151211212262

BRANZ. (2010). Construction Industry Productivity (Study Report No. SR 219; pp. 1-42). Wellington, New Zealand.

CADlearning. (2016, February 25). Understanding the Difference Between BIM and CAD. Retrieved November 12, 2019, from Autodesk website:

https://knowledge.autodesk.com/support/revit-products/learn-explore/caas/video/youtube/lesson/143344courseld-100332.html

CMA + U. (2013). 1330 Mt Pleasant Community Centre. Retrieved March 13, 2019, from CMA + U website:

http://cma-u.com/project/mt-pleasant-community-centre

DFAB House. (n.d). DFAB House. Retrieved October 13, 2019, from DFAB House website:

http://www.dfabhouse.ch/dfab-house/

Dunn, N. (2012). Digital Fabrication in Architecture. London: Laurence King Publishing Limited.

Duro-Royo, J., \& Oxman, N. (2015). Towards Fabrication Information Modeling (FIM): Four Case Models to Derive Designs informed by Multi-Scale Trans-Disciplinary Data. MRS Proceedings, 1800, mrss15-2138549.

https://doi.org/10.1557/opl.2015.647

Eastman, C., Teicholz, P., Sacks, R., \& Liston, K. (2011). BIM Handbook: A Guide to Building Information Modeling for Owners, Managers, Designers, Engineers, and Contractors. (Second). John Wiley \& Sons Inc.

Entekra. (2019). Our Company. Retrieved October 13, 2019, from Entekra website: http://www.entekra.com/about/our-company

ETH Zürich. (2018, March 22). Robotic collaboration in timber construction. Retrieved October 13, 2019, from ETH Zürich website:

http://www.ethz.ch/en/news-and-events/eth-news/news/2018/03/spatial-timber-assemblies.html 
Fuemana, J., Puolitaival, T., \& Davies, K. (2013). Last Planner System - a step towards improving the productivity of New Zealand Construction. Last Planner System - a Step towards Improving the Productivity of New Zealand Construction, 679688. Fortaleza, Brazil.

Garber, R. (2014). BIM Design: Realising the Creative Potential of Building Information Modelling. Chichester, West Sussex, UK: John Wiley \& Sons Inc.

Iwamoto, L. (2009). Digital Fabrications: Architectural and Material Techniques. Princeton Architectural Press.

Kaiser, A., Larsson, M., \& Girhammar, U. A. (2019). From file to factory: Innovative design solutions for multi-storey timber buildings applied to project Zembla in Kalmar, Sweden. Frontiers of Architectural Research.

https://doi.org/10.1016/j.foar.2018.12.001

Katerra. (2019 a). The K90 Building Project: Foundation to Finish, Reimagined (pp. 1-14) [Case Study]. Retrieved October 13, 2019, from

http://www.katerra.com/2019/08/15/k90

Katerra. (2019 b). The K90 Building Project: Foundation to Finish, Reimagined. Retrieved October 13, 2019, from Katerra website:

http://www.katerra.com/2019/08/15/k90

Kingspan Group. (n.d). The KB Home ProjeKt. Retrieved October 13, 2019, from Kingspan website: http://kingspan.com/us/en-us/product-groups/insulation/case-studies/residential/the-kb-home-projekt

Kingspan Group. (2019). The KB Home ProjeKt [Case Study]. Retrieved from

http://kingspan.com/us/en-us/product-groups/insulation/case-studies/residential/the-kb-home-projekt

Kolarevic, B. (2001). Digital Fabrication: Manufacturing Architecture in the Information Age. Reinventing the Discourse - How Digital Tools Help Bridge and Transform Research, Education and Practice in Architecture: Proceedings of the Twenty First Annual Conference of the Association for Computer-Aided Design in Architecture. Presented at the Reinventing the Discourse - How Digital Tools Help Bridge and Transform Research, Education and Practice in Architecture: Proceedings of the Twenty First Annual Conference of the Association for Computer-Aided Design in Architecture.

Laing O'Rourke. (2013). The future of DfMA is the future of construction. 77, 44-77.

Larsen, K. E., \& Schindler, C. (2008). From Concept to Reality: Digital Systems in Architectural Design and Fabrication. International Journal of Architectural Computing, 6(4), 397-413.

https://doi.org/10.1260/147807708787523312 
Larsson, M., Kaiser, A., \& Girhammar, U. A. (2012). From file to factory: Advanced manufacture of engineered wood elementsInnovative design solutions for multi-storey timber buildings throughout the entire building process. World Conference on Timber Engineering, WCTE: Final Papers, 448-453.

Leach, N. (2002). Designing for a Digital World (1st ed.). Academy Press.

Lean IPD. (2019). What is Integrated Project Delivery? Retrieved May 4, 2019, from Lean IPD website: https://leanipd.com/integrated-project-delivery/

Mackie, C. (2019). An Introduction to Lean Construction. Retrieved September 17, 2019, from BuildingsGuide website: https://www.branz.co.nz/cms_show_download.php?id=763d60e9ca86a78edea7081aa2c01a99102a9af5

Mills, F. (2019, November 6). Construction's Digital Manufacturing Revolution. Retrieved November 8, 2019, from The B1M website:

https://www.theb1m.com/video/constructions-digital-manufacturing-revolution

Oosterhuis, K., Bier, H., Aalbers, C., \& Boer, S. (2014). File to Factory and Real Time Behavior in ONL-Architecture. Fabrication: Examining the Digital Practice of Architecture, 294-305. Cambridge.

Pease, J. (2019). What Is Integrated Project Delivery: The Contract (Part 1 of 3). Retrieved May 20, 2019, from Lean IPD website: https://leanipd.com/blog/5-things-to-consider-when-setting-targets/

Pigram, D., \& McGee, W. (2011). Formation Embedded Design: A methodology for the integration of fabrication constraints into architectural design. Integration through Computation: Proceedings of the 31 st Annual Conference of the Association for Computer Aided Design in Architecture (ACADIA). Presented at the Integration through Computation: Proceedings of the $31 \mathrm{st}$ Annual Conference of the Association for Computer Aided Design in Architecture (ACADIA), Calgary/Banff, Canada.

Spellerberg, J. (2019, March 7). Project Delivery Methods: The Basics of Design-Bid-Build. Retrieved May 20, 2019, from LevelSet website:

https://www.levelset.com/blog/design-bid-build/

Stencil, C., \& Powell, S. (2018, March 26). The strengths and challenges of integrated project delivery. Retrieved May 20, 2019, from Construction Dive website:

https://www.constructiondive.com/news/the-strengths-and-challenges-of-integrated-project-delivery/519561/

Transformation is Happening. (n.d). Retrieved October 1, 2019, from Industry Transformation website: https://www.industrytransformation.nz/whats-happening/ 
Xie, X. (2003). Design for Manufacture and Assembly. Retrieved October 17, 2019, from https://pdfs.semanticscholar.org/2889/e78a24d3ce8d0f219f99acd1d891a565b242.pdf

Yuan, Z., Sun, C., \& Wang, Y. (2018). Design for Manufacture and Assembly-oriented parametric design of prefabricated buildings. Automation in Construction, 88, 12-22. https://doi.org/10.1016/j.autcon.2017.12.021 


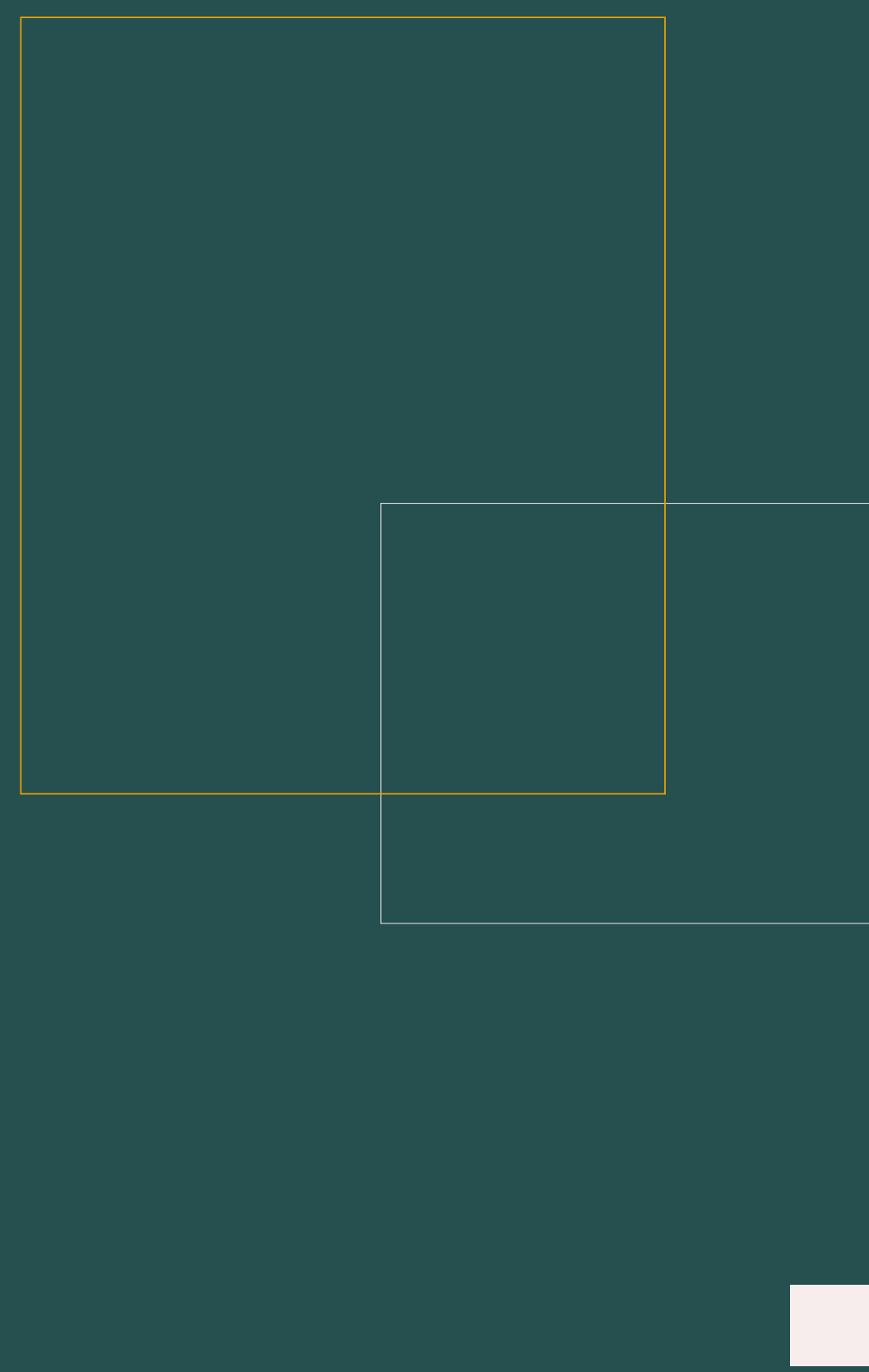


FIGURE 1.01. FILE-TO-FACTORY.

Ordinary Vis. (n.d). [File-to-Factory]. Retrieved 4th October 2019, from http://cargocollective.com/ordinaryltd/filter/masterplan/Fileto-Factory

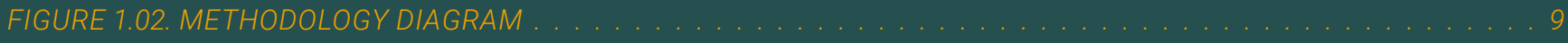

FIGURE 2.01.TRADITIONAL PROJECT DELIVERY . . . . . . . . . . . . . . . . . . 19

FIGURE 2.02. SHOP DRAWING PROCESS . . . . . . . . . . . . . . . . . . . . 20

FIGURE 2.03 INTEGRATED PROJECT DELIVERY . . . . . . . . . . . . . . . . . 21

FIGURE 2.04. PROJECT DELIVERY COMPARISON . . . . . . . . . . . . . . . . . . . 22

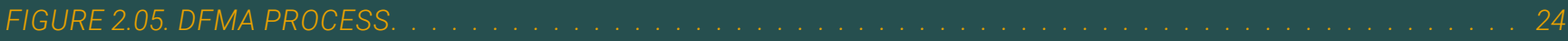

FIGURE 2.06. K90 BUILDING SITE. . . . . . . . . . . . . . . . . . . . . . . . . . . 32

[K90 Building Site]. (2019). Retrieved 13th October 2019, from https://www.architectmagazine.com/technology/q-a-katerrasemichael-marks-is-upending-everything-from-a-to-e-to-c__o

FIGURE 2.07. DFAB HOUSE.

Keller, R. (n.d.). [DFAB House]. Retrieved 13th October 2019, from https://dfabhouse.ch/2019/02/27/dfab-house-is-officially-open/

FIGURE 2.08. SPATIAL TIMBER ASSEMBLIES

ETHZZurich. (n.d.). [Spatial Timber Assemblies]. Retrieved 13th October 2019, from https://dfabhouse.ch/spatial_timber_assemblies/

FIGURE 2.09. KB HOME PROJECKT

Business Wire. (2019). KB Home Unveils Groundbreaking ProjeKt Home: Where Tomorrow Lives. [Photograph] Retrieved 13th

October 2019, from https://www.businesswire.com/news/home/20190107005317/en/KB-Home-Unveils-Groundbreaking-

ProjeKt-Home-Tomorrow

FIGURE 2.10. MT. PLEASANT COMMUNITY CENTRE

CMA+U. (n.d.). Arrival Court and Entrance [Photograph] Retrieved 13th March 2019, from http://cma-u.com/project/mt-pleasantcommunity-centre

FIGURE 2.11. EXPLORE INDUSTRIAL PARK

Institution of Civil Engineers (n.d.). [Explore Industrial Park]. Retrieved 8th November 2019, from https://www.ice.org.uk/ eventarchive/site-visit-explore-manufacturing-worksop

FIGURE 2.12.PROJECT: SUTTER HEALTH EDEN MEDICAL CENTRE

Sutter Health Eden Medical Centre. (n.d.). [Sutter Health Eden Medical Centre]. Retrieved 23rd May 2019, from https:/l hospitalpricelists.org/Eden-Medical-Center

FIGURE 2.13.PROJECT: QUAIL RUN BEHAVIOURAL HEALTH HOSPITAL

Quail Run Behavioral Health. [Quail Run Behavioural Health Hospital]. Retrieved 23rd May 2019, from http://digitalspace.info/?k=co ntact+us+quail+run+behavioral+health

FIGURE 2.14.PROJECT: MOSAIC CENTRE FOR CONSCIOUS COMMUNITY AND COMMERCE 39

Western archirib. (n.d.). Mosaic_Centre_1 [Photograph]. Retrieved 23rd May 2019, from http://www.westernarchrib.com/?page_ id $=485$ 
Griffith, T. (n.d.). [Rocky Mountain Institute Innovation Centre]. Retrieved 23rd May 2019, from https://living-future.org/lbc/casestudies/rocky-mountain-institute-innovation-center/

FIGURE 4.01. DIGITAL ARCHITECTURAL EXPLORATION

Ordinary Vis. (n.d). [Digital Architectural Exploration]. Retrieved 4th October 2019, from http://cargocollective.com/ordinaryltd/filter/ masterplan/File-to-Factory

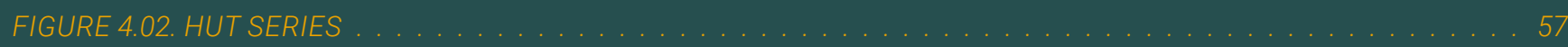

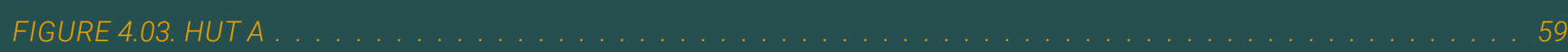

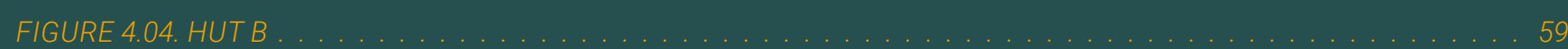

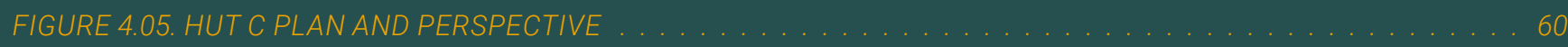

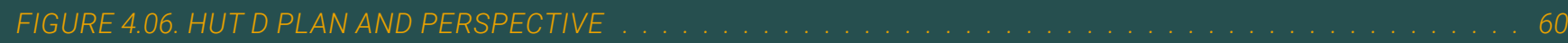

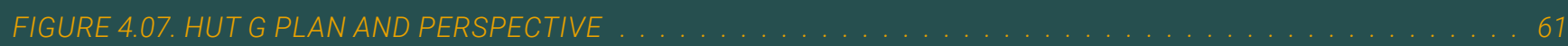

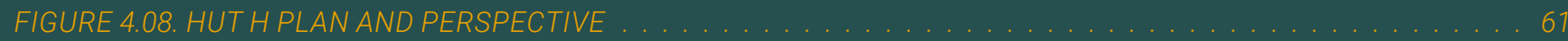

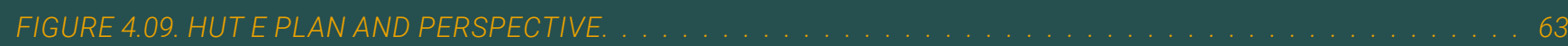

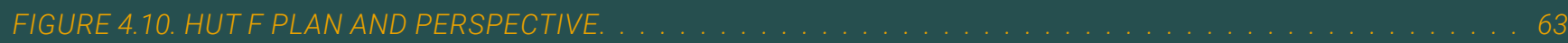

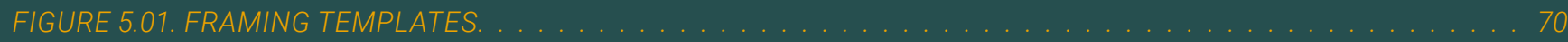

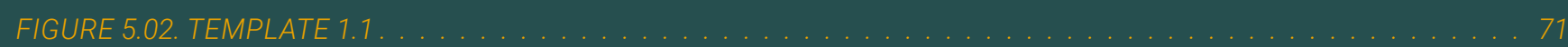

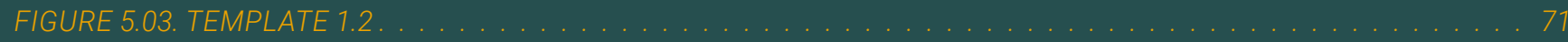

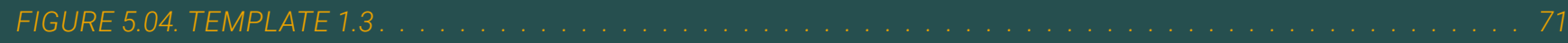

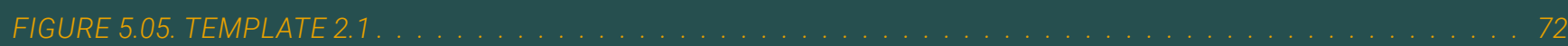

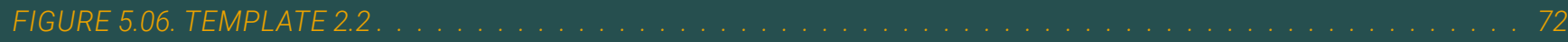

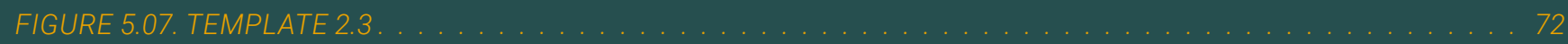

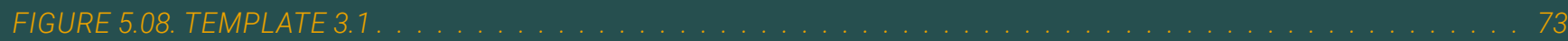

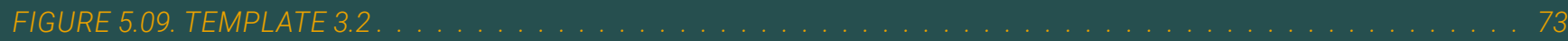

FIGURE 5.10. TEMPLATE $3.3 \ldots \ldots \ldots \ldots \ldots \ldots$

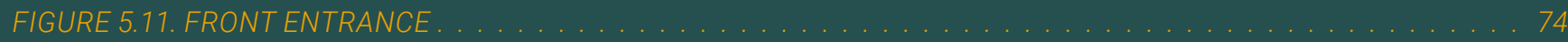

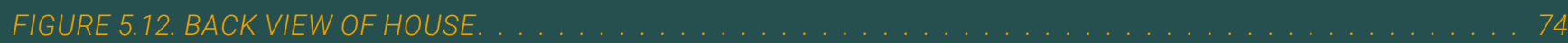

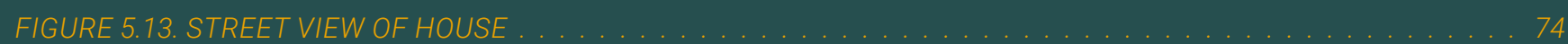

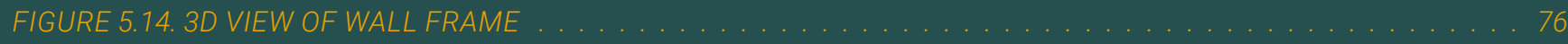

Image Screenshot by author. Content of work sourced and provided by Strucsoft Solutions

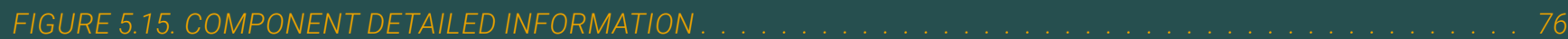

Image Screenshot by author. Content of work sourced and provided by Strucsoft Solutions

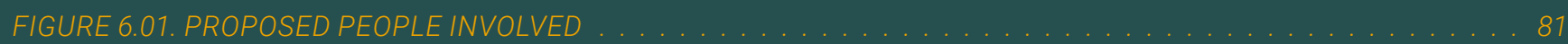

FIGURE 6.02. PROPOSED SHOPDRAWING PROCESS . . . . . . . . . . . . . . . . . . . . . . 82 
FIGURE 6.03. IMPACT DFMA AND BIN TOOLS HAVE ON THE DESIGN-TO-CONSTRUCTION PROCESS. 


\section{CHAPTER FIGURES}

Chapter 1 - Introduction

Creative Commons; Unsplash

Chapter 2 - Literature Review

Pexels Website: https://www.pexels.com/search/construction/

Chapter 3 - Interviews

Photograph by author

Chapter 4 - Initial Testing

Figure 4.01 - Ordinary Vis (n.d.). [Digital Architectural Exploration]. Retrieved 4th October 2019, from

http://cargocollective.com/ordinaryltd/filter/masterplan/File-to-Factory

Chapter 5 - Developed Testing

Pexels Website: https://www.pexels.com/search/construction/

Chapter 6 - Discussion and Outcome

(c) [Looker_Studio] / Adobe Stock

Chapter 7 - Conclusion

(c) [Sikov] / Adobe Stock

Bibliography

Creative Commons; Unsplash 


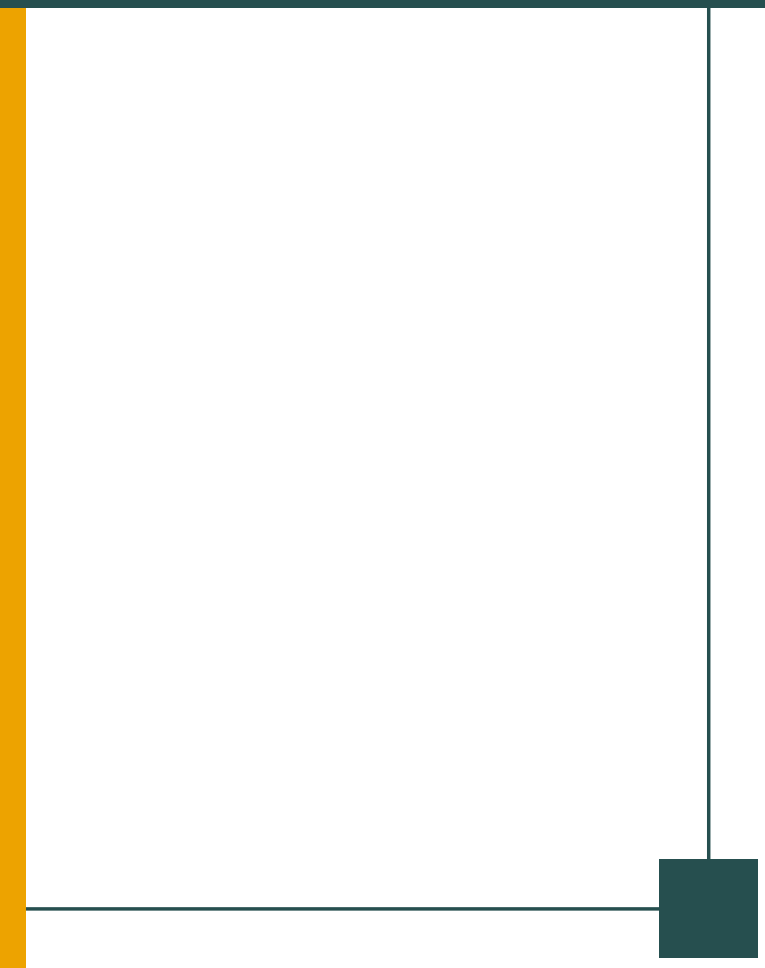




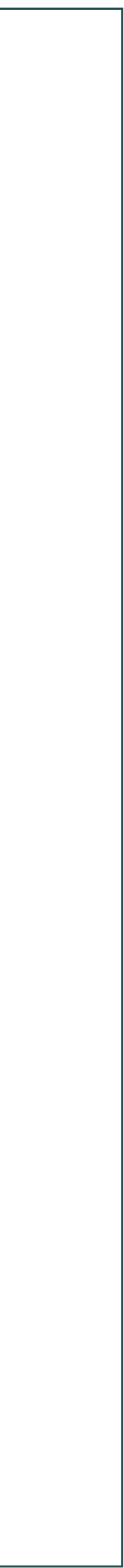

APPENDICES 


\section{APPENDIX A - ETHICS PARTICIPANTINFO SHEET}

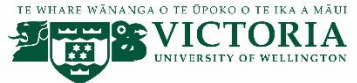

File-to-Factory: Transferring Design Intent to Manufacture

\section{INFORMATION SHEET FOR PARTICIPANTS [for Interviews]}

You are invited to take part in this research. Please read this information before deciding whether or not to take part. If you decide to participate, thank you. If you decide not to participate, thank you for considering this request.

\section{Who am I?}

My name is Maya Robinson and I am a Masters student of Architecture at Victoria University of Wellington under the supervision of Antony Pelosi. This research project is work towards my thesis.

\section{What is the aim of the project?}

This project aims to investigate how controlling the file-to-factory process can influence design opportunities and what the potential affects could be regarding the way architects digitally design and fabricate. Your participation will support this research by providing current issues you have found during the design to manufacture process. These issues can be digital, material or other challenges that you have observed. This research has been approved by the Victoria University of Wellington Human Ethics Committee ResearchMaster application reference number $\# 27413$.

\section{How can you help?}

You have been invited to participate because you are a professional within the architecture and building industry involved with the design to manufacture process. If you agree to take part, I will interview you in a bookable room at the school of Architecture and Design or at your working premises. I will ask you questions about the design to manufacture process, materials and software that you use. The interview will take approximately 30-45 minutes. I will audio record the interview with your permission and write it up later. You can choose to not answer any question or stop the interview at any time, without giving a reason. You can withdraw from the study by contacting me at any time up to two weeks after your interview. If you withdraw, the information you provided will be destroyed or returned to you.
What will happen to the information you give?

This research is confidential. This means that the researcher named below will be aware of your identity but the research data will be combined and your identity will not
be revealed in any reports, presentations, or public documentation. However, you should be be revealed in any reports, presentations, or public documentation. However, you should
aware that in small projects your identity might be obvious to others in your community.

Only my supervisor and I will read the notes or transcript of the interview. The interview transcripts, summaries and any recordings will be kept securely and destroyed on $1^{\mathrm{st}}$ May 2020.

What will the project produce?

The information from my research will be used in Masters of Architecture (Professional). My supervisor and/or myself may also use the results of my research for academic reports, ournal publications and conference presentations.

If you accept this invitation, what are your rights as a research participant? You do not have to accept this invitation if you don't want to. If you do decide to participate, you have the right to:

- choose not to answer any question;

- ask for the recorder to be turned off at any time during the interview

- withdraw from the study up until two weeks after your interview

- ask any questions about the study at any time

- receive a copy of your interview recordins

- read over and comment on a copy of your interview transcript and written summary of your interview. These will be emailed to you at your request.

- agree on another name (pseudonym) for me to use rather than your real name

- agree on another name (pseudonym) for me to use rather than your real name
be able to read any reports of this research by emailing the researcher to request a copy.

If you have any questions or problems, who can you contact?

If you have any questions, either now or in the future, please feel free to contact either my supervisor or myself.

Student:

Name: Maya Robinson

Supervisor:

University email address:

Name: Dr. Antony Pelosi

robinsmava@myvuwa

Role: Interior Programme Director

School: Architecture and Design

Email: antony.pelosi@vuw.ac.nz

Human Ethics Committee information

If you have any concerns about the ethical conduct of the research you may contact the Victoria University HEC Convenor: Dr Judith Loveridge. Email hec@vuw.ac.nz or telephone +64-4-463 6028. 


\section{APPENDIX B - ETHICS CONSENT FORM}

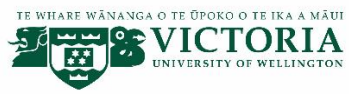

File-to-Factory: Transferring Design Intent to Manufacture

\section{CONSENT TO INTERVIEW}

This consent form will be held for a minimum of five years.

Researcher: Maya Robinson, school of Architecture and Design, Victoria University of Wellington

- I have read the Information Sheet and the project has been explained to me. My questions have been answered to my satisfaction. I understand that I can ask further questions at any time.

- I agree to take part in an audio recorded interview.

I understand that:

- I may withdraw from this study at any point up until two weeks after the interview, and any information that I have provided will be returned to me or destroyed.

- The identifiable information I have provided will be destroyed on $1^{\text {st }}$ May 2020

- Any information I provide will be kept confidential to the researcher and the supervisor.

- I understand that the findings may be used for a Masters and/or academic publications and/or presented to conferences.

- I understand that the observation notes/recordings will be kept confidential to the researcher and the supervisor.

- My name will not be used in reports and utmost care will be taken not to disclose any information that would identify me.

- I would like a copy of the recording of my interview:

Yes $\square \quad$ No $\square$

- I would like a copy of the transcript of my interview:

Yes $\square$ No $\square$

- I would like a summary of my interview:

Yes $\square \quad$ No $\square$

- I would like to receive a copy of the final report and have added my email Yes $\square$ No $\square$ address below. 


\section{APPENDIX C - CREATING A TEMPLATE}

Step 1. The new template was created by going into the drop-down menu of the Wall Model tab and clicking create.

Step 2. A pop-up window appears with all of the customisable settings that can be altered to the desired output. The sizing of the bottom and top track, lintel, cripples, studs, and dwangs were entered accordingly to NZS 3604 standards. For example, for Frame A the conditions were $2700 \mathrm{~mm}$ maximum wall height, $400 \mathrm{~mm}$ stud spacing with a low wind zone and a stud size of $90 \times 35 \mathrm{~mm}$.

Step 3. After all of the desired setting have been entered, the template can be saved and renamed as a new template. For future reference when going to use a template that has already been created this will need to be set as 'active'. 


\section{APPENDIX D - CREATING AN AUTOJOIN RULE SET}

Step 1. The new autojoin rule was created by going to the Wall Model tab and selecting Marker Manager.

Step 2. Once in the manager, click the little plus button to the left of Project, RuleSet, and PanelsAutoJoin.

Step 3. Then under PanelsAutoJoin click the default and select duplicate and rename the 'rule'. Close the Marker Manager and select the walls you want to create the RuleSet for.

Step 4. Next under the Wall Model tab, under Joins, select Create Auto Join Rule and it should bring up the different Panel Join Definitions and previews of the different ways to join the walls involved.

Step 5. After the desired Join Definition has been selected a pop up will ask what RuleSet it should be added to, just select the one you have named.

Step 6. Then it will identify what Join Definition has been applied and the wall type it applies to e.g. Generic 100 Frame which is the wall host.

Step 7. Once that has been set up select the walls you want to join. Under the Wall Model and Joins, click AutoJoin and the Rule Sets will appear.

Step 8. Select the one that was just created and the join will automatically generate. 